

\section{HARVARD UNIVERSITY.}

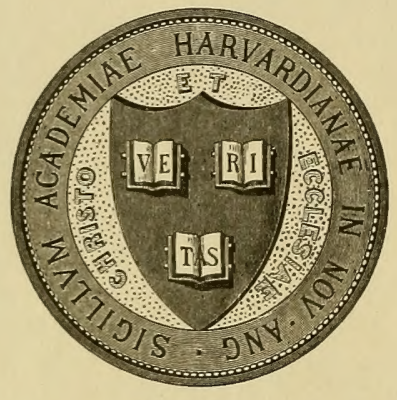

\section{LIBRARY}

OF THE

MUSEUM OF COMPARATIVE ZOÖLOGY 42,485

BEQUEST OF

WILI.IAM MCM. WOODWORTH.

April 29,1915 
42,485
Untersuchungen
über
den feineren Bau der Cestodent

Inaugural-Dissertation

einer hohen philosophischen Facultät

der

Universität Rostock

zur

Erlangung der philosophischen Doctorwürde vorgelegt von

\section{Ernst Zernecke,}

approb. Thierarzt aus Kiel.

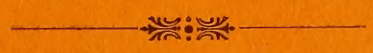

Jena,

Gustav Fischer.

1895. 


\section{valubid}

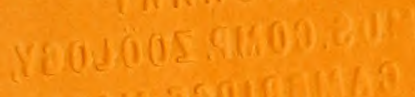
रूप. 


\title{
Untersuchungen \\ über \\ den feineren Bau der Cestoden.
}

\author{
Inaugural-Dissertation \\ einer hohen philosophischen Facultät \\ der
}

Universität Rostock

zur

Erlangung der philosophischen Doctorwürde vorgelegt von

\section{Ernst Zernecke,}

approb. Thierarzt aus Kiel.

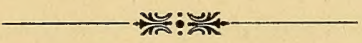

Jena,

Gustav Fischer.

1895. 
Referent: Herr Prof. Dr. Blochmann. 


\section{Seinen lieben Eltern}

\section{Hermann Zernecke und Auguste geb. Lange}

in Dankbarkeit gewidmet

vom Verfasser. 


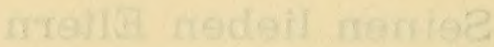

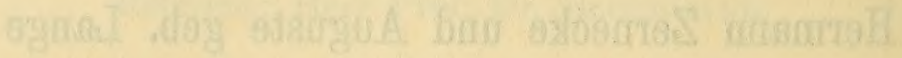

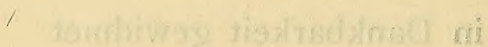

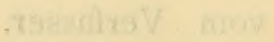


Nachdem mit Hülfe der Chromsilbermethode GoLGI's die Erkenntniss auf dem Gebiet des gesammten Nervensystems der Vertebraten bedeutend gefördert und erweitert worden war, lag es nahe, diese bewährte Untersuchungsmethode auch dem Studium des Nervensystems der Evertebraten dienstbar zu machen. FridTJOF NANSEN gebührt das Verdienst, zuerst bei Wirbellosen die GoLGI'sche Methode mit Erfolg versucht zu haben. Im Anschluss hieran sind im letzten Jahrzehnt von verdienstvollen Forschern, wie Retzius, v. LenHosséK, Smirnow u. A., auch bei den Evertebraten (Annulaten, Mollusken und Arthropoden) sowohl durch die GoLGr'sche Chromsilber- als auch durch die EHRLicr'sche Methylenblaumethode Erfolge erzielt worden, die denen bei den Vertebraten in nichts nachstehen.

$\mathrm{Da}$ bei den Plathelminthen trotz zahlreicher neuerer Arbeiten in Bezug auf die feinere Structur des centralen Nervensystems noch Vieles dunkel geblieben ist und von dem peripheren überhaupt nichts Sicheres gefunden wurde, so ist es mit Freude zu begrüssen, dass beide Methoden auch bei dieser wichtigen Thierclasse ihre anerkannten Eigenschaften bewährten und uns zur weitern Erkenntniss der einheitlichen Principien in der thierischen Organisation verhalfen.

Meines Wissens hat bisher Niemand weder bei Cestoden noch bei Plathelminthen überhaupt eine der beiden Methoden mit Erfolg in Anwendung gebracht. Herr Prof. Dr. Blochmann ist der Erste, welcher schon vor Jahren an Cestoden (Taenia cucumerina) und im Sommer vorigen Jahres an verschiedenen andern Formen, so T. serrata, Cysti- 
cercus cellulosae und Ligula mittels der Methylenblau- und Chromsilbermethode distincte Imprägnirungen gewisser Zellen und Nerven erreichte.

Bevor ich die nachstehenden Resultate meiner im Zoologischen Institut der Universität Rostock gemachten Untersuchungen der Oeffentlichkeit übergebe, ist es mir eine angenehme Pflicht, auch an dieser Stelle meinem hochverehrten Lehrer, Herrn Prof. Dr. Blochmann, meinen tiefgefühlten Dank auszusprechen, sowohl für die liebenswürdige Ueberlassung der von ihm gemachten Befunde als auch für das Wohlwollen und Interesse, welches er mir bei meinen zoologischen Studien im hiesigen Institut und besonders während der Anfertigung dieser Arbeit entgegenbrachte.

Zur Untersuchung gelangten folgende Cestoden: Ligula monogramma und digramma, Schistocephalus dimorphus, Triaenophorus nodulosus, Taenia serrata und cucumerina, Cysticercus cellulosae und pisiformis.

Was die Untersuchungsmethode betrifft, so erreichte ich mit der schnellen Gougi'schen Methode, welche ich bei Ligula und Schistocephalus ausschliesslich anwandte, die besten Resultate. Da man bei der bekannten Launenhaftigkeit der GoLGI'schen Methode eine grosse Menge frischen Untersuchungsmaterials zur Verfügung haben muss und dies aus den Cestoden der Säugethiere sehr schwer in genügender Menge zu beschaffen ist, so kam mir das in Rostock ungemein häufige Vorkommen von Ligula sehr zu statten. Die hier während des ganzen Jahres zu Markt kommenden Plötzen (Leuciscus rutilus) sind in hohem Grade mit Ligula-Larven inficirt und dann an dem aufgetriebenen Abdomen leicht von den gesunden Fischen zu unterscheiden. Ausser dem häufigen Vorkommen und der guten Schnittfähigkeit, welche die mit der GoLGI'schen Methode behandelten Ligula-Stücke erlangen, bot dieser Parasit gerade für unsere Untersuchung noch wesentliche andere Vortheile.

Die noch nicht geschlechtsreifen Thiere erleichtern im Gegensatz zu andern Cestoden das Studium des Parenchyms sowie der Musculatur und des Nervensystems ganz wesentlich, und ferner ist ihr Aufenthalt im freien Raum der Leibeshöhle ihres Wirthes insofern von günstigem Einfluss auf die Untersuchung, als sie nicht mit Fetttröpfchen erfüllt sind, die sich bei den im Darm lebenden Bandwürmern unter der Osmiumeinwirkung intensiv schwärzen und so das Studium der Präparate erheblich erschweren. Es gelingt zwar, das bei Cestoden aus dem Darmcanal durch Osmiumsäure geschwärzte 
Fett durch längeres Liegenlassen der Schnitte in altem Terpentinöl zu entfärben, doch leidet die Imprägnirung dabei immer mehr oder weniger Schaden.

Die der Leibeshöhle frisch entnommene Ligula wurde zur Vermeidung starker Contraction mässig gespannt in dem Chrom-Osmiumgemisch (4:1) abgetödtet. Nach 1-2 Stunden nahm ich die Thiere aus dieser Lösung wieder heraus, um sie in ca. $1 \mathrm{~cm}$ lange Stücke $\mathrm{zu}$ zerschneiden und in neuer Lösung auf 3-4 Tage in den auf $25^{\circ} \mathrm{C}$ regulirten Wärmschrank zu bringen. Ein längeres Verweilen im Wärmschrank ist nicht nöthig, scheint sogar auf das Gelingen der Imprägnirung nachtheilig zu wirken. Die mit Fliesspapier abgetrockneten Ligula-Stücke wurden darauf in eine 0,75-proc. Silbernitratlösung (auf $200 \mathrm{~g} 1$ Tropfen Acid. formicic. nach RAMón Y CAYAL) gebracht, nachdem sie vorher zur Vermeidung zu reichlicher Niederschläge mit schon einmal gebrauchter Lösung abgespült worden waren. In der Silberlösung blieben die Stücke 2-3 Tage, um dann, in Leber eingeklemmt, in feine Quer- und Längsschnitte zerlegt zu werden. Kleinere Objecte, wie Schistocephalus und Triaenophorus, bettete ich nach kurzer Entwässerung in absolutem Alkohol in einige Tropfen Celloidin ein, um dann ebenfalls zwischen Leber feine Schnitte anzufertigen.

Die Schnitte wurden zunächst in Nelkenöl aufgehellt, auf die Imprägnirung geprüft und dann, falls eine brauchbare Färbung erreicht war, mit dem Hydrochinon-Entwickler (nach KaLLIUs) entwickelt und in Damarlack unter dem Deckglas eingeschlossen. Da bekanntlich für dieses Reductionsverfahren nur dünn ausgefallene Schnitte geeignet sind - dickere werden undurchsichtig und zum Studium für feinere Verhältnisse unbrauchbar - so kann ich zur Conservirung dickerer Schnitte das von Herrn Prof. Blochmann zuerst angewandte Einschliessen in Paraftinum liquidum sehr empfehlen. Nach dem Entwässern in Xylol kommen die Schnitte in einen Tropfen Paraff. liquid. auf den Objectträger, werden dann mit einem Deckglas bedeckt, welches ich mit Lack etc. umrandete. Das Lichtbrechungsvermögen von Paraff. liquid. ist zwar nicht so gross wie das der gewöhnlichen Einbettungsmittel, doch immerhin stark genug, um auch noch dickere Schnitte durchsichtig zu machen. Der Vortheil vor den andern Einschlussmitteln liegt aber darin, dass auch an den nicht entwickelten Schnitten die Imprägnirung unter dem Deckglas völlig erhalten bleibt. Ich besitze jetzt Präparate, welche schon seit 4-5 Monaten auf diese Weise 
eingeschlossen sind, ohne dass etwas von der Imprägnirung verschwunden wäre.

Mit der Methylenblau-Methode, welche zur Bestätigung und Ergänzung der nach dem GoLGI'schen Verfahren gemachten Befunde vorzügliche Dienste leistete, behandelte ich die übrigen oben genannten Cestoden mit Ausnahme von Ligula und Schistocephalus.

Ich legte kleinere Stücke der Würmer oder von den Cysticerken die ganzen ausgestülpten Thiere nebst der Blase auf den Objectträger in einige Tropfen einer $0,1-1$ proc. Lösung von Methylenblau in physiologischer Kochsalzlösung. Die Färbung tritt dann, falls die Objecte überhaupt für diese Methode geeignet sind, nach 2-24 Stunden ein. Bei fortgesetzter Beobachtung solcher Präparate bemerkt man nach gewisser Zeit schon mit schwacher Vergrösserung eine deutliche Färbung gewisser Zellen (der Myoblasten); jetzt ist der für die Untersuchung günstige Augenblick gekommen. Nach Auflegen eines Deckglases erkennt man auch bald ausser den schön blau gefärbten äussern Ring- und Längsmuskelfasern nebst deren Myoblasten einzelne gut imprägnirte Sinneszellen und Nervenfasern. Ich habe einen Theil meiner Untersuchungen und Zeichnungen an diesen frischen Präparaten ausgeführt, doch auch, wegen der schnellen Vergänglichkeit der guten Färbung unter dem Deckglase, Fixirungen mit pikrinsaurem Ammonium vorgenommen und so brauchbare, in Glycerin conservirte Dauerpräparate erhalten.

Zur Controle der mit den beiden Methoden gewonnenen Resultate, und um mich jederzeit über die feinere Anatomie fraglicher Cestoden orientiren zu können, fertigte ich mir Schnittserien durch die verschiedenen Körpergegenden in Vertical-, Horizontal- und Sagittalrichtung an. Das hierzu verwandte Material wurde mässig gespannt in concentrirter wässriger Sublimatlösung oder in alkoholischer Sublimatlösung nach АРАТНY conservirt und in 95proc. Alkohol aufbewahrt. Die 5-10 $\mu$ dicken Schnitte wurden mit Eosin-Hämatoxylin, meist aber mit Orange-g Hämatoxylin behandelt.

Die mit der Chromsilbermethode gerade bei Ligula erzielten Resultate überstiegen alle meine Erwartungen. Ich erreichte, allerdings bei Aufwendung eines grossen Untersuchungsmaterials, nicht nur vorzügliche Imprägnirungen des peripheren wie centralen Nervensystems, sondern auch tadellose Färbungen von Muskelfasern nebst deren Myoblasten, Parenchymzellen, sowie einzelner Zellen der sog. Subcuticula und auf grosse Strecken hin schöne Injectionen des excretorischen Gefässsystems. 
Auf Grund dieser Erfolge hatte ich zunächst die Absicht, eine umfassende Darstellung der gesammten Anatomie dieses Parasiten, mit Ausnahme der Geschlechtsorgane, zu geben. Da ich aber zur Herstellung der nöthigen Präparate in Folge der bekannten Launenhaftigkeit dieser Methode sehr lange Zeit gebrauchte und mich augenblicklich persönliche Verhältnisse zum Abschluss der Arbeit drängen, so musste ich mir leider eine gewisse Beschränkung auferlegen, werde aber die sichern Befunde über das Nervensystem, Parenchym, die Musculatur und Excretionsorgane im Nachstehenden mittheilen. Die wichtige Frage über die Auffassung der Subcuticula werde ich am Schluss auch noch einer Besprechung zu unterziehen haben, da ich einestheils gelegentlich günstige Imprägnirungen dieser Zellenschichten erhielt, anderntheils aus den übrigen Befunden Folgerungen ableiten darf, welche für die Auffassung der Subcuticula als ein Epithel von hoher Bedeutung sind.

Beginnen wir zunächst mit der den Cestoden als parenchymatösen Würmern eigenen Grundsubstanz, dem Parenchym.

\section{Parenchym.}

Bevor ich auf die Darstellung der mit der GoLGr'schen Methode in Bezug auf die Parenchymzellen gewonnenen Resultate eingehe, will ich eine Beschreibung der histologischen Structur der Grundsubstanz, in so weit wie es an den mit Orange-g Hämatoxylin gefärbten Schnitten möglich war, zu geben versuchen. Die Schwierigkeit, welche besonders das Parenchym der Plathelminthen einer richtigen Auffassung entgegenbringt, ist jedem Zoologen hinlänglich bekannt und wohl hauptsächlich die Ursache gewesen, dass gerade über diesen Theil der Cestoden-Anatomie die widersprechendsten Darstellungen gegeben wurden.

Untersucht man einen Querschnitt von Ligula bei schwacher Vergrösserung, so findet man in einer ungefärbten Grundmasse eine grosse Anzahl durch Hämatoxylin gut gefärbter Kerne, welche in unregelmässiger Anordnung in der ganzen Gewebsmasse zerstreut liegen. Die Untersuchung mit starker Vergrösserung (ZeIss 1/18 Oel.-Imm.) zeigt aber mehr. Hier finden wir die Kerne von rundlicher bis ovaler Gestalt mit einem deutlichen Kernkörperchen versehen, umgeben von einer spärlichen Menge äusserst fein körnigen Protoplasmas. Dieses liegt in strahliger Anordnung um den Kern und von ihm sieht man nach allen Richtungen derbere oder feinere, ungefärbte Lamellen und Fäserchen ausgehen. Dadurch, dass sich solche Ausläufer wiederholt 
theilen und mit denen benachbarter Zellen - denn so darf ich diese im Hinblick auf die folgende Darstellung nennen - in Verbindung stehen und sich mit einander verflechten, entsteht ein complicirtes Maschenwerk, welches die Grundsubstanz des ganzen Thieres bildet und in welche die Muskeln eingebettet sind.

Die so gebildeten Maschen des Netzes umschliessen grössere und kleinere Hohlräume von unregelmässiger Gestalt, welche mit einer homogenen, gänzlich ungefärbten Flüssigkeit angefüllt erscheinen. Bei genauem Verfolgen der feinen Maschen und Fibrillen lässt sich bald eine gewisse Beziehung derselben $\mathrm{zu}$ den in das Parenchym eingelagerten Muskeln erkennen. Wie ich auf Fig. 20 wiederzugeben versucht habe, sieht man die Lamellen $\mathrm{zu}$ den Muskelfasern hinziehen, an diesen umbiegen und dann längs der Fasern verlaufen. Sie liegen den Muskeln eng an und scheinen diese bisweilen $\mathrm{zu}$ umspinnen. Auf Flächenschnitten, in denen die Dorso-ventralmuskeln quer getroffen sind, findet man diesen Zusammenhang von Muskel und Parenchym wieder (Fig. 21). Hier erscheint jede Muskelfaser von feinen, lamellösen Fäserchen umgeben, die an einigen Stellen direct aus dem um den Kern angeordneten Plasma hervorzugehen scheinen.

In der Grundsubstanz von Ligula sind ausser dem geschilderten Maschenwerk und den damit zusammenhängenden Kernen keine parenchymatösen Elemente zu finden. Auf die im Parenchym liegenden Ganglienzellen komme ich später zurück. Die von verschiedenen Autoren als innerhalb der Maschen liegend beschriebenen rundlichen Zellen konnte ich nirgends auffinden, ebenso wenig bei Ligula etwas von den Fasersträngen sehen, welche WILL (56) im Parenchym von Caryophyllaeus in dorsoventraler- und longitudinaler Richtung verlaufen sah und die Leuckart (22) in der Längsrichtung, besonders in den Verbindungsstücken der einzelnen Proglottiden von T. saginata beschreibt.

Vergleichen wir mit dieser Beschreibung die GoLGr'schen Präparate. Diese Methode hat mir, dank ihrer bekannten Vielseitigkeit auch für die Erkenntniss des Cestodenparenchyms wesentliche Dienste geleistet, denn erst hierdurch ist die bisher noch nicht erreichte Darstellung der Zellausbreitungen ermöglicht worden. Bei vielen nach dieser Methode behandelten Ligula-Stücken haben sich, ohne dass ich irgend eine Modification in der Behandlung vorgenommen hätte, die Parenchymzellen oft auf grosse Strecken hin in tadelloser Weise imprägnirt. Die Figg. 16-19 zeigen solche Zellen auf Querschnitten, deren weithin verbreiteten Ausläufer unter sich und mit denen benachbarter Zellen ein dichtes Netz bilden und alle Organe durchflechten. 
Die den multipolaren Ganglienzellen ähnlichen Zellen haben eine unregelmässige, viel verzweigte Gestalt. Wir finden unregelmässig vielseitige bis rundliche Formen unter ihnen, die aber alle darin übereinstimmen, dass sie nach allen Seiten hin äusserst zahlreiche derbere und feinere Ausläufer entsenden, die sich wiederum vielfach verzweigen und so dem ganzen Gewebe eine maschige Structur verleihen. Am interessantesten ist die oben schon angedeutete, hier sehr klare Beziehung der Zellausläufer zur Parenchymmusculatur. Wir sehen besonders in den Figg. 16-19 die einzelnen Ausläufer an die Dorsoventral- und Transversal-Muskelfasern herantreten und hier Seitenäste an die Muskelfasern abgeben oder selbst im rechten Winkel umbiegen um längs den einzelnen Muskelfasern zu verlaufen. Die Fortsätze dringen sogar in die zu stärkeren Bündeln angeordneten Längsmuskeln ein (Figg. 16, 19), um dann die einzelnen Fasern des Bündels zu umschlingen und auf ihrem Wege $\mathrm{zu}$ begleiten. Fig. 19 zeigt besonders deutlich, wie zwischen den dichten Zügen der Transversalmuskeln die protoplasmatischen Zellfortsätze der Parenchymzellen verlaufen. Diese Zellausläufer sind aber nicht mit den oben, an gefärbten Präparaten beschriebenen Lamellen und Fibrillen des Parenchyms identisch. Jeder protoplasmatische Zellausläufer ist umgeben von einer Scheide von ihm abgeschiedener Zwischensubstanz; diese, zusammen mit dem Zellfortsatz, stellt die auf gewöhnlichen Schnitten sichtbaren Lamellen und Fibrillen dar.

Durch diese Präparate, welche uns die Parenchymzellen in ihrer ganzen Ausdehnung und ihrem Zusammenhange mit dem Netzwerk darstellen, bekommen wir erst einen richtigen Einblick in den Auf bau der Grundsubstanz. Die Zellen dürften als reich verzweigte Bindegewebszellen aufzufassen sein, welche mit ihren Ausläufern und der von diesen abgeschiedenen Zwischensubstanz unter einander fest verbunden dem ganzen Körper den nöthigen Halt und den Muskelfasern eine feste Stütze gewähren.

Vergleichen wir nun die hier gegebene Darstellung mit den Angaben früherer Autoren. In der Auffassung des Baues der Grundsubstanz stehen sich zwei Ansichten unvermittelt gegenüber. Die einen sehen in dem reticulären Maschenwerk die Zwischensubstanz, welche von rundlichen, in den Maschen suspendirten Zellen abgeschieden wurde, während nach den neueren Arbeiten gerade das bisher als Zwischensubstanz Beschriebene das eigentliche Parenchym und die dazwischen liegenden Hohlräume die Parenchymzellen der älteren Autoren darstellen. Die erstere Auffassung wurde von STIEDA (5) begründet, welcher 
die Grundsubstanz als eine „einfache, zellige Bindesubstanz" bezeichnet, die aus einer Menge dicht an einander gelagerter, fest mit einander verkitteter, nicht isolirbarer Zellen besteht. Aehnlich wird das Parenchymgervebe von SOMmer-Landois (8), als Bindegewebe schlechthin" aufgefasst, welches „aus grossen, äusserst zahlreichen, rundlichen oder ovalen Zellen und einer wenig reichlichen Intercellularmasse gebildet wird".

Während diese Autoren noch nichts von einem fibrillären Netzwerk erwähnen, sondern die Zellen dicht an einander gelagert schildern, beschreiben zuerst Moniez (25) und LeuckaRT (22) ein aus bindegewebigen Elementen gebildetes Netzwerk. MoNIEz nennt es: „un même réticulum conjointif, qui présente, en nombre variable, des noyaux de cellules fusiformes ou arrondies".

LEUCKART (1. c.) fasst im Nachtrag der 2. Auflage seines classischen Parasiten werkes seine Ansicht in folgender Weise zusammen: „Nach allem, was ich im Laufe der Zeit selbst darüber beobachtet habe, muss ich bei der Behauptung bleiben, dass die Grundsubstanz zunächst aus einer dicht gedrängten Zellenmasse bestehe. Die Untersuchung junger Glieder lässt keinen Zweifel darüber aufkommen. Aber die Zellen differenziren sich schon sehr früh nach zweierlei Richtungen, indem die einen ihre ursprüngliche runde Form behalten, während die andern sich verästeln und $\mathrm{zu}$ einem Reticulum zusammentreten, das sich zwischen die ersteren einschiebt und sie in seine Maschenräume aufnimmt. Dieses Reticulum ist dasselbe, was ich früher als Zwischensubstanz bezeichnet habe."

Hierdurch wird zwar die Ansicht Stieda's und Sommer-Landois's verneint, doch hätten wir demnach zweierlei Zellarten zu unterscheiden, die sich am Aufbau der Grundsubstanz betheiligen, eine Auffassung, die, wie wir sahen, den Thatsachen bei Ligula nicht entspricht. Viel näher kommen diejenigen Autoren dem richtigen Sachverhalt, welche die zuerst von SchNeIDER (10) begründete Auffassung vertreten. Schneider sagt im Hinweis auf Sommer-Landois: „Was die runden Zellen betrifft, so finden sie sich in der Halsgegend noch nicht. Weiter nach hinten sieht man in dem Protoplasma zuerst einzelne helle Räume auftreten, die sich in den reifen Gliedern stark vermehrt haben, so dass das übrige Plasma nur dünue Wände zwischen ihnen bildet. Von Protoplasma sind die Räume sicher nicht erfüllt, sondern von Flüssigkeit. Wären sie Zellen, so müsste man folglich die Kerne an der Wand der Zellen sitzen sehen. Dies ist mir aber nie ge- 
lungen, die Kerne liegen vielmehr in der festen Substanz zwischen den Räumen."

In diesem Sinne fasst auch Scнмidt (36) die Grundsubstanz des Cestodenkörpers auf, indem er sagt: „Was früher irrthümlicher Weise als Intercellularsubstanz angesehen wurde, sind die Zellen des Parenchyms, die früheren rundlichen Zellen erweisen sich als Hohlräume, wofern es nicht Bildungen sind, die dem Parenchym nicht angehören." Auch WILL (56) muss sich für Caryophyllaeus „dem Resultat von Schneider und Schmidt anschliessen".

Wie aus den neuern Untersuchungen hervorgeht, zeigt das Parenchym der Trematoden einen wesentlich andern Aufbau als das der Cestoden. Looss (59, p. 14) charakterisirt es mit folgenden Worten: „Nach meiner Ansicht setzt sich das Körperparenchym der 'Trematoden, abgesehen zunächst von den verschiedenen Einlagerungen, aus ganz gleichen Zellen zusammen, von denen im ausgebildeten $\mathrm{Zu}$ stand hauptsächlich die ziemlich dicken und festen Membranen noch erhalten sind. Diese letzteren schliessen dicht an einander an und sind durch eine Intercellularmasse mit einander verkittet; sie bilden so ein dem Seifenschaum ähnliches Maschen- oder Gerüstwerk, dessen Balken in einzelnen Fällen durch theilweise Resorption der Wände in gegenseitige Communication treten. Die Lücken selbst sind während des Lebens von einer vollkommen farblosen, klaren Flüssigkeit, dem wässrig entarteten Protoplasma erfültt; manchmal erkennt man in dem frühern Zellleibe noch den verschieden, meist central gelagerten und von einem Hofe feinkörnigen, d. h. noch nicht völlig veränderten Plasmas umgebenen Kern".

Im Sinne dieser Autoren können wir im Vergleich mit meinen Befunden das Grundgewebe der Cestoden ungefähr folgendermassen charakterisiren :

In einer structurlosen, homogenen Grundmasse sind zahlreiche, reich verzweigte Zellen eingelagert, deren nach allen Seiten hin verbreitete, protoplasmatische Ausläufer rings um sich eine Scheide von Zwischensubstanz abgeschieden haben und so ein äusserst mannigfaches Maschenwerk bildend, alle Organe durchflechten. Diese Zellausläufer nebst ihrer Zwischensubstanz schliessen sich den Muskelfasern auf derem ganzen Verlauf eng an, um diese zu stützen und in der Lage $\mathrm{zu}$ erhalten.

Die von spärlichem Protoplasma umgebenen Zellkerne, welche auf gefärbten Schnitten erscheinen, sind diese Zellen selbst, während die rundlichen Zellen der ältern Autoren nichts anderes darstellen, 
als die Hohlräume des Maschengerüstes. Die Fibrillen und Lamellen bestehen also aus den protoplasmatischen Fortsätzen der Parenchymzellen, plus der sie umgebenden, von ihnen selbst abgeschiedenen Scheide von Zwischensubstanz.

\section{IInseulatur.}

In Bezug auf die Anordnung und den Verlauf der Muskeln im Körper unserer Ligulc-Larve kann ich mich den früheren Beobachtern in den meisten Punkten anschliessen. Wir haben eine äussere und eine innere Lage von Muskeln auseinander zu halten oder nach LEUCKART (1. c. p. 368) einen Hautmuskelschlauch, welcher aus den unter der Cuticula verlaufenden Muskelfasern besteht, der in die Bindesubstanz eingelagerten Parenchymmusculatur gegenüber zu stellen. Die äussere Lage, der Hautmuskelschlauch, besteht aus den dicht unter der Cuticula verlaufenden äusseren Ringmuskeln, denen nach innen zu die äusseren Längsmuskeln anliegen. Letztere bestehen aus spindelförmigen Muskelfasern, die sich an den Enden nicht selten in 2 Theile spalten. Die innere Lage besteht aus den inneren Längsmuskeln und den Transversalmuskeln. Erstere sind stark entwickelt und verlaufen in einzelnen Bündeln parallel mit einander durch die ganze Länge des Thieres. Innerhalb von diesen verlaufen die Transversalmuskeln in einer einfachen nur schwach entwickelten Lage und strahlen nach den Seitenrändern hin fächerartig zwischen die innern Längsmuskelbündel aus.

Schliesslich habe ich auch die dritte Art von Muskeln zu erwähnen, die Dorso-ventralmuskeln, welche einzeln, ziemlich dicht neben einander verlaufen und die dorsale mit der ventralen Cuticula verbinden. Ueber den Verlauf und die Insertion gerade dieser Muskeln kann ich genauere Angaben machen, da sie sich der Chromsilber-Imprägnirung besonders günstig erwiesen und oft in ihrem ganzen Verlauf imprägnirt waren. Zunächst muss ich hier auf eine Angabe, welche ich bei Kiessuring (30) finde, näher eingehen. Während von allen Autoren der Verlauf der $\mathrm{Mm}$. dorso-ventrales als ein geradliniger beschrieben wird, von dem nur an den schmalen Seitenrändern der Proglottiden eine Abweichung dahin stattfindet, dass sich hier die Fasern krümmen und dann die concave Seite dieser Krümmung dem Seitenrand zukehren, beschreibt Kiessurng für diese Muskeln bei Schistocephalus und Ligula das Gegentheil. Er sagt wörtlich: „Die Sagittalmuskeln halten ferner eine gerade Richtung inne; nur nach den schmalen Seiten des Thieres zu krümmen sie sich ein wenig, und 
zwar in der Weise, dass die convexe Seite immer nach dem schmalen Seitenrande hin gerichtet ist."

Bei der grossen Menge der von mir untersuchten Thiere habe ich dieses Verhalten auch nicht einmal angetroffen; die Muskeln bilden immer einen nach dem schmalen Seitenrand hin offenen (concaven) Bogen (Fig. 5). Es gilt dies nicht nur für Ligula und Schistocephalus sondern für alle von mir untersuchten Cestoden. Ich kann mir diese Angaben nicht anders erklären, als dass hier ein Druckfehler oder eine Verwechslung der Begriffe „concav" und „convex“ vorliegt!

Wichtiger als dies ist jedenfalls die Insertion dieser Muskeln an der Cuticula. Fast alle früheren Beobachter haben eine "dichotomische" Spaltung der Dorsoventralmuskeln vor der Insertion an der Cuticula angegeben Da sich dieses Verhalten wohl nirgends so deutlich und übersichtlich darbietet, wie im GoLGI'schen Präparat, so habe ich einige dieser Stellen abgebildet (Figg. 1, 2, 3, 5 Ligula, Fig. 4 Schistocephalus). Hieraus ist ersichtlich, dass sich jede Muskelfaser ungefähr in der Höhe des subepithelialen Nervenplexus in mehrere Fasern auflöst, welche sich bis zur Cuticula wiederholt theilen und in deren unterster (Stäbchen-)Schicht mit fein verzweigten Endästchen inseriren. Sind in besonders vollständig imprägnirten Partien die Endfasern aller neben einander verlaufender $\mathrm{Mm}$. dorsoventrales gefärbt, so bekommt man erst eine rechte Vorstellung von der grossen Ausbreitung dieser Muskeln, die, wie Fig. 1 zeigt, über der Cuticula einen wahren Wald von Muskelfasern bilden. RETzius (52) bildet auf fig. 8, tab. 5 eine ähnliche Verzweigung und Insertion von Muskelfasern im Epithel verschiedner Mollusken ab.

Gehen wir nun zum wichtigsten Theil auf diesem Gebiet über, zu der Frage nach dem histologischen Bau der Cestodenmusculatur.

Von den älteren Forschern wurden bekanntlich alle Cestodenmuskeln für kernlos erklärt. So nennt STIEDA (5, p. 181) die Muskeln von Bothriocephalus latus „nach dem Typus der sog. organischen oder glatten Muskeln des Menschen und der Wirbelthiere gebaut; es sind sehr lange, spindelförmige Zellen. Ueber die etwaigen Kerne der Muskelzellen habe ich keine rechte Anschauung gewinnen können". Da die Muskelfasern im Querschnitt aber zwei verschieden lichtbrechende Schichten aufweisen, vermuthet STIEDA schon einen Aufbau wie bei Nematoden ,aus einer Rinden- und Marksubstanz“.

SchNeIder (10) lässt die Frage, ob die Muskelfasern Zellen sind oder nicht, offen; er fasst sie als "Säulchen" auf, welche in dem den ganzen Körper erfüllenden „Protoplasma“ eingebettet liegen. 
Bei Nitsche (9) finden wir nichts über die Auffassung der Muskelfasern als Zellen, doch hebt auch dieser Forscher den Unterschied von zwei Schichten im Querschnitt der Muskelfasern hervor. Es kann , an ganz feinen Querschnitten von Ligula, ganz ebenso wie bei den Hirudineen an den Längsmuskelfasern, eine deutliche, feste, homogene, stark lichtbrechende Rindenschicht von einer innern feinkörnigen Marksubstanz unterschieden werden“. SALENSKY $(11$, p. 305) ist der Erste, welcher an den Dorsoventralmuskeln von Amphilina richtig die Zellnatur erkannte. Nach SALENSKY stellt jede Muskelfaser eine aus Rinden- und Markschicht zusammengesetzte Zelle dar. Die Rindenschicht bildet den eigentlichen fasrigen Theil der Muskelfaser und ist ein aus feinen Fasern zusammengesetzter Strang, welcher durch die Marksubstanz zusammengekittet ist. Er sagt weiter wörtlich: „Die Marksubstanz geht nur in dem Mitteltheile der Muskelfasern nach aussen heraus, um hier in Form einer Zelle anzuschwellen. In diesem Mitteltheile, wo die Fasern der Rindenschicht am dicksten sind, stellen sich die letzteren nicht mehr in Form eines Rohres dar, sondern bilden zusammen eine Rinne, durch welche nun die Zellanschwellung heraustritt. An dieser letzten Stelle der Muskelfaser kann man immer eine löffelförmig ausgehöhlte Verdickung der Rindenschicht bemerken."

Von SchiefFerdecker (12) wird wieder der ältere Standpunkt vertreten; zwar beschreibt er auch den Querschnitt aus zwei Schichten gebildet, ,einer äusseren, stärker lichtbrechenden Umhüllungsschicht von ansehnlicher Dicke" und "einem schwächer brechenden homogenen Inhalt, doch hat er einen Kern niemals bei ihnen nachweisen können“. Auch LeUCKarT (l. c. p. 369) schreibt: „Einen Kern sucht man an ihnen - im ausgebildeten Zustande - vergebens."

Inzwischen wurden die Untersuchungsmethoden wesentlich verbessert und vervollkommnet, wodurch auch auf unserem Gebiet zur Aufklärung beigetragen wurde. Wir verdanken PINTNER $(23$, p. 66) in Bezug auf die Muskelhistologie der Cestoden ausführliche Untersuchungen. Ich führe hier nur seine Resultate bei Tetrarhynchus an und behalte mir vor, auf die Einzelheiten bei der Besprechung meiner Befunde näher einzugehen. Prntner fand: „1) quergestreifte Muskelbündel ohne Kern, die hohlen Rüsselwalzen zusammensetzend; 2) glatte Muskelfasern ohne Kern, zu welchen die Myoblasten ${ }^{1}$ ) gehören würden; 3) glatte Muskelfasern ohne Kern in der contractilen Substanz, mit

1) cf. p. 41. 
siner sarkolemmartigen, Kerne enthaltenden Scheide; 4) glatte Muskelfasern mit eingeschalteten Kernen, die Gehirnscheide bildend und endlich 5) die verzweigten plattenförmigen Centralmuskelzellen". LANG (26) fand an den Sagittalmuskeln von Tetrarhynchus die von Salensky bei Amphitina beschriebenen Muskelzellen, wird aber durch ihre grosse Aehnlichkeit mit bipolaren Ganglienzellen, welche er im Gehirn und den Seitennerven fand, in der Ansicht bestärkt, dass diese letzteren" (Muskelzellen) „nicht Muskel-, sondern Nervenzellen sind." Interessant im Vergleich mit den Resultaten meiner Untersuchung ist eine Angabe, die ich bei Rовоz (29, p. 271) finde: „Erwähnenswerth scheint mir noch der interessante Umstand, dass ich mit Hülfe der oben erwähnten Isolationsmethode einzelne Muskelfasern erhielt, in deren ausgebreiteter Mitte zwei ausserordentlich feine Fibrillen endigen, welche vorher ausserhalb der Muskelfaser zu einer ganglienartigen Ausbuchtung sich vereinigen und dann nach der andern Seite in eine feine Faser übergehen. Es erinnert dies an eine Nervenendigung an den glatten Muskelfasern." Doch lässt Roвоz die Frage nach der Natur dieses Gebildes offen. Auch hierauf komme ich bei der Besprechung der Myoblasten zurück.

Hamann $(33$, p. 723) war es vorbehalten, bei einer Tänie (T. litterata) Muskelfasern in Zusammenhang mit der Bildungszelle zu finden. Er begründet sogar auf diesem Bau der Muskelfasern eine Eintheilung derselben in zwei Gruppen: „In die erste Gruppe gehören Muskelfasern, bei denen die Bildungszelle erhalten geblieben ist, in die zweite Gruppe Muskelfasern, welche keinen Rest ihrer Bildungszelle mehr zeigen. Die Ringmuskelschicht und die Dorsoventralmuskeln bilden die erste Gruppe. In die zweite Gruppe gehören die zur Längsaxe der Proglottis parallel verlaufenden Fasern." Die von ihm abgebildeten Muskelzellen stimmen mit denen SalensKY's vollkommen überein. Hamann schliesst sich der noch $\mathrm{zu}$ besprechenden Myoblastentheorie PINT'NeR's an.

Sснмidт (36) fand ebenfalls Myoblasten an den Dorsoventralmuskeln von Bothriocephalus latus, Taenia crassicollis und Triaenophorus und vermuthet diese auch an den Ring- und Längsmuskeln, ohne dass er sie hier mit Sicherheit nachweisen konnte.

Endlich bildet die Arbeit von WILL (56) in gewisser Weise den Uebergang zur Darstellung meiner Befunde. WILL fand an den Dorsoventralmuskeln von Caryophyllaeus ebenfalls Myoblasten, denen hier "die Fibrillen in tangentialer Richtung aufliegen". Ausserdem aber beschreibt er auf p. 23 Zellen von eigenthümlicher Form im Paren- 
chym um die Cirrusmusculatur herum und in der Schicht der subcuticularen Zellen, die er einerseits in Verbindung mit Nerven fand, andererseits Fortsätze der Körperoberfläche entgegenschicken sah und deshalb ,als Sinneszellen in Ansprnch nehmen zu müssen" glaubt. Er sagt dann wörtlich : „durch Methylenblaufärbung, die ich am lebenden Objecte machte, wurden die Zellen stets zuerst gefärbt". Wir werden gleich erkennen, dass hier zum ersten Mal, wenn auch ohne Wissen des Autors, die Myoblasten der Cestodenmuskeln durch die EHRLichsche Methylenblaumethode dargestellt wurden.

In der Einleitung bemerkte ich bereits, dass sich bei allen nach dieser Methode behandelten Objecten zuerst zahlreiche, verzweigte, dicht unter der Körperoberfläche gelegene Zellen intensiv blau färben, worauf dann bald die äusseren Ringmuskeln auch die Färbung annehmen. Unterzieht man solche Präparate einer näheren Betrachtung, so findet man Folgendes. In gewisser Entfernung unter der Oberfläche bemerkt man mehrfach verästelte Zellen, oft mit deutlichem Kern und Kernkörperchen, welche multipolaren Ganglienzellen sehr ähnlich sehen. Von einer Seite des fein granulirten Zellplasma aus gehen ein oder mehrere plasmatische Fortsätze nach oben gegen die Cuticula hin und stehen hier mit den blau gefärbten Fasern der äusseren Ring- bezw. Längsmusculatur in Verbindung. Gewöhnlich treffen diese Zellfortsätze die Muskelfaser ziemlich in der Mitte. Von der andern Seite der Zelle kann man ebenfalls einen oder mehrere feine Ausläufer in die Tiefe abgehen sehen, ohne diese - wenigstens nicht an Methylenblaupräparaten - weiter verfolgen zu können. Die Figg. 70, 71 a-d zeigen diese Zellen von den verschiedensten Vertretern der Cestoden. Wie sich bald aus der weiteren Betrachtung der Chromsilberpräparate ergeben wird, sind diese multipolaren Zellen die Myoblasten der äusseren Ring- und Längsmusculatur, welche unter dem Epithel liegen geblieben sind, während der contractile Theil derselben, die eigentliche Muskelfaser, bis unter die Cuticula in die Höhe gerückt ist.

Ich werde für diese Zellen nach dem Vorschlage des Herrn Prof. Dr. Blochmann (66) die Bezeichnung Sommer-Landois'sche Zellen gebrauchen ${ }^{1}$ ). Mit der Methylenblaumethode gelingt die Darstellung dieser Myoblasten im Zusammenhang mit der Musculatur nicht schwer. Ich fand sie so bei T. cucumerina, serrata, Cysticercus cellulosae und Triaenophorus und habe sie zum Theil nach lebenden Objecten ab-

1) Der Grund für diese Benennung ergiebt sich aus dem Folgenden. 
gebildet. Ausserdem konnte ich sie in der Musculatur der Blasenwand von Cycticercus pisiformis (Lepus timid.) auffinden. Ich erwähne letzteres besonders aus dem Grunde, weil hier die Sommer-LandoIsschen Zellen in der Regel mit mehr als 2 Muskelfasern in Verbindung stehen. Fig. 72 ist nach einem mit Ammon. picronitric. fixirten Präparat gezeichnet und das perlkörnige Aussehen durch das körnige Ausfallen des Methylenblaus bei der Fixirung entstanden. In diesem Fall steht ein zwischen den Muskelfasern gelegener Myoblast mit 4 einzelnen Fasern in Verbindung; es stimmt dies Bild am meisten mit dem Verhalten der Myoblasten bei Trematoden überein, wie ich mich an Präparaten überzeugen konnte, welche Herr BetTendonf bei seinen Untersuchungen über das Muskel- und Nervensystem der Trematoden im hiesigen Institut anfertigte und demnächst der Oeffentlichkeit übergeben wird ${ }^{1}$ ).

Der Zusammenhang einer Muskelbildungszelle mit mehreren Fasern findet seine Erklärung darin, dass von einer 'Lelle nicht nur eine, sondern nach und nach mehrere contractile Fasern abgeschieden wurden, die natürlich mit ihrer Erzeugerin in Zusammenhang bleiben. Diese Annahme wird dadurch bestätigt, dass die Fasern eines Myoblasten nicht alle gleich entwickelt sind. Auch in Fig. 72 findet man neben 3 grossen Fasern eine bedeutend kleinere und dünnere, welche vielleicht als die zuletzt entstandene angesehen werden dürfte. Bei Trematoden wurden diese Stadien häufig angetroffen.

Durch die GoLGI'sche Methode konnte ich diese Befunde auf die schönste Weise bestätigen und vervollkommnen. Ich wandte sie mit Erfolg an bei Schistocephalus und Triaenophorus, besonders aber bei Ligula, welcher ich auch auf diesem Gebiete sehr instructive Präparate verdanke. Auf Querschnitten an gut imprägnirten Stücken von Ligula finden wir die mit der Methylenblaumethode zuerst dargestellten Sommer-Landois'schen Zellen bald wieder. In den Figg. 6, 7, 8 sehen wir die äusseren Ring- und Längsmuskelfasern imprägnirt und mit deu eigenthümlichen Anhängseln, die an den imprägnirten Parenchymmuskeln noch deutlicher hervortreten, versehen. Diese Muskelu stehen mit den zahlreichen, in der Höhe des äusseren Gefässplexus befindlichen SOMmer-Landors'schen Zellen durch 2 oder 3 feinere Fortsätze in Verbindung. Die Zellen zeigen, wie wir es schon an den mit Methylenblau behandelten Präparaten gesehen haben, eine unregelıässige verzweigte Gestalt und lassen oft noch den Kern als hellen

1) cf. Vorlfg. Mittheilg. Bioi. Centralbl. Bd. XV. No. 6. 1895. 
Kreis erkennen (Fig. 6 u. 8). Die Grösse der Zellen beträgt, in der Längsrichtung gemessen, ca. $15 \mu$, während ihre Breite zwischen 6 und $8 \mu$ schwankt. Sie senden ihre Fortsätze nach zwei Richtungen aus, einmal die feinen Verbindungsfasern nach den Muskeln, andererseits meist etwas dickere Fortsätze nach dem dicht unter ihnen liegenden subepithelialen Nervenplexus. Gerade diesen wichtigen $\mathrm{Zu}-$ sammenhang der Myoblasten mit Muskelfasern und dem Nervensystem ist mir nur mit der GoLGI'schen Methode nachzuweisen gelungen. Auf die Fig. 7, in der wir die eine Sommen-LandoIs'sche Zelle mit einem Sinneszellenfortsatz in directer Verbindung sehen, komme ich bei der Besprechung letzterer zurück.

Was die Verbreitung dieser Zellen anbetrifft, so sind sie überall unter der Cuticula zu finden, denn ich habe sie auf Schnitten aus allen Körpertheilen immer in derselben Lage und Anordnung wiedergefunden.

Bei der Betrachtung dieser Präparate wird jedem Beobachter unwillkürlich die Abbildung Sommer-LANDOIs' in das Gedächtniss zurückkehren, welche das ,plasmatische Gefässsystem" bei Bothriocephalus latus darstellen soll. Da es trotz des eifrigsten Nachsuchens unter Anwendung der verschiedensten Färbemethoden bis heute keinem Forscher gelungen war, die Existenz dieses Gefässsystems, weder bei Bothriocephalus noch einem andern Cestoden, zu bestätigen, wurden viele Stimmen laut, welche an dieser Beobachtung der verdienstvollen Forscher gelinde Zweifel hegten. Bleibt doch aus diesen Gründen GriesBaCH (31, p. 545) „nichts Anderes übrig, als dasselbe einstweilen ins Reich der Fabel zu verlegen“. Das Verdienst, diese Beobachtung aus „dem Reich der Fabel" wieder in die Wirklichkeit zurückgebracht und richtig erkannt $\mathrm{zu}$ haben, gebührt Herrn Prof. Blochmans (66), welcher bekanntlich auch die oft bezweifelte Angabe Sommer's (13) über die ,plasmatischen Längsgefässe" der Tänien in ihr Recht einsetzen konnte.

Dass es Sommer u. Landois (8) schon vor 20 Jahren gelungen ist, diese Zellen darzustellen, darf uns um so weniger wundern, wenn wir die Methode kennen lernen, mit Hülfe deren sie das ,plasmatische Gefässsystem" auffanden. Sie haben dies nicht, wie alle späteren Autoren versuchten, durch eine gewöhnliche Färbung erzielt, sondern durch eine zufällige Chrom-Quecksilberimprägnirung. Dies geht aus der Angabe p. 47 direct hervor: „Diese Zellen mit ihren Ausläufern beobachteten wir an Schnitten solcher Glieder, welche in ganz frischem Zustande zunächst mit PAcinı'scher Conservirungsflüssigkeit (p. 42, Anm. Pacinı'sche Flüssigkeit: Hydrarg. bichlorat. corros. 1 Theil, 
Natr. chlorat. pur. 2 Theile, Glycerin (250 Beaumé) 13 Theile, Aq. dest. 113 Theile [das Ganze mit 2 Volum. Aq. dest. verdünnt]) oder stark verdünnter Lösung von Hydrarg. acet. conc. (1 Theil auf 100 Theile Wasser) behandelt und später in MüLLER'scher Augenflüssigkeit gehärtet waren:"6

SOMmer u. LANDOIs haben also die später von GoLGI entdeckte Chrom-Quecksilbermethode in umgekehrter Reihenfolge angewandt und so eine, wenn auch unvollkommene Imprägnirung einiger Myoblasten erreicht.

Dass diese relativ grossen Sommer-Landors'schen Zellen bei den vielen Untersuchungen, welche zum Studium der feineren Anatomie der Cestoden ausgeführt wurden, bereits von einigen Forschern gesehen wurden, wenn auch nicht im Zusammenhang mit Muskelfasern, ergiebt sich aus meiner Literatur-'Zusammenstellung. Ich wies gelegentlich schon darauf hin, dass WILL diese Zellen durch Methylenblau immer zuerst färben konnte, aber für Sinneszellen hielt. Es gelang ihm auch, die Muskelzellen durch die MäHRENTHAL'sche Osmiumsäure-Holzessigmethode darzustellen und dann einmal in Verbindung mit einer Nervenfaser $\mathrm{zu}$ finden; gerade dieser Befund führte ihn $\mathrm{zu}$ der Vermuthung, es hier mit Sinneszellen zu thun $\mathrm{zu}$ haben. Ferner geht aus WiLL's Angaben hervor, dass diese Myoblasten nicht nur an der äussern Ring- und Längsmusculatur vorkommen, sondern auch an den Muskeln des Cirrus, wo er diese Zellen gerade am häufigsten antraf. Ligula konnte ich hierauf nicht untersuchen, da mir nur die ungeschlechtliche Jugendform aus der Leibeshöhle von Fischen zur Verfügung stand. Herr BeTtendoRF hat aber an der Pharyngealund Darmmusculatur der Trematoden sehr schöne Myoblasten nachgewiesen, welche mit unsern völlig übereinstimmen. Besonders verdient aber PintneR's (l. c.) exacte Untersuchung über die Musculatur der Tetrarhynchen erwähnt zu werden. Er beschreibt im Kopfe dieser Cestoden ,riesig grosse Zellen von 0,0183-0,0264 mm Durchmesser", welche er "Centralmuskelzellen" nennt, „da die contractile Substanz von der Zelle nach allen Seiten plattenförmig ausstrahlt". Ausser diesen Zellen fand PrNTner aber ,allenthalben im Körperparenchym, meist in der unmittelbaren Nähe von kernlosen Muskelfasern Zellen, die in ihrem Bau und in ihrer Grösse auffallend an die eben beschriebenen Plasmamassen der Centralmuskelzellen erinnern, nur stehen sie eben nicht mit Muskelfibrillen in Verbindung". Weiter giebt Pintner für diese Zellen folgende Erklärung: „Alle diese Umstände scheinen mir darauf hinzuweisen, dass die Zellen als Myoblasten auf- 
zufassen sind, d. h. dass sie aus den embryonalartig indifferenten Parenchymzellen entstanden, die glatten kernlosen Muskelfasern bildeten, sich von diesen trennten und so die beschriebene Gestalt erhielten". Offenbar hat Pintner in diesem Fall die Sommer-Landois'schen Zellen gesehen und richtig gedeutet, ohne bei der Anwendung seiner Methoden ihren Zusammenhang mit der Muskelfaser gefunden zu haben.

Vergleichen wir schliesslich die erwähnte Abbildung von Roв0z (1. c. tab. 18, fig. 5) mit unseren Myoblasten, so stimmen auch diese überein. Rовоz bildet 2 dreieckige Zellen $a b$, welche mit 2 Ausläufern in der Mitte je einer Muskelfaser endigen, an der andern Seite aber in eine feine Faser übergehen. Rовоz vermuthet hierin eine Nervenendigung am Muskel, kommt also dem Richtigen ziemlich nahe.

Wenden wir uns nun zu den übrigen Körpermuskeln, denen die Bildungszellen, soweit sie gefunden sind, seitlich anliegen. Ich will im Voraus bemerken, dass ich bei Ligula an allen Muskelfasern eine Bildungszelle nachweisen konnte. Für die Längsmuskeln fehlten bisher diesbezügliche Beobachtungen, weil sie, ihrer Anordnung zu zusammenhängenden Bündeln wegen, der Untersuchung gewisse Schwierigkeiten darbieten. An imprägnirten Längsmuskeln konnte ich mich aber von dem Vorhandensein anliegender Myoblasten überzeugen.

Wir könnten demnach die Eintheilung Hamann's (l. c.) in Muskeln mit und ohne Bildungszelle richtig dahin modificiren, dass wir Muskelfasern mit anliegender Bildungszelle denen gegenüberstellen, welche nur noch durch protoplasmatische Ausläufer mit ihrer Bildungszelle in Verbindung stehen. $\mathrm{Zu}$ ersteren gehörten dann alle Parenchymmuskeln (innere Längsmuskeln, Transversal- und Dorsoventralmuskeln), zur zweiten Gruppe der Hautmuskelschlauch (äussere Ring- und Längsmuskeln).

Am besten kann man die Myoblasten der Dorsoventralmuskeln auf Querschnitten studiren. Schon bei schwacher Vergrösserung erscheint die ganze Mittelschicht unseres Thieres von grossen, meist spindelförmigen Zellen durchsetzt, die in dorso-ventraler Richtung einander parallel angeordnet sind (Fig. 20, 10, 13). Die Untersuchung bei stärkerer Vergrösserung zeigt deutlich, dass diese Zellen den Muskelfasern seitlich angelagert sind. Die spindligen, ziemlich grossen Zellen besitzen ein feines granulirtes Plasma, dem ein scharf begrenzter, meist ovaler Kern mit Kernkörperchen eingelagert ist. Der Zellkörper sitzt der Faser immer seitlich an. Bei Schistocephalus geht die Muskelzelle oft von der spindligen in die kuglige Gestalt 
über und sitzt dann nicht selten nur noch an einer kleinen Stelle der Faser tangential an, wie ich es in Fig. 13 a abgebildet habe.

Die Structur der Faser selbst, sowie deren Zusammenhang mit der Bildungszelle, lässt sich am besten auf den Flächenschnitten, welche die Dorsoventralfasern quer treffen, ermitteln. Hier finden wir denn auch die von SAlEnsky für die Muskeln von Amphilina beschriebene Differenzirung der Fasern in eine centrale (Mark-) und eine periphere (Rinden-)Schicht. Letztere umgiebt den centralen Theil als ein breiter Ring und ist von diesem durch die intensive Färbung zu unterscheiden. Sie ist von homogener Structur und stärker lichtbrechend als das Centrum. Letzteres erscheint im Querschnitt als eine dunklere, feinkörnige plasmatische Markmasse (Fig. 21). Beim Studium solcher Flächenschnitte trifft man oft Stellen an, in denen der Schnitt die Faser gerade an der Stelle getroffen hat, wo ihr die Bildungszelle anliegt. Hier ist der Zusammenhang der Marksubstanz mit der Zelle zu sehen. Die Rindenschicht bildet hier nicht mehr ein geschlossenes Rohr um die Markmasse, sondern öffnet sich an einer Seite, so dass eine Rinne entsteht, durch welche das Plasma der Bildungszelle mit dem Mark communicirt.

Die Innervirung der Muskelfasern konnte ich mit der GoLGI'schen Methode an vielen Präparaten nachweisen und werde ich das Nähere hierüber bei der Besprechung des Nervensystems berichten. Hier sei jedoch bemerkt, dass die Nervenfaser nicht nur vermittelst der Myoblasten, wie wir dies schon bei den Sommer-Landois'schen Zellen :sahen, mit der Muskelfaser verbunden ist, sondern bei den übrigen Muskeln theils mit, theils ohne Vermittlung der Myoblasten an die Faser herantritt.

Ueberblicken wir nun die gesammte Musculatur der Cestoden, so sehen wir, dass alle Muskelelemente ihre Zellnatur noch deutlich bewahrt haben. Alle Muskelfasern stehen mit ihrer plasmatischen, kernhaltigen Bildungszelle in directem Zusammenhang. Wir finden, wie eine kurze Betrachtung zeigen wird, bei den Cestodenmuskeln Uebergänge von der nematoiden Grundform bis zu den Muskeln der Annulaten.

Die erstern, die nematoiden Muskeln, bestehen bekanntlich aus einer Bildungszelle, welche der von ihr abgeschiedenen contractilen Substanz seitlich anliegt. Ausser dieser Production der contractilen Faser hat aber hier die Zelle noch eine andere Function übernommen, nämlich die Verbindung zwischen contractilem Theil einerseits und Nervensystem andererseits herzustellen. Dass die Bildungszelle, um 
dies zu erreichen, lange Fortsätze bis zu der dorsalen und ventralen Mittellinie aussendet, ist für die Nematoden allbekannt und in neuester Zeit auch für die Oligochäten von Hesse (64) nahe gelegt worden.

Stimmen mit diesem Typus unsere äussern Ring- und Längsmuskeln nicht völlig überein? Dass die Sommer-Landors'schen Zellen nicht mehr den Nuskelfasern ihrer Länge nach unmittelbar anliegen wie bei den typischen Nematoden-Muskeln, dürfte leicht in einer Verlagerung der Muskelfasern an die Oberfläche seinen Grund haben. Als mesodermales Gebilde haben wir die Muskelzelle ursprünglich im Parenchym zu suchen, hier hat sie sich aus dem embryonalen Gewebe differenzirt. In der Entwicklung des Thieres ist nun die contractile Substanz, um als Hautmuskel fungiren zu können, aus der Tiefe zwischen das Epithel empor gerückt, um schliesslich in dessen obersten Regionen seinen Platz zu finden. Die Mutterzelle der Faser hat ihren ursprünglichen Platz im Parenchym beibehalten und ist nur noch durch einen oder mehrere Verbindungsfäden mit der Faser im: Zusammenhang geblieben. Von hier aus war es der Bildungszelle leicht, auch den zweiten Theil ihrer Function zu übernehmen und die Verbindung mit dem Nerven herzustellen. Ich mache besonders darauf aufmerksam, dass nicht die Nerven aus dem Plexus die Zelle aufsuchen, sondern dass es gerade die Sommer-Landors'sche Zelle ist, welche Fortsätze gegen den Plexus ausschickt. Die Figg. 7 und 8 zeigen deutlich, dass die Fortsätze der Zellen gegen den Plexus hin bedeutend stärker sind als die Plexusnerven.

Ferner stehen die Cestodenmuskeln denen der Annulaten nahe und zwar auch aus zwei Gründen. Nach den Untersuchungen Hesse's bilden gerade die Muskeln der Oligochäten eine Reihe von Uebergangsformen zwischen der nematoiden Grundform und dem Verhalten der Muskelfasern bei den Hirudineen, sowohl im Bau als auch in der Innervirung. Als eine solche Zwischenstufe zwischen Nematoden- und Hirudineen-Muskelfaser können wir die übrigen Muskeln des Cestodenkörpers ebenfalls auffassen. Zum Theil liegt die Bildungszelle noch frei neben der Faser, zum Theil ist sie schon von der contractilen Rindenschicht umschlossen, wie dies bei den Hirudineen in vollendeter Weise ausgebildet ist.

Wie ist es nun hier mit der Innervirung? Ich weise auch hier auf die interessante Untersuchung Hesse's hin, welcher bei den Oligochäten das Verhältniss zwischen Muskel und Nerv bei den verschiedensten Formen verfolgt hat. Je mehr die Bildungszelle von der contractilen Substanz umschlossen wird, desto kürzer werden auch 
die von ihr dem Nerven entgegengesandten Fortsätze und umgekehrt, desto weiter kommen die Nerven der Zelle entgegen, bis schliesslich im extremen Falle die Zelle ganz eingeschlossen ist (Hirudineen, Vertebraten) und dann der Nerv durch die contractile Hülle hindurch bis in den Plasmarest eindringt, wie dies von Lustig (27) für die glatte Musculatur der Wirbelthiere nachgewiesen wurde. Kehren wir zu unsern Muskelfasern zurück, so finden wir nirgends mehr seitens der Zelle einen Fortsatz gegen die Nerven ausgesandt; diese kommen selbst heran und gehen, wie wir sehen, ein Mal an die Bildungszelle (Figg. 9, 13a, 15), das andere Mal aber ohne deren Vermittlung an die contractile Substanz (Figg. 10, 11, 13, 14), wo ich über ihren Verbleib an GoLGI'schen Präparaten nichts näheres ermitteln konnte.

\section{Excretionssystem.}

Auch für das Studium des Excretionssystems hat die GoLGr'sche Methode Präparate geliefert, die in vieler Beziehung durch keine noch so gute Injection erreicht werden. In derselben Weise, wie sich bekanntlich die Gallencapillaren durch die Chromsilber-Methode sehr schön darstellen lassen, erfolgte auch bei Ligula eine, oft auf weite Strecken hin vollständige Imprägnirung feinerer und gröberer Excretionscanäle. In einzelnen, allerdings seltnen Fällen erhielt ich auch eine gute Imprägnirung der Wimpertrichter nebst deren Capillaren. Da ich trotz vielfacher vergeblicher Versuche keine vollständige Imprägnirung des Gefässverlaufes im Vorder- und Hinterende von Ligula erreichen konnte, nahm ich hierzu Injectionen mit löslichem Berlinerblau vor und erhielt, allerdings nach einigen Misserfolgen, brauchbare Präparate.

Bevor ich zur Darstellung meiner eignen Untersuchungen über das Excretionsgefässsystem von Ligula schreite, will ich kurz das hierüber aus frühern Arbeiten bekannt Gewordene zusammenfassen. Duchaмp (14) kennt an jeder Seite des Körpers von Ligula Längsgefässe, die den ganzen Wurm durchziehen um am Hinterende in einer „vésicule pulsatile“ zu enden. Ausserdem erwähnt er ein Gefässnetz zwischen der Cuticula und den innern Längsmuskeln. Duснамp hebt besonders hervor, dass beide Gefässsysteme weder ein ,tube alimentaire" noch ein Blutgefässsystem seien, sondern der Excretion vorstehen. Von ihm angestellte Injectionsversuche haben zu keinem Resultat geführt.

Trotzdem beschreibt Donnadieu (16) ein Jahr später bei Ligula ein Gefässsystem, welches er, conform den damals durch VAN BENEDEN 


\section{$-26-$}

und Leuckart noch nicht ganz beseitigten Anschauungen Platner's (1), Blanchard's (2), Blumberg's (15) u. A., für einen digestiven Apparat hält. Er sah jederseits einen Gefässstamm, der durch ein Netz von Anastomosen mit dem der andern Seite in Verbindung steht, vorn in den Bothridien ausmündet, am Hinterende aber blind endigt. Aus seiner Abbildung (tab. 17, fig. 35 u. 36) ist leicht ersichtlich, dass er die Längsnervenstämme (deren Existenz er leugnet) für Gefässe hielt. Der subcuticulare Plexus scheint ihm entgangen zu sein. STEUdener (18) erwähnt sodann in seinen „Untersuchungen über den feinern Bau der Cestoden" für Ligula ein Gefässsystem, das vorn mit zwei feinen Gefässen beginnend, sich allmählich in 14 bis 18 Längsstämme spaltet. Dann sagt er wörtlich: „Dieselben verlaufen in leichten Zickzackbiegungen dicht unter den Subcuticularzellen nach dem hintern Körperende und bilden zablreiche, quer und schräg verlaufende Anastomosen untereinander. Am hintern Körperende scheinen sich mehrere der Längsgefässe $\mathrm{zu}$ einem Stamme zu vereinigen; die dann noch vorhandenen Stämme münden aber getrennt". Hier liegt offenbar ein Irrthum in so fern vor, als STEUDENER den innern und äussern Gefässplexus verwechselt; fig. 10 auf tab. 28 stellt einen Flächenschnitt dar, auf dem der Längsnerv getroffen ist und daneben nach innen zu der innere Gefässplexus, der aber nicht „dicht unter den Subcuticularzellen" verläuft, denn sonst könnte er nicht in einer Ebene mit dem Längsnerven auf einem Schnitt neben einander erscheinen.

Moniez (25) beschreibt ferner bei Ligula einen centralen Gefässplexus, der aus einer verschiedenen Anzahl von Längsstämmen besteht, welche durch viele Anastomosen mit einander communiciren; ausserdem fand er ein subcuticulares Gefässsystem, welches am Vorderund Hinterende mit vorigem in Verbindung steht; zwischen den äusseren Längsgefässen hat er zwar keine Verbindungen gesehen, doch vermuthet er deren Vorhandensein. Wenn er aber sagt, das subcuticulare Gefässsystem sei bisher nicht bekannt gewesen, so scheint er Duchamp's Arbeit nicht zu kennen, die er auch nirgends erwähnt. Besonders wichtig scheint mir eine Angabe MonIez's über das Hinterende. In einigen Fällen fand er dieses in einen sehr dünnen und langen ,appendice“ ausgezogen, in andern vermisste er diesen Anhang und fand dafür eine Endblase, wie sie bei Tetrarhynchen und Tänien vorkomme, in welche dann die Gefässe ausmündeten. Sobald aber dieser Anhang zu beobachten wäre, endeten die Gefässe blind, wie Moniez p. 96 sagt: ,aller se terminer, à l'extérieur pour ainsi dire, 
au ras de la cuticule: toutefois, dans ce dernier cas, ils semblaient obturés par une très mince membrane anhiste."

KIESSLING (30), welcher bei seiner Beschreibung des Gefässsystems von Ligula nur auf die Arbeit von DoNnAdieu und STEUDENER hinweist, bringt wenig Neues hinzu. Das äussere Gefässsystem kennt er überhaupt nicht, von dem innern sagt er, dass die einzelnen Gefässe nicht in einer Ebene liegen, sondern ein verworrenes, aus engen und weiten Canälen bestehendes Netzwerk bilden, welches die ganze Mittelschicht des Thieres durchsetzt. In der Schwanzregion käme jederseits ein starker Stamm zur Entwicklung, der die kleinen Canäle zu sammeln scheint und in der terminalen Proglottis nach aussen mündet. „Nach dem Kopfe hin konnte ich dagegen nirgends ein oder mehrere constant auftretende, stärkere Gefässe nachweisen, wie es mir denn auch nicht gelungen ist, im Kopfe selbst ein Ringgefäss oder einen Plexus solcher mit Bestimmtheit zu erkennen".

Rienm (27) hat seine Studien über die Topographie des Excretionssystems an Injectionspräparaten bei Schistocephalus und Liqula gemacht. p. 276 heisst es: „Dieselben zeigten ihm bei beiden Parasiten ein überaus feines und zierliches Maschenwerk von Canälen und Canälchen, wie es auch nicht annähernd von irgend einem Cestoden bekannt geworden ist. Im Kopfe fehlt beiden Liguliden ein Gefässring; die Gefässe sind dort vielmehr äusserst eng aber um so zahlreicher und umfassen das Vorderende der Binnenschicht korbartig". Für Schistocephatus beschreibt RIEHм (l. c.) am Seitenrand und zwar am vordern Ende einer jeden Proglottis jederseits eine seitliche Mündung des Excretionssystems. In einer weitern Arbeit desselben Autors (46) werden die eben angeführten Befunde näher ausgeführt, für Ligula aber besonders hervorgehoben, dass sie sich viel schwerer injiciren lasse als Schistocephalus und dass hier die Injectionsmasse nur in das oberflächliche Netzwerk eindringe, nicht aber in das innere. Seitliche Oeffnungen werden bei Ligula nur vermuthet: „Es scheint, als ob auch hier seitliche Oeffnungen beständen."

Meine eigenen Untersuchungen ergeben nun in Bezug auf die Topographie des Excretionssystems von Ligula folgendes: Das Gefässsystem besteht aus einem innern, $d$. h. einem in der Mittelschicht zwischen den beiden Längsnervenstämmen verlaufenden Gefässplexus und einem äusseren zwischen den Subcuticularzellen und der inneren Längsmusculatur liegenden Gefässnetz, welches das ganze Thier netzartig umspinnt. Eine Verbindung zwischen diesen beiden Gefässsystemen besteht in zweifacher Weise. Am Vorderende des Thieres 
gehen die beiden Gefässplexus vermittelst zahlreicher, relativ weiter Canäle in einander über; es ist deshalb hier allein nöglich, eine Injection der inneren Gefässe vom äusseren Plexus her zu erreichen. Ausserdem sind die beiden Plexus durch eine beträchtliche Menge feiner Capillargefässe mit einander verbunden, die, von dem inneren Gefässnetz ausgehend, in den äusseren Plexus einmünden. Einen andern Theil dieser Capillaren sehen wir, ohne sich mit diesen zu verbinden, der subcuticularen Zone zustreben.

Der innere Gefässplexus setzt sich aus einer verschieden grossen Anzahl (10-16) Längsstämmen zusammen, die (wie Kressling 1. c. richtig angiebt) nicht in einer Ebene liegen, sondern durch zahlreiche, verschieden weite Anastomosen unter einander verbunden, ein Netzwerk bilden, welches die ganze Mittelschicht des Thieres durchsetzt. Während ihres ganzen Verlaufs vom Vorder- bis zum Hinterende geben diese Längsstämme, wie auch ihre Anastomosen eine sehr grosse Menge von Capillaren ab, die büschelförmig aus den grossen Canälen austreten, sich bald auflösen und nach allen Richtungen der Peripherie zu streben. Fig. 30 (ein GoLGI'sches Präparat) zeigt die Hälfte eines Querschnittes mit dem inneren Gefässplexus und die aus den hier im Querschnitt sichtbaren Längsstämmen und deren Anastomosen hervorgehenden Büschel von Capillaren. Letztere nehmen nach ihrem Austritt aus den grössern Gefässen gewöhnlich eine gerade Richtung zur dorsalen oder ventralen Oberfläche hin, so dass sie mehr oder weniger senkrecht gegen den äussern Plexus gerichtet erscheinen. Eine Ausnahme hiervon machen nur die aus den beiden am weitesten nach aussen, also den Längsnerven am nächsten, liegenden Längsgefässen kommenden Capillargefässe. Letztere nehmen ihre Richtung auf den Seitenrand des Thieres zu und umgreifen auf diese Weise, ehe sie in allen Richtungen auf den Seitenrand hin ausstrahlen, die Längsnerven von beiden Seiten oft so vollkommen, dass. diese in ein Gewirr von Capillaren eingeschlossen erscheinen (Fig. 33). Sind in einem solchen Präparat auch noch die von den Längsnerven zur Peripherie abgehenden Nervenfasern imprägnirt, so ist es sehr schwierig, oft unmöglich, dieses Gewirr von Gefässcapillaren und Nervenfasern $\mathrm{zu}$ entziffern.

Der äussere Gefässplexus unserer Ligula, welcher sich von allen Organen am leichtesten und häufigsten mit dem Chromsilberniederschlag imprägnirt, erscheint auf dem Querschnitt als eine schwarze Grenzzone zwischen der inneren Längsmusculatur und der Lage der Subcuticularzellen. Um eine genaue Vorstellung von der reichen Aus- 
bildung dieses Gefässnetzes zu bekommen, sind Flächenschnitte am geeignetsten. Fig. 29 zeigt eine kleine Partie dieses colossal entwickelten Gefässnetzes von der Fläche. Eine grosse Anzahl von ungefähr parallel zu einander verlaufenden Längsstämmen, die zum Theil direct in einander übergehen, zum Theil durch stärkere und feinere Anastomosen unter sich verbunden sind, neben einer grossen Anzahl von feinen und feinsten Canälchen stellen dieses reich entwickelte, oberflächliche Gefässnetz der Ligula dar.

Wie ich schon oben bemerkte, steht dieses periphere Gefässnetz mit dem centralen ausser durch die noch zu besprechende Verbindung im Vorderende, durch einen Theil der Capillaren in Verbindung. Bei stärkerer Vergrösserung gelingt es, auf Querschnitten nachzuweisen, dass die gegen die Peripherie gerichteten Capillaren zum Theil in diesen Plexus übergehen, zum Theil aber, ohne mit ihm in Verbindung $\mathrm{zu}$ treten, noch weiter gegen die Cuticula hin zu verfolgen sind und plötzlich frei zu endigen scheinen. Auf diese scheinbar frei endenden Capillaren komme ich bei der Besprechung der Wimpertrichter zurück. Wie in Fig. 22 zu erkennen ist, findet sich an der Einmündungsstelle einer Capillare in einen Ast des äusseren Plexus jedesmal eine, wenn auch noch so winzige, kegelförmige Auftreibung des Capillargefässes.

Ausser diesem wichtigen Zusammenhang des äusseren Plexus mit dem centralen zeigt ersterer noch beachtenswerthe Beziehungen zur Cuticula bezw. zur Aussenwelt. Zunächst kann ich die von RIEHM (1. c.) für Schistocephalus nachgewiesenen, für Ligula nur vermutheten seitlichen Mündungen des Gefässsystems auch für Ligula feststellen. Die Figg. 31 und 32 zeigen seitliche Oeffnungen des äussern Plexus auf Querschnitten, und zwar Fig. 31 nach einem GoraI'schen, Fig. 32 nach einem Injectionspräparat. Jede solcher Ausmündungen stellt einen Seitenast des äusseren Plexus dar, welcher dicht unter der Cuticula ampullenartig erweitert ist um dann mit einem feinen Canal durch die Cuticula nach aussen zu münden. Diese Seitenöffnungen des Excretionssystems finden sich bei Ligula in ihrer ganzen Länge; dicht hinter dem Vorderende anfangend, wiederholen sie sich in kurzer Aufeinanderfolge bis zur Endspitze des Wurms. Sie sind nicht immer streng auf den Seitenrand beschränkt, sondern zeigen bisweilen geringe Verschiebungen nach der ventralen oder dorsalen Seite (Fig. 31), doch niemals weit vom Seitenrand sich entfernend. Seitliche Oeffnungen habe ich ausserdem bei Schistocephalus und Triaenophorus gesehen, wo sie schon von Rienu (1. c.) bezw. Pintiner (23) abgebildet 
wurden. Dass solche Foramina secundaria nicht gerade selten vorkommen, beweisen die in der Literatur hier und da zerstreuten Angaben von verschiedenen Cestoden, welche ich hier kurz zusammenstellen will. Ausser den erwähnten Fällen fanden sie HowK (19) bei Tetrarhynchus sp.?, LEUCKART (4) im Halstheil von $T$. serrata, WAGNer (3) bei Dibothrium clavaeceps und T. osculata, FraIPONT (20) bei Bothriocephalus punctatus und trygonis-pastinacae, LöNNBERG (43) bei Tetrarhynchus tetrabothrius und KRÄмeR (45) bei zwei Fischtänien, $T$. torulosa und filicollis.

Neben diesen wahren Oeffnungen des Gefässplexus fand ich bei meinen mit der GoLGI'schen Methode hergestellten Präparateu von Ligula sehr häufig blind gegen die Cuticula hin endende Seitenäste des äussern Gefässnetzes. Dasselbe fand ich an meinen Injectionspräparaten bestätigt (Figg. 26-28). In der Literatur finde ich nur die eine oben citirte Stelle bei MoNIEZ, welche man hiermit vielleicht in Zusammenhang bringen kann. Diese Ausbuchtungen liegen immer in derselben Region, wie die wahren Seitenöffnungen, also unmittelbar am Seitenrande oder in dessen nächster Nähe und sind noch zahlreicher, mindestens aber ebenso oft vorhanden, wie die Seitenöffnungen. Sie entspringen wie diese in dem äussern Gefässplexus um sich unter der Cuticula $\mathrm{zu}$ einer weiten, oft glockenförmigen Ausbuchtung zu erweitern (Fig. 26), die sich bisweilen bis in die Cuticula hinein erstreckt. In einigen Fällen findet eine gablige Theilung dieses blinden Gefässastes statt (Fig. 28).

Meine erste Vermuthung, es möchten dies doch wahre Seitenöffnungen sein, die sich nur unvollständig mit dem Chromsilberniederschlag angefüllt hätten, wurde durch die Injectionen widerlegt, denn hier erhielt ich ebenfalls diese blind endenden Gefässe neben frei nach aussen ausmündenden. Diese oder ähnliche blind endende Gefässe sind meines Wissens bisher noch bei keinem Cestoden beschrieben. Pintwer (23), der gewiss eine grosse Menge Cestoden gerade in Bezug auf das Excretionssystem untersucht hat, stellt deren Vorhandensein direct in Abrede. Er sagt p. 41: „Sämmtliche von den Längsstämmen abgehende Aeste kehren entweder zu den eigenen Muttergefässen zurück oder münden in benachbarte, so dass es nirgends blind sackartige Enden, baumförmige Verästelungen oder ähnliche Bildungen giebt."6

Die Frage, ob wir es hier vielleicht mit neu angelegten Seitenöffnungen zu thun haben, bei denen der Durchbruch durch die Cuticula noch nicht erfolgt ist, scheint mir einige Berechtigung zu haben, 
ohne sie auf Grund dieser einen Beobachtung entscheiden zu wollen. Uebereinstimmend mit den wahren Seitenöffnungen ist sowobl die Lage an oder dicht neben dem Seitenrand des Thieres als auch die Gestalt dieser Gebilde; abweichend davon ist die einige Mal beobachtete Verzweigung, die ich an den wahren Seitenöffnungen niemals constatiren konnte.

Betrachten wir nun das schon mehrfach erwähnte Verhalten der beiden Gefässsysteme im Vorder- und Hinterende unseres Thieres. Wie ich bereits in der Einleitung zu diesem Capitel bemerkte, liess mich hier die GoLgr'sche Methode im Stich und erreichte ich hier das Ziel durch wiederholt versuchte Injectionen mit löslichem Berlinerblau. Im Vorderende finden wir den äusseren Plexus scheinbar in noch reicherer Weise ausgebildet als im übrigen Körper; die Canäle des Netzes scheinen hier etwas enger, dafür aber um so zahlreicher und umgeben die Binnensubstanz korbartig ${ }^{1}$ ). Man kann sich hier an einem Injectionspräparat leicht überzeugen, dass im Vorderende ein Uebergang einzelner Gefässe vom äussern zum innern Plexus stattfindet. Durch Heben und Senken des Tubus sieht man diese Gefässe den äussern Plexus verlassen, in die Tiefe steigen und hier nach mehrfacher Theilung in den innern Plexus übergehen. An dieser Stelle ist allein eine Injection des innern Gefässnetzes vom äussern her zu erreichen, während sonst die Injection immer nur Gefässe des oberflächlichen Netzes erfüllt; die Capillaren leiten die Injectionsmasse nicht weiter.

Beim Studium des Gefässverlaufs im Hinterende stiess ich auf grössere Schwierigkeiten, da eine gleichzeitige Injection beider Plexus hier nicht möglich war. Wie Fig 34 zeigt, verhält sich der äussere Plexus hier ebenso, wie an den andern Körperstellen. Er umschliesst. das Hinterende ebenso vollkommen wie das vordere, doch scheint hier das Netz aus weniger zahlreichen Gefässen zusammengesetzt. Seitliche Oeffnungen finden wir hier auch an den Seitenrändern und auf der Endspitze.

Für den innern Plexus konnte ich das Verhalten der Gefässe nicht so sicher ermitteln wie für den äussern. Auf einer grössern Anzahl von Schnittserien, die ich durch die Endspitze anfertigte, habe ich mich von dem Vorhandensein einer Endblase im Sinne Duchamp's

1) Dies dürfte zum Theil darin seine Erklärung finden, dass das Vorderende beim Abtödten nicht gespannt werden konnte und sich deshalb etwas contrahirt hatte. 
und MoNrez's nicht überzeugen können. Vielmehr scheinen hier die inneren Gefässe getrennt neben einander auszumünden. Ich will aber nicht unerwähnt lassen, dass ich in einem Falle das Hinterende besonders lang ausgezogen fand und auf einem hiervon angefertigten Totalpräparat zwei seitlich von der Endspitze liegende Endbläschen sah, in die von vorn her je ein Gefäss des innern Plexus mündete, während sie nach der Mitte $\mathrm{zu}$ in je einen Kanal ausliefen, welche sich vereinigten und auf der Spitze mit einem unpaaren Endrohr mündeten. Auf diese eine Beobachtung darf ich aber nicht allzu viel Gerwicht legen, da es an einem nicht injicirten Präparat wegen der Menge der Gefässe sehr schwierig ist, ein einzelnes Gefäss mit Sicherheit zu verfolgen und man bei der reichen Ausbildung des äussern Plexus leicht Täuschungen ausgesetzt ist. Ich muss diese Frage vorläufig noch offen lassen, da mich besondere Umstände zum Abschluss meiner Arbeit drängten und ich nicht mehr die hierfür erforderliche Anzahl von Injectionsversuchen ausführen konnte.

Da ich unter der grossen Anzahl meiner mit der GoLGI'schen Methode hergestellten Präparate auch einige wenige besitze, bei denen die Wimpertrichter des Excretionssystems gut imprägnirt sind, so will ich auch hierüber Einiges mittheilen. Wenn auch diese Methode nicht. geeignet sein dürfte, auf diesem Gebiet Aufschlüsse ïber feinere histologische Details zu geben, so hat sie doch auch hier vorzügliche Präparate in so fern geliefert, als sie einmal die Wimpertrichter im Zusammenhang mit den Capillaren darstellt, andrerseits so gute Uebersichtsbilder über die Lage und Vertheilung dieser Organe giebt, wie sie wohl kaum mit einer andern Methode erreicht werden können. Zunächst hat bisher keiner der Autoren, soweit ich aus der Literatur ersehen kann, bei Ligula die Wimpertrichter gesehen, doch sprechen Pintaer (1. c. p. 17) und Kiessling (1. c. p. 25) die Vermuthung aus, dass auch Ligula in Betreff des Vorhandenseins dieser Organe keine Ausnahme machen werde.

Die Imprägnirung der Trichter ist in so fern eine unvollständige, als die den Trichter abschliessende Geisselzelle nicht gefärbt ist. Fig. 35 zeigt, dass die Anordnung und Vertheilung der Trichter genau den Angaben Pintwer's entspricht; sie liegen am dichtesten in der Region des äussern Plexus, dringen aber auch zwischen die innern Längsmuskeln ein und sind in einigen Fällen sogar über diese hinaus bis in die Mittelschicht zu verfolgen. Die von den Trichtern ausgehenden, feinen Capillaren verlaufen bald einzeln, bald noch zwei oder drei von andern Trichtern herkommende Capillaren aufnehmend 
- ohne jedoch an Dicke zuzunehmen - zu den Gefässen des Plexus. Es findet nun nicht immer eine Einmündung der Trichtercapillaren in die am nächsten gelegenen Gefässe statt, denn ich sehe Capillaren von Trichtern, die in der Mittelschicht liegen, in den äussern und umgekehrt in den innern Plexus Capillaren einmünden, deren Trichter zwischen den Subcuticularzellen liegen. Die meisten Trichtercapillaren scheinen aber die Canäle des äussern Gefässnetzes aufzusuchen, während nur immer wenige Capillaren bis zum innern Plexus hin zu verfolgen sind. Gerade diese letztern Capillaren sind es, von denen schon oben gesagt wurde, dass sie, vom innern Plexus herkommend, bis über den äussern hinaus zu verfolgen wären, ohne mit diesem in Verbindung zu treten, also scheinbar frei im Gewebe zu endigen. In diesen Fällen waren eben die dazu gehörigen Wimpertrichter nicht imprägnirt.

Wenn es auch nicht in meiner Absicht liegt, über die histologische Structur der Gefässwände ausführliche Angaben zu machen - dazu sind die GoLGI'schen Präparate nicht geeignet - so will ich doch zum Schluss auf eine Erscheinung hinweisen, die ich beim Studium meiner Präparate nicht gerade selten antraf. Ich fand wiederholt, in grösseren und kleineren Gefässstämmen beider Plexus, in den Fällen, wo der Silberniederschlag nicht das Lumen des Gefässes erfüllte, eine scharf contourirte Längsstreifung der Gefässwand.

In Figg. 23 und 24 habe ich zwei Aeste des äussern Gefässnetzes, welche diese Längsstreifung deutlich erkennen lassen, abgebildet. Die schwarz imprägnirten Fasern sind glatt, überall gleich dick, und verlaufen in der Längsrichtung, theils einander parallel, theils einander kreuzend in der Gefässwand. In Fig. 25 sehen wir diese Fasern in der Wand eines inneren Längsstammes und von diesem auf die $a b$ gehende Anastomose übergehen. Durch diese Erscheinung aufmerksam geworden, habe ich alle meine Präparate gerade in Bezug hierauf einer genauen Musterung unterworfen und diese Längsstreifung wiederholt angetroffen, während ich nach circulären Fasern stets vergebens fahndete.

Was die Beschreibungen der frühern Beobachter anlangt, so gehen diese in puncto Gefässmusculatur wesentlich auseinander. Pintwer (23) und Kahane (21) negiren das Vorkommen von Längsstreifen in den Gefässmembranen und erklären die von Steudener (18) bei Bothriocephalus proboscideus beschriebenen Quer- und Längsstreifen in der Gefässwand für Schrumpfungserscheinunger. Im Widerspruch hiermit haben RIенм (24) bei Dipylidium leuckarti eine stark ent- 
wickelte Ringmusculatur, und Rовоz (29) bei Solenophorus ein System von kernlosen Ring- und Längsmuskelfasern in der Gefässwand beobachtet. Auch WiLL (56) erwähnt Ringmuskeln in der Gefässwand von Caryophyllaeus. Ich wage es nicht, auf Grund dieser einen und zumal nur durch die Anwendung einer Methode gemachten Beobachtung die Frage nach der Natur dieser Längsfasern zu entscheiden, halte es aber für sehr wahrscheinlich, dass wir es hier mit Muskelelementen in der Gefässmembran zu thun haben.

\section{Nervensystem.}

Wenden wir uns nun der Betrachtung des Nervensystems, der, wie SchIEFFERnecKer (12) sagt, ,kitzlichsten Frage" der Untersuchung, zu. Hier, auf ihrem ureignen Gebiet hat die Golgr'sche Methode neben der EHRLICH'schen Resultate gezeitigt, die in der That als überraschend zu bezeichnen sind. Dass diese ausschliesslich als Entoparasiten lebenden Thiere in Bezug auf Reichthum und Entwicklung von Nerven- und Sinneszellen andern frei lebenden Würmern keineswegs nachstehen, hätte ihnen wohl Niemand zugetraut.

Ich werde zunächst auf das periphere und dann das centrale Nervensystem eingehen. Im Voraus sei bemerkt, dass ich die beiden Längsstämme nebst deren Gehirncommissur als centrales, dagegen alle hiervon abgehenden Nerven bis zu ihrer peripheren Endigung als peripheres Nervensystem auffasse und später unten begründen werde.

\section{a) Peripheres Nervensystem.}

Iu der reichen Literatur über die feinere Anatomie der Cestoden, welche gerade in den letzten Jahrzehnten oft Gegenstand zum Theil sehr eingehender Untersuchungen geworden sind, finden sich auch hier und da einzelne Angaben über das periphere Nervensystem.

Zuerst glaubte SchiefFERDECKer (12) bei T. solium sensible und motorische Nervenendapparate gefunden zu haben, deren physiologische Function er auf das genaueste erklärte, bis Pintner (23) auf Grund seiner Studien über das Excretionssystem diese "Nervenendapparate“ richtig als die von ihm gefundenen Wimpertrichter wiedererkannte.

Blumberg (15) sagt ferner bei der Beschreibung der Tänien aus dem Pferdedarm (T. plicata, perfol., mamillana) auf p. 42: „die Nerven endigen in der Cuticula als zarte Fädchen, welche mit einer leichten Anschwellung abschliessen". Da ich diese Angabe ohne jeden Commentar und Abbildung vorfinde, wage ich nicht $\mathrm{zu}$ entscheiden, 
ob BlumberG wirklich die von mir zu beschreibenden Nervenendigungen bei diesen Tänien gesehen hat.

ZografF (50) bildet auf tab. 13, fig. 1 einige Epithelzellen von Triaenophorus ab und daneben zwei spindlige "Parenchymzellen", welche in der That die von mir gefundenen Sinneszellen sind. Ich habe mich gerade an Präparaten von Triaenophorus überzeugt, dass man hier die Sinneszellen durch gewöhnliche Färbungen darstellen kann, allerdings ohne Zusammenhang mit dem Nervensystem.

Die von WrLL (l. c.) an der Oberfläche des Kopfes von Caryophyllaeus vermutheten Sinneszellen habe ich schon bei der Beschreibung der Musculatur als die Myoblasten der äussern Ring- oder Längsmuskeln in ihr Recht eingesetzt.

Ausserdem geben verschiedene Autoren an, dass sie von den Längsnerven seitliche Nervenfasern abgehen sahen, ohne diese aber weiter verfolgen zu können.

Legt man in der schon beschriebenen Weise kleine Stücke der genannten Bandwürmer lebend in die Methylenblaulösung und wartet, bis sich die äussern Ringmuskeln nebst deren Myoblasten anfangen blau zu färben, so wird man an diesen Präparaten, besonders am Scolex und in der Halsregion, bald einzelne, ebenfalls blau gefärbte, spindelförmige Zellen erkennen. Bei näherer Untersuchung dieser Zellen sieht man von ihnen zwei Fortsätze ausgehen, einen langen zarten Faden, der in die Höhe steigt, in die Cuticula eintritt und hier mit einer birnförmigen Anschwellung endet, der andere Fortsatz geht in die Tiefe und ist oft noch eine Strecke weit zu verfolgen.

Diese Zellen sind, wie sich aus dem Zusammenhang ergeben wird, Sinneszellen. In den Figg. 68, 69 habe ich solche Zellen abgebildet, wie ich sie bei T. serrata und Triaenophorus oftmals gesehen habe. Während des Beobachtens der frischen Präparate treten nicht selten an den Nervenfasern feine Varicositäten auf; so dass die Fasern ein perlschnurartiges Aussehen gewinnen. Mit der EHrLICH'schen Methode ist es mir gelungen, diese Sinneszellen bei allen oben genannten Formen (mit Ausnahme von Ligula und Schistocephalus) wiederzufinden, doch habe ich niemals ordentliche Färbungen grösserer Nervenstämme oder Ganglienzellen erhalten, um so einen Zusammenhang der Sinneszellen mit dem Nervensystem festzustellen. Dies gelingt dagegen leicht mit der GoLGr'schen Methode, und so will ich zunächst die mit dieser Methode bei Ligula erlangten Resultate niederlegen:

Auf feinen Querschnitten gelungener Präparate erkennt man, um 
die Peripherie gleichmässig vertheilt, die Sinneszellen, welche wir mit Methylenblau färben konnten, sofort wieder. Sie liegen theils einzeln, theils, bei guter Imprägnirung, in grosser Menge neben einander in der Zone zwischen den Subcuticularzellen und den inneren Längsmuskeln, also in gleicher Höhe mit dem äusseren Gefässplexus, Fig. 37 -41. Bei der Eigenart der GoLGI'schen Methode, von der vorhandenen Anzahl gleicher Elemente meist nur einen Theil zu färben, lässt sich über die Anzahl dieser Zellen auf einer bestimmten Randpartie mit genauen Ziffern nicht antworten; sie scheinen weder an einzelnen Stellen besonders angehäuft zu sein, noch an andern ganz zu $\mathrm{zu}$ fehlen. Jedenfalls liegen sie in grosser Menge dicht neben einander, und darf man eher annehmen, dass noch mehr vorhanden sind, als auf den meisten Präparaten durchschnittlich gefärbt erscheinen. Zeigen doch oft besonders vollkommene, man möchte sagen, zu reichlich imprägnirte Schnitte ein solches Gewirr und Durcheinander von Sinneszellen, dass deren Entzifferung im Einzelnen kaum möglich ist.

Der Zellkörper der Sinneszellen ist meist von spindelförmiger Gestalt und ziemlich gleicher Grösse; bisweilen erscheint er kuglig aufgetrieben und kürzer, in andern Fällen etwas mehr in die Länge gezogen. Der Längendurchmesser der Zellen beträgt im Durchschnitt 12-20 $\mu$, die Breite ca. $5 \mu$. In einigen Fällen bleibt der Zellkern als heller Raum in der schwarzen Zelle aufgespart und zeigt dann eine ovale oder kreisrunde Form.

Die Richtung der Sinneszellen zur Cuticula ist auch etwas verschieden; im Allgemeinen ist ihre Längsaxe mehr oder weniger senkrecht gegen die Oberfläche gerichtet; manche Zellen liegen aber schräg, andere sogar parallel zur Cuticula. Im Abstand von der Cuticula finden sich nur unwesentliche Schwankungen, sie liegen alle in ziemlich gleicher Entfernung von der Oberfläche, in der Höhe des äussern Gefässplexus; ganz vereinzelt nur fand ich Sinneszellen tiefer ins Innere gerückt, zwischen den innern Längsmuskeln.

Alle Zellen stimmen ausnahmslos darin überein, dass sich der Zellkörper in mindestens zwei Fortsätze auszieht, in einen zur Cuticula aufsteigenden peripheren und einen, dem Innern zustrebenden centralen Fortsatz.

Der periphere Fortsatz ist meist etwas dicker als der centrale und steigt in ziemlich gerader Richtung zur Cuticula auf, dringt in diese ein und endet hier dicht an ihrem basalen Rande mit einer bläschenartigen Anschwellung, der oft noch ein feines Stiftchen aufsitzt. In vielen Fällen liegen diese Endbläschen unter einer der zahl- 
reichen trichterförmigen Einsenkungen der Cuticula, welche sich auf allen Präparaten mit dem Chromsilberniederschlag angefüllt haben, auf die ich noch später zurückkomme. Eine genaue Vergleichung aller GoLGI'schen Präparate sowie der nach der gewöhnlichen Methode gefärbten Schnitte, an denen diese Endbläschen auch zu sehen sind, ergab jedoch, dass im Allgemeinen eine Beziehung der Endbläschen zu den Durchbrechungen der Cuticula nicht bestehen kann. Ich fand diese Endorgane häufiger ohne eine Einstülpung wie mit einer solchen in Verbindung stehen. Da nun diese Endbläschen fast immer durch den Chromsilberniederschlag als tief schwarze Kugeln erscheinen, ohne einen Einblick in ihre Structur zu gewähren, so versuchte ich dies an den Orange-Hämatoxylinschnitten zu ermitteln. Sowohl auf den Quer- als auch Längsschnitten, also immer, wenn die Cuticula senkrecht durchschnitten ist, findet man in dieser, dicht an der Basis, bläschenartige Hohlräume, von kugliger bis birnförmiger Gestalt, welche von den Nervenfasern von unten nach oben senkrecht durchsetzt werden. An der obern Seite endet die Faser mit einer plattenartigen Verbreiterung (Fig. 46). Auch in Fig. 61 ist dies an einem GoLGIschen Präparat zu sehen, wo der Chromsilberniederschlag das Bläschen nicht ausgefüllt hat. Hier sehen wir auch den auf dem Bläschen sitzenden, senkrecht zur Cuticula gerichteten Stift, welcher ungefähr halb so lang ist als letzteres. Da sich dieser Stift nicht auf allen Präparaten fand und niemals auf den Methylenblaupräparaten mit Sicherbeit nachzuweisen war, so hielt ich ihn zunächst für ein durch die Imprägnirung erzeugtes Trugbild. Ich habe mich jetzt aber an den Präparaten, welche Herr BeTTENDORF ${ }^{1}$ ) mit der Methylenblaumethode von Cercariaeum (aus Helix hortensis) herstellte, überzeugt, dass hier die Sinneszellen der Saugnäpfe mit änlichen Endbläschen in der Cuticula endigen, denen jedesmal ein Stiftchen deutlich aufsitzt.

Der centrale Fortsatz der Sinneszellen bietet bei seiner Verfolgung ins Innere wesentlich mehr Schwierigkeiten als der periphere. Dieser, gewöhnlich feinere Fortsatz nimmt in den meisten Fällen vom Zellkörper her direct seinen Weg ins Innere des Thieres und ist oft, begleitet von einer grossen Anzahl von andern Sinneszellen herkommender Fortsätze, bis in die innere Längsmusculatur eine Strecke weit $\mathrm{zu}$ verfolgen. In andern Fällen biegt er, aus dem Zellkörper ausgetreten, bald seitlich um, um in den Fasern des subepithelialen Nervenplexus zu verschwinden. Nach langem Suchen und erst nach

1). cf. pag. 19. 
dem genauen Studium einer grossen Anzahl von Präparaten ist es mir gelungen, diesen Fortsatz bis zu seinem Ende, d. h. bis in den Längsnervenstamm zu verfolgen. Mit Sicherheit konnte ich dies zuerst bei dem seiner geringen Grösse wegen hierfür besonders geeigneten Triaenophorus feststellen. In Fig. 41 habe ich die Hälfte eines Querschnitts durch dieses Thier gezeichnet, auf dem die centralen Fortsätze von zwei Sinneszellen bis in die Längsnerven zu verfolgen sind. Bei Ligula ist es wegen der ungleichen Imprägnirung und wegen des weiten Weges, den hier die Faser von der Peripherie bis zu den Längsnerven zu machen hat, schwerer, den Verlauf einer einzelnen Faser ihrer ganzen Länge nach darzustellen. Ich habe aber in sehr vielen Fällen die centralen Fortsätze der Sinneszellen bis in die innere Längsmuskelschicht und darüber hinaus bis in das Parenchym verfolgen können und hier sich grösseren, vom Längsnerven herkommenden Nervenstämmen anschliessen sehen, Fig. j̃1. Ich kann als höchst wahrscheinlich annehmen, dass auch bei Ligula alle centralen Sinneszellfortsätze in das centrale Nervensystem eindringen um hier fein verästelt frei zu enden. Auf das Nähere hierüber werde ich beim centralen Nervensystem zurückkommen.

Der Vollständigkeit wegen will ich hier schon erwähnen, dass sowohl vom Zellkörper der Sinneszellen, als auch von den peripheren und centralen Fortsätzen bisweilen feine Fäserchen abgehen, welche zum grossen Theil noch eine Strecke weit im Epithel zu verfolgen sind und schliesslich frei endigen. Ich komme hierauf bei der Vergleichung meiner Befunde an Cestoden mit denen an andern Evertebraten zurück.

Ich will nun zunächst $\mathrm{zu}$ einem zweiten wichtigen Theil des peripheren Nervensystems der Cestoden, zu dem schon erwähnten subepithelialen Nervenplexus übergehen. Wir finden ihn etwas tiefer als die Sinneszellen, und zwar innerhalb des äusseren Gefässnetzes (Fig. 36-38, 40). Der für die GoLGı'sche Behandlung ziemlich günstige Nervenplexus setzt sich aus einer grossen Anzahl feiner Nervenfasern zusammen, die unter einander vielfach gekreuzt, theils parallel mit einander, theils unter sich verbunden, gleich dem äusseren Gefässplexus das ganze Thier umspinnen. Die Fasern scheinen der Hauptrichtung nach circulär um die Längsaxe des Thieres zu verlaufen, denn am besten sind sie auf Quer- und Flächenschnitten zu sehen, während sie auf Sagittalschnitten fast nur als Punkte oder kurze Faserabschnitte erscheinen. Dieser Plexus wird zum kleinen Theil aus den centralen Sinneszellfortsätzen gebildet, zum grössten 
Theil aber aus Nervenfasern, die direct von den Längsstämmen herkommen (Fig. 51). Ausserdem finden sich in diesem Plexus eine grosse Anzahl reich verzweigter Ganglienzellen, deren Verzweigungen zur Complicirung des Plexus beitragen, andererseits aber einem Theil der zahlreichen freien Nervenendigungen im Epithel der Ligula ihren Ursprung geben. Diese Ganglienzellen senden oft unmittelbar aus ihrem Zellkörper eine grosse Anzahl äusserst feiner varicöser Fäserchen gegen die Cuticula, welche sich wiederholt theilen, unter sich Verbindungen eingehen, um schliesslich dicht unter der Cuticula mit feinen Endbäumchen zu endigen (Fig. 39 a, 36). Ausserdem treten in vielen Fällen aus den Ganglienzellen stärkere Nervenstämme aus, die sich eine Strecke weit im subepithelialen Plexus hinziehen und von da aus zahlreiche, senkrecht gegen die Cuticula gerichtete Seitenäste abgeben, die sich unter der Cuticula in feinste Endbäumchen auflösen oder sich zwischen den Epithelzellen baumförmig verästeln und dann in zierlichen Dendriten unter der Cuticula enden (Fig. 36, 39a). An der Bildung dieser freien Nervenendigungen betheiligen sich auch Fasern, deren Ganglienzellen theils in den Längsnerven selbst liegen, theils auf dem Wege der Faser zur Peripherie zu finden sind.

Die Endbäumchen enden meist frei als feinste Fäserchen dicht unter der Cuticula, bisweilen scheinen sie aber an ihrem Ende fein punktförmig verdickt. Ausser diesen eigentlichen Endbäumchen fand ich auch frei endende Nervenfasern, die, wie besonders in Fig. 39 schön zu sehen ist, aus der Tiefe kommen, im Epithel sich wiederholt theilen und dann, unter der Cuticula angelangt, rechtwinklig umbiegen, eine Strecke weit unter der Cuticula hinziehen und hier zahlreiche, nach dieser hin gerichtete, feine Fäserchen abgeben.

In Fig. 42 habe ich eine Abweichung von der gewöhnlichen Lage dieser den freien Nervenendigungen ihren Ursprung gebenden Ganglienzellen abgebildet. Ich habe diesen Fall einmal auf dem Seitenrande eines Schnittes dicht vor dem Hinterende des Thieres beobachtet; bier liegen die Ganglienzellen nicht im subepithelialen Plexus, sondern sind nach innen bis in die innern Längsmuskeln verlagert. Sie liegen gerade so weit vom äussern Gefässnetz nach innen, als dessen Abstand von der Cuticula beträgt, und bilden hier durch ihre Ausläufer ein feines Netzwerk von Nervenfasern, die zum Theil nach der Cuticula ziehen, um hier mit Endbäumchen frei zu endigen.

Was die Vertheilung der freien Nervenendigungen über die Körperoberfläche anlangt, so finden sie sich gerade so zahlreich wie die Sinneszellen, so dass die gesammte Oberfläche unseres Thieres mit 
diesen beiden Arten der Nervenendigungen überaus reichlich versehen ist. Es ist mir niemals gelungen, bei irgend einem der untersuchten Bandwürmer diese freien Nervenendigungen mit der MethylenblauMethode darzustellen, während ich sie bei den drei mit der GoLGIschen Methode behandelten Thieren (Ligula, Triaenophorus, Schistocephalus), besonders aber bei ersterer in vorzüglicher Weise zur Darstellung bringen konnte.

Vergleichen wir nun das periphere Nervensystem der Cestoden mit dem bei andern Wirbellosen bekannt gewordenen.

Zunächst war es v. LenHosséK (53) mit Hülfe der GoLGI'schen Methode gelungen, bei Lumbricus in der Haut Zellen nachzuweisen, die, im Verbande der Epithelzellen gelegen, an ihrem basalen Theil mit einer frei im Bauchmark endenden Nervenfaser zusammenhingen. Diese Beobachtung wurde bald darauf von Retzius (51) bestätigt. Beide Autoren erkannten und beschrieben diese Zellen als Sinneszellen. Sie weichen von unsern Sinneszellen in so fern ab, als sie, noch im Epithel gelegen, des peripheren Fortsatzes entbehren und mit dem Zellkörper selbst an die Cuticula heranreichen. In völliger Uebereinstimmung mit den Sinneszellen der Cestoden siud die von Retzius (52) bei Polychäten und Mollusken mit beiden Methoden nachgewiesenen Sinneszellen. Hier finden wir dieselben spindelförmigen Zellen, welche theils noch im Epithel gelegen, meist aber aus diesem heraus in die Tiefe gerückt sind und jede durch die beiden Fortsätze mit der Cuticula bezw. dem Centralorgan in Verbindung stehen. In der neuesten Zeit. sind nun diese im Princip überall gleich erscheinenden Sinneszellen bei vielen andern Formen der Wirbellosen gefunden worden, so von SAMASSA (58) bei Helix pomatia, von O. vom RATH (65) bei Arthropoden.

Interessant ist es, dass sich auch bei den höchsten Wirbelthieren bis zum Menschen herauf dieses ursprüngliche Verhalten der Sinneszellen noch an verschiedenen Körperstellen erhalten -hat. So finden wir dank der eingehenden Untersuchungen zahlreicher neuerer Forscher in der Geruchsschleimhaut und in den Geschmackspapillen dieselben Sinneszellen wieder, welche wir bei den Evertebraten über die ganze Körperoberfläche verbreitet angetroffen haben. Auch im Gehörorgan der Wirbelthiere treffen wir diese bipolaren Sinueszellen wieder an, doch sind es hier, wie vaN GEHUCH'TEN und Retzius nachgewiesen haben, nicht die im Epithel gelegenen Hör- oder Haarzellen, sondern die im Verlauf des Acusticus befindlichen bipolaren Zellen, deren centrale Fortsätze frei im Centralorgan endigen, während die peripheren 
im Gehörorgan zwischen den Haarzellen in den Maculae, Cristae und Papillae acusticae mit feinen Spitzen auslaufen.

In allen diesen Fällen haben wir es mit Sinnesnervenzellen zu thun, die, wie Retzius (1. c. p. 18) hervorhebt, nicht im Sinne der ältern Autoren als ,specifische Epithelzellen aufzufassen sind, die nur peripher mit einer Nervenfaser zusammenhängen, deren Ganglienzellen aber im Centralorgan liegen, sondern diese bipolaren, sensiblen Zellen sind selbst die Nervenzellen (Ganglienzellen), von welchen die fraglichen Nervenfasern entspringen, um in ihrem centralwärts angeordneten Verlauf die Centralorgane aufzusuchen und auf ihre Elemente in irgend einer Weise, wahrscheinlich nur durch Berührung (Contact), die Reizimpulse überzuführen".

Das einfachste, wahrscheinlich auch ursprüngliche Verhalten dieser Sinneszellen nebst ihren Fortsätzen ist in allen den Fällen gegeben, wo wir von der bipolaren Zelle einen Fortsatz nach der Cuticula, einen nach dem Centralorgan abgehen sehen, die auf ihrem Verlauf weder Seitenäste abgeben noch mit andern Fasern in irgend welche Verbindung treten. Sowohl Lenhossék als Rétzius und Samassa haben aber bei den von ihnen untersuchten Thieren überall mehr oder weniger erhebliche Abweichungen von diesem ursprünglichen Verhalten gefunden. Da ich auch bei Ligula nicht selten Aehnliches beobachten konnte, will ich darauf etwas näher eingehen. Wie schon oben erwähnt wurde, gehen nicht selten sowohl von den Sinneszellen selbst, als auch von deren beiden Ausläufern seitlich feine Fäserchen ab, die meist nach kürzerem oder längerem Verlauf frei zwischen den Epithelzellen endigen, in einigen Fällen aber wichtige Verbindungen herstellen, die mir einer eingehenden Beachtung werth erscheinen.

Von dem peripheren Zellfortsatz gehen nicht gerade selten feine Fäserchen $a b$, die in den meisten Fällen bald im Bereich der Epithelzellen endigen. Dasselbe bildet Savissa (56) für die peripheren Fortsätze von Helix pomatia ab, ohne, ebenso wenig wie ich, eine Erklärung dafür abgeben zu können. Auch Retzius (52, p. 10) beschreibt seitliche Verzweigungen des peripheren Sinneszellfortsatzes im Fühler von Lepidonotus.

Mit den Dendriten v. LenhosséK's, welche sich an der Basis der meisten Sinneszellen von Lumbricus finden, könnten feine Fäserchen verglichen werden, die bisweilen vom Körper der Sinneszellen abgehen und bald frei endigen, ohne dass ich sie deshalb damit identificiren will.

Am häufigsten konnte ich aber von den centralen Fortsätzen der 
Sinneszellen ein Abgehen von Seitenfasern verfolgen, die meist auch frei endeten, bisweilen aber auch direct in Fasern des subepithelialen Plexus übergehen. In Fig. 38 und 8 habe ich einige Fälle abgebildet, in denen ich eine Verbindung der Sinneszelle durch feine Ausläufer mit Plexusnerven sicher nachweisen kounte. Fig. 40 stellt einen, allerdings allein stehenden Fall dar; hier gehen von dem peripheren Fortsatz hinter einander zwei Fasern ab, die zum Plexus zurücklaufen, und von denen die eine, wie ich sicher feststellen konnte, in eine Nervenfaser des Plexus übergeht. Retzius $(52$, p. 16) fand bei den Sinneszellen der Limacinen auch nicht selten unzweifelhafte Verästelungen und Seitenzweige des centralen Sinneszellenfortsatzes, die sogar in einzelnen Fällen bis in das Epithel emporsteigen und hier „Knotig varicös"6 frei endeten. Er lässt die an dieser Stelle aufgeworfene Frage: ,entweder sind hier wirklich frei endende Seitenzweige (Collateralen), oder auch sind den centralen Forsätzen Fasern anderer Art (motorische) beigemischt, welche sich später wieder von ihnen trennen", unbeantwortet. Für letztere Annahme würde eine Beobachtung, die ich hier anführen will, sprechen, ohne dass ich an diesen einen Befund $\mathrm{zu}$ weitgehende Speculationen knüpfen will. In einem Fall fand ich nämlich eine directe Verbindung zwischen einer vom Zellkörper einer Sinneszelle herkommenden Faser mit einer Sommer-Landoisschen Zelle der äussern Ringmusculatur (Fig. 8). SAMASSA (58, p. 603) beschreibt aber eine ganz ähnliche Beobachtung am Fühler von Helix pomatia. Am peripheren Ende des Tentakelmuskels fand Samassa Zellen, die etwas grösser als die Sinneszellen sind und „einen starken, unverzweigten Fortsatz zur Körperoberfläche senden, während ein oder mehrere Fortsätze centralwärts entspringen, die sich im Muskel verzweigen; diese Endverzweigungen haben grosse Aehnlichkeit mit den Verzweigungen der motorischen Nerven in den Muskeln der Körperwand von Arion, wie sie von Retzius beschrieben und abgebildet werden".

Diese Beobachtung legt die Vermuthung nahe, dass man es hier mit einer „motorischen Sinneszelle" zu thun hätte, deren Function darin bestände: ,mit ihrem peripheren Fortsatz Sinnesreize aufzunehmen und mit ihren centralen Fortsätzen auf den Muskel zu übertragen". Zu demselben Schluss muss mich diese Beobachtung an Ligula führen. Wir haben hier (Fig. 8) eine Sinneszelle, welche ausser ihrem peripheren, mit dem typischen Endbläschen und Stiftchen versehenen Fortsatz noch drei andere abgiebt und zwar den centralen, in diesem Fall bis in die Region der innern Längsmuskeln zu verfolgenden Fortsatz, ferner einen in den Plexus übergehenden und 
drittens einen langen varicösen Faden, der mit dem Myoblasten in Verbindung tritt, nachdem er vorher noch zwei Seitenfortsätze abgegeben hat.

In Bezug auf die Endigung der peripheren Sinneszellfortsätze in der Cuticula will ich noch zwei Angaben erwähnen, die ich bei Hesse (64) und RoHDE (60) für Lumbricus herculeus und Ascaris finde, und die mit meinen Endstiftchen in der Cuticula übereinstimmen. Hesse fand bei Lumbricus herculeus ausser den LeNHOsséK'schen Zellen, besonders schlanke Sinneszellen, welche in grösserer Anzahl zu ,Sinnesknospen" vereinigt liegen. Diese Zellen tragen an ihren peripheren Enden „feine Härchen oder Stiftchen, welche die Cuticula durchbohren". - „Es hat manchmal den Anschein, als ob die Stiftchen an ihrem Ende ein feines Knöpfchen tragen." RовDE hält die sog. Pulpa in den Papillen von Ascaris ,für das kolbig angeschwollene Ende der Nervenfaser, eine Art nervösen Endorgans, welche durch die Papille zu Tage tritt". Die Endspitze tritt dann als feine Fortsetzung dieser Anschwellung „durch dic Cuticula zu Tage, äusserlich nur von einem äusserst. feinen Chitinhäutchen bedeckt".

Ueber die zweite Art von sensiblen Nervenendigungen, über die freien Nervenendigungen im Epithel, wie ich sie für Ligula beschrieben habe, ist bisher bei Evertebraten wenig bekannt geworden.

ReTzius (52) beschreibt zuerst in den Parapodien verschiedener Polychätenarten freie Nervenendigungen, ,welche in ihrer reichlich dendritischen Endverzweigung die bei den höher stehenden Thieren normale Endigungsweise sensibler Nerven darzubieten scheinen". Bei Mollusken sind freie Nervenendigungen ebenso wenig gefunden, wie bei Arthropoden. Auch sind bei Lumbricus den verdienstvollen Forschern LenhosséK und Retzius freie Nervenendigungen entgangen und erst jüngst durch SmInNow (62) auch hier gefunden und von Retzius (52a) und F. Langdon (63) bestätigt worden. Smirnow beschreibt im Epithel der Körperhaut und des ganzen Nahrungsschlauches von Lumbricus feine, varicöse Nervenfäden, die sich wiederholt theilen und schliesslich in verschiedener Höhe im Epithel knopfförmig verdickt oder fein zugespitzt enden. Diese Fasern nehmen Antheil an der Bildung des subepithelialen Nervenplexus und verlaufen dann mit den centralen Fortsätzen der Sinneszellen und den motorischen Fasern zusammen zum Bauchmark. Da diese freien Nervenendigungen oft die in der Haut von Lumbricus so ungemein zahlreichen Schleimdrüsen umspinnen, schreibt SyIRNow ihnen ausser der sensiblen auch noch eine secretorische Function zu. Ausserdem 
beobachtete dieser Forscher, dass die Blutgefässe des Regenwurms von „Nervenfasern und nervösen Zellfortsätzen umsponnen werden, denen wahrscheinlich die Bedeutung von Vasomotoren zukommt".

Gehen wir nun zur Betrachtung des motorischen Nervensystems über. Für die Innervirung von Muskelfasern ist bei Cestoden bis auf eine Angabe bei SchiefFerdecker (12, p. 479) meines Wissens nichts bekannt geworden ${ }^{1}$ ). SCHIEFFERdecker fand an einem Zerzupfungspräparat von $T$. solium zwei Muskelfasern, ,bei denen sich in ihrem dicksten Theil ein kleiner feiner Fortsatz fand“. Dieser war „eine Faser von feinkörnigem Gefüge, welche bei beiden Muskeln ohne Grenze in die äussere, stark lichtbrechende Schicht überzugehen schien. Bei der einen Muskelfaser theilte sie sich vor ihrem Eintritt noch gabelförmig“6

Die Innervirung der Muskelfasern geschieht auf zweierlei Art, einmal vermittelst der Myoblasten, zweitens direct an der contractilen Substanz. Auf erstere Art der Innervirung wurde schon bei der Beschreibung der Myoblasten hingewiesen. Ausschliesslich durch die Myoblasten innervirt werden alle die Muskelfasern, denen die Myoblasten nicht direct anliegen, sondern durch protoplasmatische Fortsätze mit den contractilen Fasern in Verbindung stehen. Die Myoblasten dieser Muskelfasern - die Sommer-Landors'schen Zellen senden, wie wir schon sahen, einen oder mehrere Fortsätze in die Tiefe, um hier mit den Nerven des subepithelialen Plexus in Verbindung zu treten (Fig. 6, 7, 8). Man kann sich leicht überzeugen, dass ein einzelner Myoblast nicht nur mit einer, sondern oft mit 2 oder mehr Nervenfasern des Plexus zusammenhängt. Bei den andern Muskelfasern, denen die Bildungszelle seitlich anliegt, tritt die Nervenfaser nun theils durch die Myoblasten, theils an der contractilen Faser heran. Beides scheint gleich oft der Fall zu sein (Fig. 9-15). Ueber die Beziehung der Nerven zum Inhalt des Muskels kann ich keine nähern Angaben machen, da die GoLGI'sche Methode ein Studium dieser Verhältnisse nicht erlaubt. In einigen Fällen. schien sich die Nervenfaser mit einer kleinen dreieckigen Verbreiterung an die Muskelfaser $\mathrm{zu}$ heften (Fig. 14), doch erlaubt dies vereinzelte Vorkommen sicher keinen Schluss auf eine bestimmte Art der Innervirung, da diese kleine Hervorwölbung ebenso gut eines der zahlreichen eigenthümlichen Anhängsel der Muskelfasern sein kann, wie sie die mit Chromsilber imprägnirten Muskelfasern fast immer zeigen. In Fig. 11 habe ich zwei Transversalmuskeln abgebildet, die von zwei zwischen

1) Auf die Angabe von Roвоz (29) habe ich schon bei der Besprechung der Musculatur (S. 30 u. 42) eingehend hingewiesen. 
ihnen verlaufenden Nervenstämmen aus innervirt werden. Wir sehen hier einmal die von SCHIEFFERDECKER beobachtete gabelförmige Theilung der Nervenfaser kurz vor ihrem Ansatz an den Muskel und ferner die eine Faser durch eine äusserst feine, durch zahlreiche Knötchen perlschnurartig erscheinende Nervenfaser umsponnen werden.

Ueber die Herkunft dieser motorischen, der Muskelinnervirung dienenden Nerven kann ich Folgendes angeben: Die äussern Ring- und Längsmuskeln sahen wir von Nervenfasern innervirt werden, die dem subepithelialen Nervenplexus angehören. Recht häufig konnte ich auch Nervenfasern, welche die im Innern des Thieres gelegenen Transversalund Dorsoventralmuskeln versorgen, bis in diesen Plexus hinein verfolgen. Bei andern Muskeln dieser Systeme, besonders bei solchen, die nicht weit von den Längsnerven entfernt lagen, sah ich die motorischen Fasern direct aus den Längsstämmen hervorgehen (Fig. 10, 12). Wo liegen die zu diesen Nervenfasern gehörigen Ganglienzellen? Um diese Frage zu beantworten, müssen wir zuerst feststellen, wo überhaupt Ganglienzellen zu finden sind. Mit Ausnahme der schon erwähnten, den freien Nervenendigungen ihren Ursprung gebenden Ganglienzellen des subepithelialen Plexus finden wir Ganglienzellen, welche ia oder dicht neben den Längsnerven liegen, und solche, die in die hiervon abgehenden Nervenstämme eingelagert sind. Beide kommen, meiner Meinung nach, für unsere Frage in Betracht. Wenn ich auch nicht einen ununterbrochenen Zusammenhang zwischen den Muskeln einerseits und den Ganglienzellen andererseits habe finden können, so kann ich als wahrscheinlich annehmen, dass die bis in die Längsnerven $\mathrm{zu}$ verfolgenden motorischeu Nerven die Ausläufer von einigen der hier in grosser Menge vorkommenden Ganglienzellen sind. Ich komme hierauf bei der Besprechung des centralen Nervensystems zurück. Da ferner, wie ich schon ausführte, sehr viele der von dem Längsnerven zum Plexus hinziehenden Nervenstämme durch spindelförmige Ganglienzellen unterbrochen sind, andererseits aber viele Muskeln ihre Nerven aus diesem Plexus beziehen, so möchte ich auch einen Theil dieser Ganglienzellen für motorische halten, während ein anderer Theil $\mathrm{zu}$ den freien Nervenendigungen gehören wird, die nicht mit Zellen des Plexus in Verbindung stehen, sondern, wie wir sahen, über diesen hinaus in die Tiefe verliefen.

Wir würden also bei Ligula eine scharfe Trennung zwischen motorischem und sensiblem Nervensystem haben, doch im Vergleich zu Lumbricus insofern eine Abweichung, als hier nach Retzius (51) die motorischen Nervenzellen alle in den Ganglien des Bauchmarks 
liegen und von hier aus ihre Stammfortsätze an die Körpermuskeln entsenden; während auch bei Ligula die sensiblen Nervenzellen unter dem Epithel liegen und ihre Stammfortsätze in das Centralorgan senden, wo sie percipirte Sinneseindrücke durch Contact auf die motorischen Fasern übertragen.

Jedenfalls bedarf es gerade hier noch weiterer Untersuchungen, um auch für die Cestoden diese Fragen ihrer definitiven Beantwortung näher zu bringen.

b) Centrales Nervensystem.

Leider ist es mir trotz zahlreicher Versuche nicht gelungen, eine brauchbare Imprägnirung des Kopfes von Ligula zu erhalten, und ich werde im Folgenden nur meine Befunde über den Bau und die Structur der Längsnerven angeben, welche sich für die Imprägnirung günstiger erwiesen.

Ich werde bei der Beschreibung des centralen Nervensystems zunächst die mit Sublimat conservirten und mit Orange-g Hämatoxylin gefärbten Schnitte berücksichtigen und das hieran Ermittelte mit den nach der GoLGI'schen Methode behandelten Präparaten vergleichen.

Bei Ligula verlaufen die beiden Längsnervenstämme durch das ganze Thier hindurch in der Mittelschicht ausserhalb des inneren Gefässplexus. Sie besitzen, wie man sich auf Flächenschnitten leicht überzeugen kann, in ihrem ganzen Verlauf annähernd den gleichen Durchmesser. Quercommissuren, wie sie WILL (56) be1 Caryophyllaeus und KöHLER (61) bei $T$. expansa feststellten, sind nicht vorhanden. Niemals habe ich die von KIESSL_ING (30) bei Ligula beobachteten „Anschwellungen der Längsnerven, welche immer mit der Strobilation Hand in Hand gehen", nachweisen können. In unregelmässiger Aufeinanderfolge sieht man oft nach innen und aussen Seitennerven aus den Hauptstämmen austreten, die bisweilen bis in die Längsmusculatur $\mathrm{zu}$ verfolgen sind, sich aber dann in einzelne Fasern auflösen und in dem umgebenden Gewebe verschwinden.

Was nun die histologische Structur der Längsstämme betrifft, so zeigen diese auf ihrem ganzen Verlauf den gleichen Bau. Sie sind vom umgebenden Parenchym deutlich abgesetzt, indem sich letzteres um die Längsstämme herum besonders dicht zusammenlagert und für die Nervenstämme eine ziemlich dichte Hülle mit zahlreichen Kernen bildet. Auf Querschnitten zeigen die Längsnerven einen eigenthümlichen maschigen, spongiösen Bau. Inmitten der umgebenden Hülle sehen wir ein feines spongiöses Netzwerk, dessen verschieden dicke 
Maschen aus feinen, an einander gelagerten Punkten und Fäserchen gebildet erscheinen, während die Maschen selbst leer sind.

Längsschnitte dagegen lassen die Nerven fein fibrillär zu einzelnen Zügen neben einander angeordnet erscheinen, die nicht selten durch grosse, theils mitten in der Nervenmasse, theils an der Seite liegende Zellen unterbrochen sind. Diese Zellen besitzen Spindelform und liegen mit ihrer Längsaxe im Verlauf der Nervenfaser; sie scheinen in zwei Fortsätze ausgezogen, die oft eine Strecke weit zwischen den Fasern verfolgt werden können (Figg. 53, 54). In diesen Zellen sind Kern und Protoplasma gut differenzirt. Der Kern tritt als scharf begrenztes helles Bläschen aus dem Plasma hervor und zeigt meist mehrere grössere Nucleolen, ist aber sonst wie das Zellplasma fein granulirt. Auffallend ist die Grösse dieser Zellen; ihre Länge beträgt 35-50 $\mu$, ihre Breite 5-9 $\mu$. Einmal auf diese Zellen aufmerksam geworden, fand ich sie nicht nur sehr oft in den Längsstämmen wieder, sondern auch in den abgehenden Seitennerven und nicht selten mitten im Parenchym, scheinbar ohne Verbindung mit Nervenfasern (Fig. 5\%). $\mathrm{Zu}$ verwechseln sind sie ihrer Grösse und des hell gefärbten Inhalts wegen nicht leicht mit andern Zellen.

Vergleichen wir diese Befunde mit den GoLGr'schen Präparaten, so finden wir hier nicht nur eine Bestätigung des oben Angeführten, sondern so viel neue und überraschende Thatsachen, dass sie uns das Nervensystem der Cestoden in einem ganz andern Lichte erscheinen lassen. Auch hier gelangt man am besten zum Verständniss des Faserverlaufs an Sagittal- und Horizontalschnitten. Auf beiden findet man denn gewöhnlich eine Anzahl von in der Längsrichtung verlaufenden Fasern imprägnirt und die oben beschriebenen grossen Zellen, über deren Natur als Ganglienzellen nun kein Zweifel mehr bestehen kann (Figg. 49, 50). Hier sehen wir diese Ganglienzellen in der Längsund Querrichtung angeordnet und die beiden spindelförmig ausgezogenen Enden in zwei stärkere Nerven auslaufen, während vom Körper der Zelle her feinere, oft mehrfach verzweigte Fasern in die Masse der Längsnerven ausstrahlen. Liegen die Ganglienzellen in der Längsrichtung, so ziehen auch die beiden Hauptfortsätze in der Längsrichtung innerhalb des Nervenstranges hin, hier und da feine Seitenzweige abgebend. Ueber den Verbleib dieser Fasern kann ich nur angeben, dass sie oft zwischen den Längsfasern auszulaufen scheinen, oft aber auch weite Strecken hin bis an die Grenze des Präparats zu verfolgen waren. Die andern, querliegenden Ganglienzellen bleiben mit den feinen, vom Zellkörper selbst abgehenden Fasern in der Substanz der 
Längsstämme, senden aber ihre stärkeren Ausläufer gewöhnlich nach der entgegengesetzten Richtung in den Körper hinaus.

Einen weiteren höchst wichtigen Aufschluss geben uns diese Schnitte über das Verhalten der aus den Längsstämmen austretenden Seitennerven. Diese stellen keine Umbiegungen der Längsfasern nach aussen dar, sondern sie entspringen immer als neue Fasern, welche äusserst reichhaltig wurzelförmig verzweigt in den Längsstämmen entstehen und dann rechtwinklig zu diesen in den Körper austreten.

Die Figg. 47, 48 zeigen dieses Verhalten in schönster Weise. Die Nervenfasern treten einzeln oder zu mehreren vereinigt von allen Seiten an die Längsstämme heran und lösen sich, im Innern derselben angelangt, sofort unter zahlreichen Verzweigungen und Verästelungen $\mathrm{zu}$ einer fast unentwirrbaren Dendritenmasse auf. Nicht selten beobachtet man (Fig. 48) einzelne Fasern rechtwinklig von dem Seitennerven abbiegen und dann, feine Seitenfasern abgebend, eine Strecke weit in den Längsstämmen auf- und abwärts hinziehen, um endlich frei auszulaufen.

Die zahlreichen freien Verästelungen der Seitennervenwurzeln greifen nun sowohl mit den benachbarten und gegenüberliegenden, als auch mit den Ausläufern der im Längsnervenstamm verlaufenden Nervenfasern und Ganglienzellfortsätzen so in und durch einander, dass ein schier unentwirrbares Nervengeäst entsteht, wie es die beste Zeichnung kaum wiederzugeben im Stande ist. Jedenfalls, das sei hier schon besonders hervorgehoben, ist ein Ineinanderübergehen von verschiedenen Nervenfasern niemals mit Sicherheit zu constatiren.

Ausser den im Innern der Längsnerven liegenden Ganglienzellen finde ich nicht selten in unmittelbarer Nähe der Längsnerven multipolare Ganglienzellen, die mit den an gefärbten Schnitten beobachteten identisch sind. In Fig. 59 habe ich solche im Querschnitt und in Fig. 50 im Flächenschnitt abgebildet. Diese Zellen sind nicht spindlig gebaut, sondern unregelmässig verzweigt; sie senden (Fig. 50) einen oder mehrere Ausläufer (Fig. 59) in den Körper, eine grössere Anzahl feiner und vielfach verzweigter Fortsätze aber in die Längsnerven, welche dann hier frei ausstrahlen. In der Fig. 50 ist ausserdem eine sehr grosse bipolare Ganglienzelle imprägnirt, die auch ausserhalb der Längsstämme liegt und einen Fortsatz ins Parenchym, einen centralwärts entsendet. Letzterer giebt zunächst einen reich verzweigten Seitenfortsatz ab und verlässt dann auf der anderen Seite das Centralorgan wieder, wo er nicht weiter imprägnirt war. Die ungewöhnliche Dicke des einen Fortsatzes ist bier jedenfalls dadurch bedingt, dass 
sich der Chromsilberniederschlag nicht in, sondern auf der Oberfläche der Faser gebildet hat.

Fassen wir nun den Verlauf der im Längsnervenstamm entspringenden Seitennerven ins Auge, so können wir hier drei Arten von Seitennerven unterscheiden :

1) Die peripheren Fortsätze der in den Längsnerven liegenden Ganglienzellen.

2) Solche Seitennerven, in deren Verlauf zur Peripherie Ganglien eingeschaltet sind.

3) Die centralen Fortsätze der Sinneszellen.

Die Seitennerven, welche als unmittelbare Fortsätze der Ganglienzellen der Längsnerven austreten, besitzen jedenfalls motorische Function. Einentheils konnte ich sie bis zum äusseren Nervenplexus verfolgen, von dem wir sowohl die Sommer-LANDoIs'schen als auch manche Parenchymmuskeln innervirt sahen, anderntheils konnten wir die von Muskeln in der Nähe der Längsnerven kommenden Nervenfasern bis in die Längsstämme verfolgen. Dass diese Ganglienzellen sensiblen Fasern den Ursprung geben, möchte ich deshalb bezweifeln, weil wir die sensiblen Ganglienzellen im subepithelialen Plexus in grosser Menge antreffen. Höchstens könnten sie zum Theil zu den Fasern gehören, die unter der Cuticula mit Endbäumchen frei endigen, dann aber in die Tiefe zu verfolgen waren.

Zur zweiten Art von Seitennerven, in deren Verlauf zur Peripherie eine Ganglienzelle eingeschaltet ist, gehören die meisten aller Seitennerven. Zunächst kämen die peripheren Fortsätze der dicht neben den Längsstämmen liegenden Ganglienzellen in Betracht, welche nicht weit zu verfolgen waren, während die centralen im Längsnerven verästelt ausliefen. Ferner die Seitennerven, welche auf sehr vielen Querschnitten $\mathrm{zu}$ finden sind und im Längsstamm wurzelförmig entspringen (Figg. 51, 60), dann in mehr oder weniger grosser Entfernung vom Ursprung eine spindelförmige Anschwellung zeigen, die etwas grösser ist als die Sinneszellen. Peripherwärts von dieser bipolaren Ganglienzelle verlaufen diese Fasern dann bisweilen verzweigt, meist aber unverzweigt zum subepithelialen Plexus. Diese Zellen sind jedenfalls mit den von mir an Sublimatpräparaten beschriebenen Zellen identisch, welche ich mitten im Parenchym antraf, ohne eine Verbindung mit Nervenfasern zu sehen. Diese Zellen dürften mit motorischen, vielleicht auch sensiblen Fasern in Verbindung stehen, denn vom Plexus wissen wir viele Muskeln innervirt; sie können aber auch mit den in die Tiefe $\mathrm{zu}$ verfolgenden freien Nervenendigungen in Zusammenhang stehen. 
Dass schliesslich die centralen Fortsätze der Sinneszellen im Centralorgan frei endigen, habe ich bei Triaenophorus gesehen und ist für Ligula wahrscheinlich. $\mathrm{Zu}$ den im Längsstamm sich wurzelförmig: auflösenden Seitennerven dürften ausser diesen Sinneszellfortsätzen auch die Fasern gehören, welche die Verbindung zwischen den Ganglienzellen des äussern Nervenplexus mit den Längsnerven herstellen.

Schon beim Studium der gefärbten Längs- und Querschnitte von Ligula ist, wie bereits erwähnt wurde, unschwer zu erkennen, dass die Längsnerven deutlich vom Parenchym abgegrenzt sind. Es ist allerdings sehr schwierig, hier zu einem Urtheil zu gelangen, ob sich nur die Parenchymzellen mit ihren Ausläufern in dichter Aneinanderlagerung um die Nervenfasern gruppirt haben und so eine dunkler gefärbte Hülle darstellen oder ob den Längsnerven eine eigene Hülle zukommt. Auch diese Frage ist durch die Golgr'sche Methode für Ligula zur Entscheidung gebracht worden.

Die Längsnerven von Ligula besitzen eine eigene, aus verästelten Zellen gebildete Hülle. Wir können diese Hüllzellen am besten auf Sagittal- und Horizontalschnitten übersehen, auf denen sie sich so darstellen, wie ich in Figg. 57, 58 abgebildet habe.

Diese Hüllzellen stehen in gewisser Uebereinstimmung mit den Parenchymzellen, unterscheiden sich aber von diesen durch bedeutend kürzere Ausläufer, welche den aus der Kleinhirnrinde bekannten Moosfasern sehr ähnlich sind. Von einem relativ kleinen, unregelmässig gestalteten Zellkörper strahlen nach allen Richtungen Fortsätze aus, die vielfach verzweigt und verästelt sind und durch kleine Seitenanhängsel und Verdickungen dem Ganzen ein moosartiges Aussehen verleihen. Die Fortsätze dieser Hüllzellen nehmen ihre Hauptausdehnung in der Richtung der Längsnerven und umhüllen diese von allen Seiten, indem sich oft mehrere über einander an die Nervenstämme anlegen, so vollständig, dass für diese hierdurch eine feste Hülle geschaffen ist. Figg. 55,56 zeigen dieses Verhalten sehr deutlich im Querschnitt. Niemals habe ich mich davon überzeugen können, dass Fortsätze der Hüllzellen in das Innere der Längsnerven hineinragen, wohl aber davon, dass einzelne Fasern der Hüllzellen in das umgebende Parenchym ausliefen. Vielleicht sind diese Hüllzellen aus Parenchymzellen entstanden, welche für den besonderen Zweck, die Nervenstämme zu umbüllen, modificirt wurden.

Ich will nun versuchen, die im Vorstehenden angeführten Thatsachen mit den Beobachtungen früherer Forscher zu vergleichen.

Nachdem zunächst die Frage, ob den Cestoden überhaupt ein 
Nervensystem zukomme, durch Nitsche (9), Schneider (10), SchiefferDECKer (12), Leuckart (22), Steudener (18) u. A. in bejahendem Sinne entschieden war und die spongiösen Längsstämme als die Längsnerven erkannt worden waren, trat die Frage nach der morphologischen Bedeutung dieses Organs in den Vordergrund. So sagte KaHane (21) am Schlusse seiner Betrachtung über das Nervensystem : „Wenn man nun das Nervensystem als erwiesen und als aus den hier aufgezählten Theilen bestehend ansieht, so entsteht die Frage, welcher Antheil als Centralorgan zu gelten habe und was uns an peripheren Gebilden bekannt ist."

Diese Untersuchung führt natürlich auch zur Berührung der wichtigen Frage, in wie weit man das Nervensystem der Cestoden mit dem centralen Nervensystem höherer Thiere homologisiren darf.

Vor allem gehen die Ansichten der Autoren sehr aus einander in der Beurtheilung der Fragen, ob in dem Verlauf der Längsnerven Ganglienzellen mit Sicherheit zu finden sind und ob ausser Nervenfasern auch noch Bindegewebselemente, sei es als Hülle, sei es als inneres Stützgewebe, am Aufbau der Längsstämme theilnehmen.

Beschäftigen wir uns zunächst mit der zweiten Frage. Von den Forschern, welche Ligula selbst untersucht haben, behauptet STEUDENER (18), dass die Längsstämme aus feinen Fibrillen bestehen, die neben einander in dem Maschenwerk verlaufen, welches als Stützsubstanz dient. Dasselbe giebt Kressling (30) an, er sagt (p. 22) wörtlich: „Besonders auf Querschnitten, welche von den durchschnittenen Längsfasern fein punktirt erscheinen, zeigen uns die Nervenstränge ausserdem noch ein feinfaseriges Maschenwerk, anscheinend von Intercellularsubstanz und Bindegewebe - womit es grosse Aehnlichkeit hat - zusammengesetzt und mag dasselbe zur Stütze, vielleicht auch zur Isolirung der Nervenfasern nicht unwesentlich beitragen, wie denn auch eine dichtere Zusammenlagerung von Bindegewebszellen in der unmittelbaren Umgebung der Stränge diesem Zweck dienen und zugleich dem so wichtigen Apparat Schutz sichern dürfte." Dieser nicht nur für die Längsstämme von Ligula, sondern auch fast aller Cestoden wiederkehrenden Auffassung tritt zuerst PinTNER (23) entgegen. Nach ihm sind die im Querschnitt erscheinenden Maschen nicht bindegewebiger Natur und nur zur Stütze und Isolirung der Nervenfasern da, sondern die Nervenfaser selbst.

„Die Masse, die ich in den Zwischenräumen fand, war ziemlich homogen, und ich glaube, dass die queren, das Maschenwerk bildenden Bälkchen selbst die Querschnitte der wahrscheinlich reihenweise neben einander stehenden Fibrillen darstellen." 
TiEvIC (3 4 ) kommt auf Grund seiner Untersuchungen an Ligula und anderen Cestoden ebenfalls zu dem Schluss, „dass das zarte Balkenwerk das nervöse Element ist", weil er besonders bei Ligula die verzweigten Enden der im Gehirn gefundenen Ganglienzellen in dem Balkenwerk verlaufen sah, ,und weil aus ihnen die Seitennerven entspringen". Doch er fügt noch einen Zweifel an dieser Auffassung an: „Es ist jedoch dabei nicht ausser Acht zu lassen, dass Zellen von aussen her, d. h. vom umgebenden Grundgewebe, stellenweise den Nervenstrang durchsetzen und an der Balkenbildung theilnehmen können."

In Vergleich mit meinen Befunden bestehen diese Angaben Pntrner's und Niemic's - diese bis auf den eben citirten Satz völlig zu Recht. Denken wir einen Augenblick an die Figg. 47, 48, welche uns das Verhalten der Seitennervenwurzeln im Längsstamm zeigen, so können wir uns leicht einen Begriff von dem wirren Durcheinander machen, wie es ein Querschnitt durch dieses Organ bieten muss. Finden wir doch auf dem Querschnitt nicht nur die querdurchschnittenen Längsfasern, die dann als Punkte erscheinen, sondern auch die nach allen Richtungen verästelten Seitenwurzeln, welche im Querschnitt theils als Punkte, theils als Fäserchen und Maschen wiederkehren. Querschnitte, wie sie die Figg. 59, 60 wiedergeben, zeigen deutlich, dass die Maschen gerade von den einmündenden Seitennerven und Ganglienzellfortsätzen gebildet werden. Hier gerade sieht man die zum grossen Theil ungefärbten Maschen von den imprägnirten Verästelungen einmündender Fasern gebildet werden.

Wenn NiEuic (1. c.) ausserdem noch, "Zellen von aussen her den Nervenstrang durchsetzen und an der Balkenbildung theilnehmen" lässt, so muss ich für Ligula mit Sicherheic dies Verhalten für andere als Ganglienzellen ausschliessen. Ich halte es für leicht möglich, dass dieser exacte Beobachter hier dasselbe gesehen hat, ohne die Zellen als Ganglienzellen erkannt zu haben.

Von fast allen Autoren, bei denen ich Angaben über das Nervensystem von Ligula finde, wird mit mehr oder weniger Nachdruck eine Umhüllung der Längsnerven durch enger angeordnetes Grundgewebe mit zahlreichen Kernen betont. Von anderen Forschern aber, welche genaue Untersuchungen über die Anatomie der Cestoden ausgeführt haben, finde ich diesen Punkt nur zum geringsten Theil bestätigt; im Gegentheil, von den meisten wird besonders hervorgehoben, dass die Lüngsnerven ohne besondere Hülle unmittelbar im Parenchym eingebettet erscheinen. Ich glaube deshalb, dass sich die verschiedenen 
Formen hierin verschieden verhalten, Ligula besitzt jedenfalls eine eigene Hülle für die Längsnervenstämme. Auch hier dürften Versuche mit der GoLGI'schen Methode zu interessanten Resultaten führen.

Ebenso wie in diesen Fragen weichen die Ansichten der Autoren über das Vorhandensein von Ganglienzellen in den Längsnerven und der daraus gefolgerten Schlüsse über die Bedeutung dieser Organe aus einander.

Bei Ligula sind bisher keine Ganglienzellen in den Längsnerven beschrieben worden.

Zuerst berichtet KaHANE (21) von Zellen in den Längsnerven von T. perfoliata, welche „untrügliche Charaktere von Ganglienzellen tragen", er schlägt auf Grund dieser Beobachtung vor, die bislang als „,spongiöse Stränge“ bezeichneten Längsstämme passender als ,ganglionäre" Stränge zu bezeichnen.

LEUCKART $(22$, p. 378) bestätigte bald darauf diese Befunde von KaHANE.

Pintner (23) beschreibt für Tetrarhynchus im Verlauf der Längsnerven Kerne, „die sich kaum von Parenchymkernen unterscheiden, sie besitzen alle ein höchst spärliches Protoplasma, welches spindel- oder vielmehr fadenförmig angelagert ist, eine ellipsoide Gestalt, die Längsaxe dem Längsverlauf der Stämme orientirt und legen sich so dicht gedrängt dem Stamm an, dass es, zumal auf Querschnitten, den Anschein hat, als ob sie einen Zellbelag desselben bildeten".

Ebenso fand Lang (26) bei Amphilina bipolare Ganglienzellen in der Gehirncommissur und den Seitennerven, in letzteren besonders da, „wo Aeste nach aussen abgehen".

Rовоz (29) beschreibt für die Längsnerven am Solenophorus megalocephalus sehr schöne „bipolare Nervenzellen", die einen Kern und Kernkörperchen besitzen, welcher, von ,fein granulirtem Plasma umgeben" ist, "welches sich meistens in zwei lange Ausläufer fortsetzt, die in den meisten Fällen mit den Nervenfasern in Verbindung stehen". Dieser Befund wird von GrIESBACH (31) bestätigt. Auch Hamann (33) sah in den Längsstämmen von T. lineata ,Nervenfibrillen mit aufliegenden und dazwischen liegenden Ganglienzellen". NiEnic (34) stellt das Vorhandensein von Ganglienzellen in den Längsnerven für nicht so sicher hin wie die früheren Forscher; er sagt nämlich: „In den lateralen Strängen sind oft zahlreiche, stark tingirte Kerne vorhanden, um welche jedoch der Plasmaleib kaum zu erkennen ist. Hier bei Bothriocephalus gestaltet sich die Beantwortung der Frage nach der Natur dieser Kerne ebenso schwierig bei wie bei Schistocephalus. 
Nur die Annalıme, dass die Kerne theils den in plasmischen Zügen sich erstreckenden Nervenzellen, theils dem eindringenden Grundgewebe angehören, kann uns über diese schwierige Frage theilweise hinweghelfen."

WILL (56) fand bei Caryophyllaeus ebenfalls spindelförmige Zellen in den Längsnerven, welche er mit feinen Fortsätzen in die Längsfibrillen verlaufen sah und im Anschluss an die angeführten Autoren für Nervenzellen deutet.

Diese an den verschiedensten Formen aller Cestodengattungen erlangten Resultate stellen einmal das Vorhandensein von Nervenzellen in den Längsstämmen sicher und stimmen darin überein, dass dies spindelförmige (bipolare) Ganglienzellen sind. Auch bei Ligula gehören die in den Längsstämmen selbst liegenden Zellen dem Typus der bipolaren Ganglienzellen an. Jetzt dürfte auch der Zweifel NrEwC'S (l. c.) gehoben sein, ob er die genannten Zellen dem Bindegewebe oder dem Nervensystem zurechnen soll. Bei Ligula beschrieb ich ganz ähnliche Zellen (Figg. 52-54), über deren Bedeutung die GoLGI'sche Methode keinen Zweifel übrig liess.

In Berücksichtigung all dieser Befunde kann man jetzt das Vorhandensein von Ganglienzellen ausserhalb des Gehirns bei den Cestoden als gesichert betrachten, und zwar sind die Ganglienzellen nicht nur in den Längsstämmen, sondern auch ausserhalb dieser im Körper zu finden. Letztere stehen dann mit den Längsstämmen durch einen oder mehrere Fortsätze in Verbindung.

In Würdigung des wenigstens für einen Cestoden von mir festgestellten Aufbaues der Längsnervenstämme und zwar ihrer Zusammensetzung aus Längsnerven, Ganglienzellen und deren Ausläufern sowie der wurzelförmig abgehenden Seitennerven dürfte es jetzt nicht mehr als verfrüht angesehen werden, diese Organe mit dem nervösen Centralorgan höherer Thiere zu homologisiren. Dieser Versuch, die Längsnerven der Cestoden mit dem Bauchmark höherer Thiere für homolog zu erachten, ist schon von frühern Autoren mit mehr oder wenig Reserve gemacht worden. KaHANE (21) legt auf Grund der von ihm bei $T$. perfoliata gefundenen Ganglienzellen die Deutung nahe, dass man ,die Stränge selbst entweder in der ganzen Proglottidenreihe oder in jede Proglottis insbesondere füglich als ein noch undifferenzirtes Bauchmark ansehen dürfte".

Nieuic (34) vertritt auf Grund umfassender Untersuchungen des Nervensystems der meisten Cestoden einen entgegengesetzten Standpunkt. Er kann sich, trotzdem er an der Existenz von Ganglienzellen 
in den Seitensträngen nicht zweifelt, ,dennoch der Auffassung KaHAnE's bezüglich der Längsstämme als Nervencentren nicht anschliessen. Die Nervenstränge, mögen sie noch so kräftig ausgebildet sein, bieten stets andere Structurverhältnisse als der centrale Knoten, in welchem sämmtliche Nervenzweige entspringen".

Nach dieser Auffassung bätten wir die Längsstämme nur als Sammelbahnen für alle die gemeinschaftlich zum Gehirn, dem einzigen Centralorgan, verlaufenden Nervenfasern anzusehen, in deren Verlauf allerdings hier und da Ganglienzellen eingelagert wären. Dass dies aber keineswegs dem thatsächlichen Verhalten entspricht, habe ich wiederholt betont.

Wenn das Vorkommen von Ganglienzellen allein noch nicht genügen sollte, die Längsstämme für ein nervöses Centralorgan zu halten, so ist dies, meines Erachtens nach, mit Sicherheit dadurch bewiesen, dass die Seitennerven und Sinneszellfortsätze nicht als lateral vom Stamm abbiegende Fasern austreten, sondern als selbständige Fasern mit wurzelförmigen Verzweigungen zwischen den Fasern und Ganglienzellfortsätzen der Längsstämme entspringen bezw. endigen und so schon hier eine Reizübertragung von sensiblen auf motorische Fasern ermöglichen.

Haben wir aber die Längsnerven der Cestoden als ein Centralorgan erkannt, dann liegt die Versuchung nahe, dieses mit dem Centralorgan höherer Thiere zu vergleichen. In erster Reihe dürften hierfür die Seitennerven der Nemertinen (BüRGER, 68) und das Bauchmark der gegliederten Würmer in Betracht kommen. Da nun gerade in der neuesten Zeit die feinere Anatomie des Bauchmarks der Oligochäten durch LenhosséK und Retzius in hervorragender Weise gefördert und zu einem gewissen Abschluss gebracht wurde, so will ich meinen Vergleich an der Hand dieser Untersuchung durchzuführen suchen.

Nach diesen Forschern besteht das Bauchmark der Oligochäten aus einer doppelten Reihe ganglionärer Anschwellungen, welche jederseits durch Längscommissuren, unter sich aber durch kurze Querconnective verbunden sind. Von jeder Ganglienanschwellung entspringen drei Nervenstämme, von denen die beiden letzteren ihres nahen Aneinanderliegens wegen als ein Doppelnervenpaar aufgefasst werden. Innerhalb der Ganglienanschwellung liegt stets je eine multipolare Ganglienzelle und in bilateraler Symmetrie angeordnet eine grosse Menge unipolarer Zellen. Hin und wieder kommen auch vereinzelte bipolare Zellen vor. Die Stammfortsätze der unipolaren Zellen verlassen das Bauchmark stets durch die distale Wurzel des Doppel- 
nerven und gehen als motorische Fasern an die Musculatur. Durch alle drei Lateralnerven, besonders aber durch die proximalen Wurzeln, treten die centralen Fortsätze der Sinneszellen in das Bauchmark ein, um hier, meist in einen auf- und absteigenden Ast getheilt, mehrfach verzweigt frei zu enden. Die bilaterale Symmetrie ist bei allen austretenden Fasern in so fern gewahrt, als diese immer nur die Körperhälfte versorgen, auf deren Seite sie das Bauchmark verlassen. Die multipularen Zellen stehen vielleicht mit den jüngst von SuIRNow (62) entdeckten freien Nervenendigungen in Verbindung.

Beim Vergleich dieses Centralorgans mit unserer Ligula müssen wir zunächst von den Unterschieden absehen, welche durch die Segmentation der Oligochäten bedingt sind, aber nicht so gross erscheinen, dass sie diesen Vergleich von vornherein illusorisch machten.

Bei beiden Thieren haben wir zwei im Vorderende durch eine Commissur verbundene Längsstämme. In den Längsstämmen beider Ganglienzellen in grosser Menge, hier den Segmenten entsprechend concentrirt, dort im ganzen Verlauf unregelmässig vertheilt. Die Ganglienzellenanhäufungen der Oligochäten sind durch Connective regelmässig mit einander verbunden, welche bei Ligula fehlen; hier sind zwei Beobachtungen an Cestoden besonders wichtig. Einmal die erwähnten, regelmässig wiederkehrenden Quercommissuren zwischen den Längsnerven von Caryophyllaeus (WILL, 56) und T. expansa (KöHLER, 61) und zweitens eine Angabe RIEнм's (24). R. fand in den Längsnerven von Dipylidium pectinatum RIEHм, ,in ihrem Verlauf durch die Proglottidenkette, dem Hinterrande einer jeden Proglottis genähert eine, wenn auch nur schwache Anschwellung, von welcher sowohl nach der Rindenschicht als auch nach der Innenschicht der Proglottis zu ein kräftiger Nerv entspringt, ja auf Querschnitten wollte es sogar erscheinen, als sei ein jeder derselben aus zwei zusammengesetzt. Ob die Anschwellung die Ganglienzellen, welche sich in den Kopfganglien finden, in reichlicher Menge enthalten, wage ich nicht mit Bestimmtheit zu entscheiden, da das bezügliche Material vor der Bearbeitung bereits fast 4 Monate in Spiritus conservirt war.". Dass ich eine ähnliche Beobachtung KIEssLing's (30) an Ligula nicht bestätigen konnte, erwähnte ich bereits.

Kehren wir zu unserer Gegenüberstellung zurück, so finden wir bei beiden Thieren in den Längsstämmen Fasern in der Längsrichtung verlaufen, sehen Ganglien in ihnen liegen, die einen Theil ihrer Fortsätze im Längsstamm verbreiten und mindestens einen zur Peripherie schicken; gänzlich übereinstimmend aber sind die centralen 
Sinneszellfortsätze, die bei beiden frei im Centralorgan verästelt auslaufen. Die bilaterale Symmetrie, welche sich bei den Oligochäten auch in der Verbreitung der Nervenfasern auf der Seite ihres Austrittes aus dem Ganglion ausspricht, ist bei den Cestoden nicht so streng durchgeführt, als hier die Nerven nach allen Richtungen unregelmässig die Längsstämme verlassen und auch bisweilen, wie ich feststellen kounte, von der Seite ihres Austritts aus dem Centralorgan nach der andern überwechseln.

Ziehen wir das Facit aus diesem Vergleich, so steht meines Erachtens der Auffassung nichts entgegen, dass die Längsnervenstämme der Cestoden als ein noch nicht differenzirtes Bauchmark aufzufassen und diesem Organ der höheren Thiere homolog zu erachten sind.

Eine niedere Stufe nimmt es insofern ein, als die Ganglien noch unregelmässig in oder neben den Längsstämmen vertheilt liegen, noch nicht concentrirt sind und indem die Seitennerven nicht in regelmässig wiederholten Wurzeln entspringen, wodurch die scharfe Trennung in motorische und sensible Wurzeln, wie wir sie bei den Annulaten schon finden, bei den Cestoden noch fehlt. Uebereinstimmend ist nicht nur das Vorkommen von Ganglienzellen, sondern auch deren gleiches Verhalten im Centralorgan und die Art der centralen Endigung der Sinneszellfortsätze, wodurch bei beiden im Centralorgan eine Uebertragung der Sinnesreize durch Contact ermöglicht wird.

\section{Körbchenzellen.}

Beim Studium der peripheren Sinneszellfortsätze an den GoLGIschen Präparaten von Ligula fand ich gelegentlich eigenthümliche Gebilde in der Cuticula, welche mit tiefer liegenden Zellen in Verbindung standen, über deren Zugehörigkeit oder Function ich im Unklaren blieb. Weder von Cestoden noch anderen Thieren her ist mir ein ähnliches Gebilde bekannt.

Zur bessern Orientirung will ich der Beschreibung der von mir als "Körbchenzellen" bezeichneten Gebilde eine kurze Bemerkung über die Cuticula vorausschicken. Porencanäle, wie sie früher für viele andere Cestoden beschrieben wurden, kommen in der ziemlich dicken Cuticula von Ligula nicht vor; in dieser finden sich aber zahlreiche breite Einsenkungen, welche dicht über der Basis der Cuticula blind enden.

Schon an gewöhnlich gefärbten Präparaten sind diese Einsenkungen wahrzunehmen, doch von ihrer Menge und Verschiedenheit geben erst 
GoLGI'sche Präparate Aufschluss. Wie ich auch auf allen Zeichnungen wiedergegeben habe, imprägniren sich diese relativ grossen Canäle fast immer mit dem Chromsilberniederschlag. Man findet dann die zahlreichen Einsenkungen neben einander liegen. Sie haben eine Breite von $1-4 \mu$ und erstrecken sich bis $\mathrm{zu}^{3} / 4$ bis $4 / 5$ der Dicke der Cuticula in diese hinein, um blind zu enden. Völlige Durchbohrungen der Cuticula habe ich nie beobachten können. In seltenen Fällen theilen sie sich gablig, noch seltener in drei oder mehr blind endende Aeste.

$\mathrm{Zu}$ diesen Cuticulareinsenkungen stehen nun die Körbchenzellen in eigenthümlicher Beziehung. Bei Anwendung starker Vergrösserungen finden wir in der Cuticula unter einigen dieser Einsenkungen zierliche körbchenartige Gebilde, welche durch einen Fortsatz mit einer Zelle in Verbindung stehen. Auf Figg. 61-67 habe ich die verschiedensten Formen dieser Zellen abgebildet. Wir sehen in diesem Fall den Boden der Einsenkung von einer Anzahl feiner Stäbchen umgeben, die in zwei Reihen angeordnet sind. Der Zellfortsatz löst sich jedesmal genau an der Basis der Cuticula in eine Anzahl kurzer und etwas längerer Stäbchen auf, welche an ihrem Ende mit einer feinen knopfartigen Anschwellung versehen sind. Figg. 61 und 67 zeigen dies besonders deutlich, da hier die Einsenkung nicht mit imprägnirt ist. Die Zahl dieser Stäbchen beträgt ungefähr 8-16. Die kürzeren erreichen mit ihrem freien Ende gerade den Boden der Einsenkung, während die längeren diese etwas weiter nach aussen $\mathrm{zu}$ von allen Seiten umklammern und deren Wand dicht angelagert erscheinen. An der Vereinigungsstelle dieser Stäbchen geht ein dicker Fortsatz in die Tiefe, um in eine spindlige Zelle überzugehen. Diese Zellen liegen in der sogen. Subcuticularschicht, ungefähr in der halben Entfernung des Nervenplexus von der Cuticula. Die Zellen, welche besonders in Figg. 62 und 63 gut imprägnirt sind, haben eine Länge von ca. $15 \mu$, während sie $5 \mu$ breit sind. In Fig. 62 ist in beiden Zellen ein ovaler Kern deutlich zu erkennen. Die Zellen und ihre Verbindungsstücke mit den Körbchen zeigen meist unregelmässige Anhängsel in Form von spitz auslaufenden Fortsätzen und Verdickungen. In zwei Fällen, Figg. 63 und 65, ist die Verbindung zwischen Zelle und Körbchen eine doppelte, indem neben der starken Faser eine bedeutend feinere die Verbindung vermittelt. In seltnen Fällen beobachtete ich sogar Zellen mit zwei Körbchen, welche dann mit zwei neben einander liegenden oder mit einer gablig getheilten Cuticulareinsenkung zusammenhingen. Ich habe dies in Figg. 63 und 66 wieder- 
gegeben. Es theilt sich dazu der Zellfortsatz unter der Cuticula in zwei gleich starke Theile, denen dann je ein Körbchen aufsitzt.

In Figg. 64 und 66 sind die Zellen nicht imprägnirt. In Bezug auf die Vertheilung über die Körperoberfläche kann ich angeben, dass sie nirgends in besonderer Menge zusammen angeordnet erscheinen und auf Schnitten aus allen Körpergegenden angetroffen wurden. Ich fand sie bei Ligula monogramma und digramma, sonst bei keinem der andern Cestoden wieder, doch ich will deshalb keinen Schluss auf ihr Vorhandensein machen, da sie vielleicht hier nicht imprägnirt wurden. Auch bei Ligula traf ich sie nur auf einzelnen Präparaten, jedenfalls imprägniren sie sich bedeutend seltener als die Excretionsgefässe und die Sinneszellen.

Die interessante Frage nach der Bedeutung dieser Zellen nebst ihren Körbchen kann ich nur durch eine Vermuthung zu beantworten suchen. Anfangs, als ich diese Zellen vereinzelt antraf, dachte ich es mit einer besondern Art Sinneszellen $\mathrm{zu}$ thun $\mathrm{zu}$ haben, suchte aber immer vergebens nach einer Nervenfaser.

Wenn nun auch ein negatives Resultat gerade mit der launischen GoLGI'schen Methode nicht allzu viel auf sich hat, so möchte ich doch den Zusammenhang mit Nervenfasern mindestens sehr bezweifeln, denn bei den Sinneszellen war die Verbindung mit dem Nerven eigentlich immer zu sehen. Ausserdem fand ich die Körbchen in der Cuticula an Stellen, in denen rings herum Sinneszellen und freie Nervenendigungen nebst deren Verbindung mit dem Plexus aufs schönste und vollkommenste imprägnirt waren, ohne dass eine Spur von einer Verbindung mit den Körbchenzellen bestand. Weshalb sollte gerade dieser Theil der Imprägnirung verschlossen sein?

Die Beziehungen $\mathrm{zu}$ den Cuticulareinstülpungen aber führen mich zu der Annahme, dass wir es hier mit Zellen zu thun haben, welche bei der Nahrungsaufnahme eine Rolle spielen. Liegen doch die Körbchen nicht nur gelegentlich wie die Sinneszellendbläschen, sondern regelmässig unter den Cuticulareinsenkungen. Das enge Anliegen und allseitige Umklammern der Einstülpung seitens der feinen Stäbchen spricht sehr für diese Auffassung.

Letztere hätten dann die Aufgabe, die in die Einsenkung eindringende Flüssigkeit (also bei Ligula die Producte der durch den Parasitismus in der Leibeshöhle erzeugten Peritonitis) zu resorbiren und durch das Verbindungsstück der Zelle zuzuführen, welche es ihrer. seits durch die vielen Ausläufer und Anhängsel an die Grundsubstanz des Körpers weiter abgiebt. 
Doch um mich hier nicht weiter in Hypothesen $\mathrm{zu}$ verlieren, wollte ich diese Erklärung nur andeuten, da sie mir, bis wir nähern Aufschluss über diese räthselhaften Gebilde erhalten, vorläufig für die plausibelste erscheint.

\section{Schlussbetrachtung:}

Wenn es mir, wie ich bereits in der Einleitung bemerkte, aus persönlichen Umständen nicht möglich war, meine Untersuchung ausser auf die besprochenen Organe auch noch auf die Cuticula und Subcuticula auszudehnen, so will ich doch wenigstens die Befunde angeben, welche ich auf diesem Gebiet machen konnte. Ausserdem dürften sich aus vorstehenden Angaben schon wichtige Folgerungen für die Frage nach der Bedeutung der Subcuticula ergeben.

Nächst dem Parenchym ist jedenfalls die Subcuticula der Cestoden nicht minder häufig Gegenstand eingehender Untersuchungen gewesen, ohne dass sich bis heute eine einheitliche Auffassung weder über ihre Structur noch ihre morphologische Bedeutung allgemeine Geltung verschaffen konnte. Bei der Durchmusterung der reichhaltigen Literatur kann man drei verschiedene Ansichten über die Bedeutung der Körperschichten der Cestoden, unvermittelt neben einander stehend, antreffen, welche durch anatomische und entwicklungsgeschichtliche Gründe gestützt werden.

Die sicher am nächsten liegende Auffassung, dass die Subcuticula als ein Epithel unter der Cuticula aufzufassen sei, wird auch von den ältesten Beobachtern getheilt. So stellen Sommer, Landois, SchiefferDecker, Steudener, Zograff, Kahane und Pintner die Subcuticularschicht aus spindelförmigen Epithelzellen bestehend dar, welche die Cuticula abgeschieden haben.

Dieser Ansicht widersprechen RindFueisch (3), Schneider (10), Leuckart (22), Roboz (29) und Griesbach (31), welche die Subcuticularschicht der bindegewebigen Grundsubstanz zurechnen und die Cuticula als eine „Basimentmembran“, eine structurlose Grenzschicht des Bindegewebes gegen die Aussenwelt auffassen. Gerade diese Ansicht erfreut sich heute durch die Autorität LEUCKAR'T'S der weitesten Verbreitung und Anerkennung.

Die dritte Auffassung, welche besonders von Monticell und Braun vertreten wurde, rechnete ebenfalls die Subcuticularschicht zum Parenchym, hielt aber die Cuticula für ein durch Verlust der Kerne und Zellgrenzen zum Syncytium metamorphosirtes Epithel. 
Diese Theorie wurde von Monticelli auf entwicklungsgeschichtliche Vorgänge zurückgeführt und besonders durch das von einigen Autoren beobachtete Vorkommen von Kernen in der Cuticula aufrecht erhalten.

Nachdem schon von Looss und Brandes die Unhaltbarkeit dieser Theorie nachgewiesen worden war, gelang es auch Herrn Prof. Dr. Blochmann (66) bei Monostomum mutabile an dem vermeintlichen Kern in der Cuticula nachzuweisen, dass dies keine Zellkerne, sondern die Endbläschen der periphern Sinneszellfortsätze darstellen.

Die Gründe, welche SchneIDER und LeuckarT gegen die Epithelnatur der Subcuticula anführen, sind zum Theil aus der Beschaffenheit und dem Verhalten dieser Zellen zum Parenchym, anderntheils aber aus der Erwägung abgeleitet, dass diese Zellen von der Cuticula durch eine Muskellage getrennt sind, und dass Organe in sie eindringen, die man gewöhnlich nicht innerhalb des Epithelverbandes antrifft.

Dass der Bau der Zellen und ihr Verhalten zur Nachbarschaft oft recht schwer zu ermitteln war und deshalb leicht zu Trugschlüssen Anlass gab, dürfte einmal durch die nicht immer geeignete Conservirung des Untersuchungsmaterials zu erklären sein, anderseits verhalten sich die einzelnen Formen in Bezug auf Grösse und Anordnung der Epithelzeilen sehr verschieden. Während beispielsweise bei Ligula die Subcuticularzellen relativ klein und ihre Grenzen nicht deutlich von einander zu unterscheiden sind - wozu auch die Einlagerung einer grossen Menge von Kalkkörperchen nicht wenig beiträgt - sind sie bei Triaenophorus sehr gross und regelmässig angeordnet. Hier lassen schon gut gefärbte Querschnitte keinen Zweifel aufkommen, dass wir es hier mit einem typischen Epithel zu thun haben. ZografF (47) bildet diese Zellen auf tab. 13, fig. 2 recht gut ab.

Mir gelang es, an Triaenophorus auch einzelne Epithelzellen zu imprägniren, welche ich in Figg. $43-45$ wiedergebe. Man erkennt hier leicht, dass wir es mit cylindrischen, scharf begrenzten Zellen $\mathrm{zu}$ thun haben, welche neben einander senkrecht zur Cuticula angeordnet sind und einen ovalen Kern besitzen. Gegen das Parenchym sind sie scharf abgesetzt, schicken aber durch die äussern Ring- und Längsmuskeln hindurch feine Fortsätze zur Cuticula, die in Figg. 43, 45 sehr deutlich hervortreten, während in Fig. 44 der Chromsilberniederschlag die Zwischenräume dieser Fortsätze gleichmässig erfüllt hat. Auf Grund dieser Beobachtung wie aus nachstehenden Gründen schliesse ich mich der Epithelauffassung der Subcuticula von BLOCHMANN (66) in allen Punkten an. 
Ich habe niemals, weder bei Ligula noch Triaenophorus eine Verbindung zwischen Parenchym und Epithelzellen gesehen. Selbst wenn eine solche Verbindung bei irgend einem Cestoden nachgewiesen werden sollte, so wäre es noch lange nicht ein Beweis gegen die Epithelnatur, da selbst bei Vertebraten ein Zusammenhang zwischen Epithel- und Bindegewebe von Schuberg (66) nachgewiesen wurde. Das Fehlen einer Grenzmembran zwischen Epithel und Parenchym dürfte auch nicht gegen meine Behauptung angeführt werden, denn auch dies Verhalten finden wir an zweifellosen Epithelien wieder. RetziUs (51) stellte z. B. bei den Epithelzellen von Arion das Fehlen einer Grenzmembran gegen das "spongiöse Fachwerk" fest, in welches die Zellen sogar mit Fortsätzen hineinragen.

Die andern Einwände, welche gegen unsere Auffassung geltend gemacht werden, wie die Einlagerung mesodermaler Gebilde in die Subcuticula - ich denke hauptsächlich an die äussern Ring- und Längsmuskeln, welche die Cuticula vom Epithel trennen sollten dürften jetzt erst recht nicht mehr von Belang sein. Denn einmal sehen wir die Epithelzellen von Triaenophorus mit ihren Ausläufern durch diese Muskelfasern hindurch mit der Cuticula in Verbindung bleiben, und vor allem finden wir die Bildungszellen für diese Muskelfasern, die Sommer-LandoIs'schen Zellen in der Tiefe, unter dem Epithel liegen. Offenbar ist hier das Eindringen der Fasern ein secundärer Vorgang, welchen wir auch bei zahlreichen andern Vertretern der Evertebraten antreffen. Ich erinnere nur an die Haut der Oligochäten, Hirudineen, Mollusken und Arthropoden, wo wir Muskelfasern und Blutgefässe in das Epithel eingedrungen finden. Dass auch Leukocyten das Epithel durchwandern, ist allbekannt. Mit dieser Auffassung stimmt auch die Beobachtung LANG's (26) überein, welcher einzellige Drüsen unter der Cuticula der Cestoden fand, welche bekanntlich auch immer an ein Epithel gebunden sind.

Doch nicht nur diese Gründe, welche wir aus dem Bau und der regelmässigen Anordnung der Epithelzellen herleiten, drängen uns zu der richtigen Auffassung, sondern ebenso das Verhalten des periphern Nervensystems. Genau so wie wir es bei den Würmern, Arthropoden und Mollusken antrafen, finden wie bei unsern Thieren unter dem Epithel specifische Sinneszellen, einen subepithelialen Nervenplexus und zahlreiche frei zwischen den Epithelzellen endigende Nervenfasern (Endbäumchen).

Die aus der Embryonalentwicklung abgeleitete Behauptung, dass die bewimperten Embryonen im Lauf der Entwicklung ihr Wimper - 
kleid und mit diesem zusammen das Ectoderm abwerfen, wurde bereits von ZoGRAFF (50) bestritten, denn er fand bei der Entwicklung von Triaenophorus, „dass, nachdem der wimpernde Embryo seine äussere Hülle abgeworfen hat, auf dem ausschlüpfenden bhakigen Embryo eine Zellenlage bleibt, die mit dem Wimperkleid durch besondere plasmatische Fäden vereinigt war. Es ist daher die Meinung unbegründet, dass der Embryo mit dem Abwerfen des Wimperkleides auch das ganze Ectoderm abwirft".

Aus diesen Thatsachen und Beweisgründen ergiebt sich also die wichtige Folgerung: Die Subcuticularschicht der Cestoden ist das Epithel dieser Thiere, die Cuticula aber eine wahre Cuticula und nicht ein zum Syncytium metamorphosirtes Epithel.

Indem ich meine Arbeit hier abschliesse, stelle ich die Resultate derselben nochmals kurz zusammen:

\section{Resumé.}

1) Das Parenchym der Cestoden besteht aus vielfach verzweigten Bindegewebszellen, deren protoplasmatische Ausläufer unter sich und mit denen benachbarter Zellen in Verbindung treten. Diese Zellfortsätze sind von einer Scheide der von ihnen abgeschiedenen Zwischensubstanz umgeben und bilden so ein den ganzen Körper durchsetzendes Maschenwerk von feinen Lamellen und Fibrillen, welches dem Gewebe die reticuläre Structur verleiht. Diese Lamellen gewähren den Parenchymmuskeln die nöthige Stütze, indem sie ihnen fest anliegen und sie auf ihrem ganzen Verlauf begleiten. Ausser diesen verzweigten Zellen und der die Ausläufer dieser Zellen umhüllenden Zwischensubstanz finden sich in dem Maschenwerk keine andern, dem Parenchym angehörenden Zellelemente. Die Hohlräume der Maschen sind mit einer homogenen unfärbbaren Flüssigkeit erfüllt.

2) Die Cestoden besitzen ein wahres Epithel (die Subcuticularzellen der Autoren), als dessen Product die Cuticula aufzufassen ist.

3) Die Muskeln der Cestoden bestehen alle aus Muskelzellen, welche auf die nematoide Grundform zurückzuführen sind. Die Zellen liegen den Fasern zum Theil unmittelbar an, zum Theil sind sie nur durch plasmatische Ausläufer mit ihnen verbunden (Sommer-LANDOIssche Zellen). Die Innervirung der Muskeln geschieht theils durch die Myoblasten, theils direct an der contractilen Substanz.

4) Das Excretionsgefässystem von Ligula setzt sich aus einem innern und äussern Gefässplexus zusammen, welche im Vorderende in 
einander übergehen und auf ihrem Verlauf durch zahlreiche Capillaren verbunden sind. Ein andrer Theil der Capillaren steht mit Wimpertrichtern in Verbindung. An den Seitenrändern und auf der Endspitze mündet der äussere Gefässplexus wiederholt durch Seitengefässe aus.

5) Das Nervensystem der Cestoden besteht aus einem centralen und peripheren Theil.

Als Centralorgane sind die Längsstämme nebst der Gehirncommissur aufzufassen. Sie sind bei Ligula von einer eigenen Hülle umgeben, besitzen zahlreiche Ganglienzellen und wurzelförmig entspringende Seitennerven. Die Längsstämme der Cestoden sind den Seitennerven der Nemertinen (BürĞER, 68) und dem Bauchmark der Anneliden homolog.

Das Periphere Nervensystem besteht aus sensiblen und motorischen Fasern und einem subepithelialen Nervenplexus. Der sensible Theil besteht aus specifischen Sinneszellen unter dem Epithel, deren centrale Fortsätze frei in den Längsstämmen endigen und deren periphere Fortsätze mit Endbläschen in der Cuticula in Verbindung stehen. Ferner aus frei im Epithel endigenden Endbäumchen, deren Ganglienzellen zum Theil im subepithelialen Plexus, zum Theil aber in der Tiefe liegen.

Der motorische Theil des Nervensystems besteht aus den Muskelnerven, welche theils aus den Längsstämmen kommend, direct in die Muskeln gehen, theils aus dem Plexus stammen. Der Plexus ist mit den Längsstämmen durch zahlreiche Nervenfasern verbunden, in deren Verlauf bipolare Ganglienzellen eingeschaltet sind.

6) In der Cuticula von Ligula liegen unter den Einsenkungen dieser verästelte Zellen, deren Endfortsätze die Einsenkungen körbchenartig umklammern. Sie stehen vielleicht im Dienste der Nahrungsaufnahme.

Rostock, im Januar 1895. 


\section{Verzeichniss der eitirten und benutzten Literatur.}

(Die mit einem Stern (*) bezeichneten Aufsätze waren mir leider nicht zugänglich.)

1) Platwer, Beobachtungen am Darmcanal der Taenia solium, in: MülleR's Archiv f. Anat. Physiol., 1838.

2) Blanchard, E., Recherches sur l'organisation des vers, in: Ann. Sc. Nat. Zool., (3. sér.) V. 7 u. 10, 1847, 1848.

3) Wagener, G. R., Die Entwicklung der Cestoden, in: Verhdlgn. Leop. Caral. Acad. Naturf., V. 24, Suppl., Breslau 1854.

4) Leuckart, Rud., Die Blasenbandwürmer und ihre Entwicklung, zugleich ein Beitrag zur Kenntniss der Cysticercusleber, Giessen 1856.

5) Stieda, L., Ein Beitrag zur Anatomie des Bothriocephalus latus, in: Arch. Anat. Physiol, 1864.

6) Rindfieisch, E., Zur Histologie der Cestoden, in: Arch. Mikrosk. Anat., V. 1, 1865.

7) Feuereisen, J., Beitrag zur Kenntniss der Taenien, in: Z. wiss. Zool., V. 18, 1868.

8) Sommer, F., und Landois, L., Ueber den Bau der geschlechtsreifen Glieder von Bothriocephalus latus Brems., in: Z. wiss. Zool., V. 22, 1872.

9) Nitsche, H., Untersuchungen über den Bau der Cestoden, in: Z. wiss. Zool., V. 23, 1873.

10) Schnemer, A., Untersuchungen über Plathyhelminthen, in: 14. Jahresber. Oberhess. Ges. Natur- und Heilkunde, 1873 - auch separat, Giessen 1873.

11) Salmensy, W., Ueber den Bau und die Entwicklungsgeschichte der Amphilina, in: Z. wiss. Zool., V. 24, 1874.

12) SCHIEFFERDECKk, P., Beiträge zur Kenntniss des feineren Baues der Taenien, in: Jenaische Z. Naturw., V. 8, 1874.

13) Sommar, F., Ueber den Bau und die Entwicklung der Geschlechtsorgane der Taenia mediocanellata KcHм. und T. solium L., in: Z. wiss. Zool., V. 24, 1874. 
14) Duchamp, G., Recherches anatomiques et physiologiques sur les Ligules, in: Journ. Zool., V. 5, 1876 - auch separat, Paris 1876.

15) Blumberg, C., Ein Beitrag zur Anatomie der Taenia plicata, T. perfoliata und T. mamillata, in: Arch. wiss. u. prakt. Thierhlkd., hrsg. von Gerlach, V. 3, 1877.

16) Donnadiev, A. L., Contribution à l' histoire de la Ligule, in : Journ. Anat. Physiol., 1877.

17) Zograff, N., Der Bau von Triaenophorus nodulosus, Ref. in: Z. wiss. Zool., V. 28, 1877.

18) Steudener, F., Untersuchungen über den feineren Bau der Cestoden, in: Abhandl. Naturf. Ges. Halle, V. 13, 1877.

19) Новк, P. P. C., Ueber den encystirten Scolex von Tetrarhynchus, in Niederländ. Arch. Zool., V. 5, 1879.

20) Fratpont, J., Recherches sur l'appareil excréteur des Trématodes et des Cestodes, in: Arch. Biol., V. 1, 1880, V. 2, 1882.

21) Kahane, Z., Anatomie von Taenia perfoliata G., als Beitrag zur Kenntniss der Cestoden, in: Z. wiss. Zool., V. 34, 1880.

22) Ledckart, R., Die Parasiten des Menschen und die von ihnen herrührenden Krankheiten, 2. Aufl., V. 1, Leipzig 1881.

23) Pintner, Tн., Untersuchungen über den Bau des Bandwurmkörpers mit besonderer Berücksichtigung der Tetrabothrien und Tetrarhynchen, in: Arb. Zool. Inst. Wien, V. 3, 1881.

24) RieHм, G., Studien an Cestoden, in: Z. ges. Naturw. Halle, V. 54, 1881 - auch separat: In.-Diss., Halle 1881.

25) Montez, R., Mémoire sur les Cestodes, in: Travaux Inst. Zool. Lille, V. 3, 1881.

26) Lang, A., Untersuchungen zur vergleichenden Anatomie und Histologie des Nervensystems der Plathelminthen. III. Das Nervensystem der Cestoden im Allgemeinen und dasjenige der Tetrarhynchen im Besonderen, in: Mitth. Zool. Stat. Neapel, V. 2, 1881.

27) Lustig, A., Ueber die Nervenendigung in den glatten Muskelfasern, in: Sitzgsber. Acad. Wiss. Wien, V. 83, 1881.

28) Rленм, G., Fütterungsversuche mit Ligula simplicissima, in: Z. ges. Naturw. Halle, V. 55, 1882.

29) v. Rовоz, Z., Beiträge zur Kenntniss der Cestoden, in: Z. wiss. Zool., V. 37, 1882.

30) Kiessling, Fr., Ueber den Bau von Schistocephalus dimorphus und Ligula simplic. Rud., in: Arch. Naturg., Jahrg. 48, V. 1, 1882 auch separat, In.-Diss., Leipzig 1882.

31) Griesbach, H., Bindesubstanz und Cölom bei Cestoden, in: Biol. Ctrbl., V. 3, 1883/84.

32) Griesbach, H., Ueber das Nervensystem von Solenophorus megalocephalus. Beiträge zur Kenntniss der Anatomie der Cestoden, in: Arch. Mikrosk. Anat., V. 22, 1883, p. 365-368 u. p. 525-584.

33) Hamann, O., Taenia lineata Gozze, eine Tänie mit flächenständigen Geschlechtsöffnungen, in: Z. wiss. Zool., V. 42, 1885.

34) Nifmic, J., Untersuchungen über das Nervensystem der Cestoden in: Arb. Zool. Inst. Wien, V. 7, Wien 1886. 
35) Zsснокке, F., Studien über den anatomischen und histologischen Bau der Cestoden. Vorlf. Mittheil., in: Ctrbl. Bakt. u. Parasitenkd., V. 1, Jena 1887.

36) Sснмгот, F., Beiträge zur Kenntniss der Entwicklung der Geschlechtsorgane einiger Cestoden, in: Z. wiss. Zool., V. 46, 1888 - separat, In.-Diss., Rostock 1888.

37) Zsснокке, F., Recherches sur la structure anatomique et histologique des Cestodes, Genève 1888, in: Mém. Inst. Nation. Genévois, V. $17,1886-1889$.

38) Pintner, P., Neue Untersuchungen über den Bau des Bandwurmkörpers, in: Arb. Zool. Inst. Wien, V. 8, 1889.

39) Zografr, N. J., Zur Frage über die Existenz ectodermatischer Hüllen bei erwachsenen Cestoden, in: Biol. Ctrbl., V. 10, 1890/91.

*40) Cretr, C., Ricerche anatomiche ed istologiche sul genere Solenophorus Crepl., in: Atti Accd. Lincei Mem., (Ser. 4) V. 6, 1890.

*41) Linton, E., On two species of larval Dibothria from the Yellowstone National Park, in: Bull. Un. St. Fish. Commiss., V. 9, 1891, p. $65-79$, with $3 \mathrm{pl}$.

*42) Linton, E., A contribution to the life-history of Dibothrium cordiceps Leidx, ibid., Vol. 9, 1891, p. 331-358, with 3 pl.

43) Lönnberg, E., Anatomische Studien über skandinavische Cestoden, in: Kgl. Vetensk.-Akad. Handl., V. 24, No. 6, Stockholm 1891.

44) Monticelli, Fr. S., e Cretr, C., Ricerche intorno alla sottofamiglia Solenophorinae Montic., Cretx, in: Mem. R. Accad. Sc. Torino, (Ser. 2) V. 41, 1891, p. 381-402, c. 1 tav.

45) Krämer, A., Beiträge zur Anatomie und Histologie der Cestoden der Süsswasserfische, in: Z. wiss. Zool., V. 53, 1892.

46) Rienm, G., Ueber die excretorischen Canäle von Schistocephalus dimorphus, in: Z. ges. Naturw. Halle, V. 65, 1892.

47) Zograff, N., Les cestodes offrent-ils des tissus d'origine ectodermique? in: Arch. Zool. expér. et gén., (Sér. 2) V. 10, 1892.

48) Lönnberg, E., Anatomische Studien über skandinavische Cestoden, 2., in: Kgl. Vetensk.-Akad. Handl., V. 24, No. 16, Stockholm 1892.

49) Monticelli, Fr. S., Sulla cosidetta subcuticola dei Cestodi, in: Rend. R. Accad. Sc. Fis. e Matem. Napoli, Ann. 31, 1892.

50) Zograff, N., Note sur la myologie des Cestodes, in: Congr. Internat. Zool., 2. sess. Moscou 1892, 2. partie, Moscou 1893.

51) Retzius, G., Das Nervensystem der Lumbricinen, in: Biol. Unters., (Neue Folge) V. 3, 1892.

52) Retzius, G., Das sensible Nervensystem der Polychäten und Mollusken, ibid., V. 4, Stockholm 1892.

53) v. Lenнosséк, M., Ursprung, Verlauf und Endigung der sensiblen Nervenfasern bei Lumbricus, in Arch. Mikrosk. Anat., V. 39, 1892.

54) Blochmann, F., Ueber Sommer's sog. „plasmatische Längsgefässe" bei Taenia saginata G. und Taenia solium L., in: Ctrbl. Bact. u. Parasitenkd., V. 12, 1893. 
55) Strues, C. W., Bemerkungen über Parasiten. 17. Ueber die topographische Anatomie des Gefässsystems in der Familie Taeniadae, ibid., V. 13, 1893.

56) WrLu, H., Anatomie von Caryophyllaeus mutabilis RdD., ein Beitrag zur Kenntniss der Cestoden, in: Z. wiss. Zool., V. 56, 1893 auch separat, In.-Diss., Rostock 1893.

57) Prntner, Th., Studien an Tetrarhynchen nebst Beobachtungen an andern Bandwürmern, in: Stzgsber. Acad. Wiss. Wien, Math.-nat. Cl., V. 102, 1. Nov. 1893.

58) Samassa, P., Ueber die Nerven des augentragenden Fühlers von Helix pomatia, in: Zool. Jahrb., V. 7, Abth. f. Morph., 1893.

59) Looss, A., Zur Frage nach der Natur des Körperparenchyms bei den Trematoden, in: Ber. Sächs. Ges. Wiss., Mathem.-physik.-Classe, 9. Jan. 1893.

60) Rонре, E., Muskel und Nerv, in: Zool. Beiträge, V. 3, p. 69-98.

61) KöHLER, E., Der Klappenapparat in den Excretionsgefässen der Taenien, in: Z. wiss. Zool., V. 57, 1894.

62) Surrawow, A., Ueber freie Nervenendigungen im Epithel des Regenwurms, Vorlfg. Mittheil., in: Anat. Anz.; V. 9, No. 18, 1894.

63) Langdon, Fanny E., The sense organs of Lumbricus agricola Hofrm., Preliminary Notice, in: Anat. Anz., V. 10, No. 3. 4, 1894.

64) Hesse, R., Zur vergleichenden Anatomie der Oligochaeten, in: Z. wiss. Zool., V. 58, 1894.

65) चом $R_{\triangle T H}, \mathrm{O}$., Ueber die Nervenendigungen der Hautsinnesorgane der Arthropoden nach Behandlung mit der Methylenblau- und Chromsilber-Methode, in: Ber. Naturf. Ges. Freiburg i. B., V. 9, Heft 2, 1894.

66) Blochmann, F., Ueber freie Nervenendigungen und Sinneszellen bei Bandwürmern, in: Biol. Ctrbl., V. 15, No. 1, 1. Jan. 1895.

67) Bradn, M., Würmer, in: Brons's Classen und Ordnungen des Thierreichs, V. 4, 31.-37. Lieferung.

68) BÜRger, O., Untersuchungen über die Anatomie und Histologie der Nemertinen, in: Z. wiss. Zool., V. 50. 


\section{Erklärung der Abbildungen.}

Die Figuren sind in ihren Contouren mit einem AввE'schen Zeichenapparat entworfen und dann weiter ausgeführt worden. Die Figg. 6, $46,69 \mathrm{a}, \mathrm{b}, 70 \mathrm{a}, \mathrm{b}, 71 \mathrm{a}$-d sind von Herrn Prof. Dr. Buochmann gezeichnet. Wenn nichts Anderes bemerkt, beziehen sich die Abbildungen auf Golgr'sche Präparate.

Die Figg. 2-4, 7--13a, 14-17, 22-24, 29-34, 39-41, 47-50, $59-60,72$ sind bei der angegebenen Vergrösserung gezeichnet und bei der Reproduction um 1/3 verkleinert.

Allgemeine Buchstabenbezeichnung.

A. G. Plex. äusserer Gefässplexus, A.R.M. äussere Ringmuskeln, Cap. Capillargefässe,

C.Esk. Cuticula-Einsenkung,

Cu. Cuticula,

Do. Dotterstock,

D. V.M. Dorsoventralmuskel,

E.B. Endbäumchen,

$E . B l$. Endbläschen d. Sinneszellfortsätze in Cuticula,

Ex. Excretionsgefässe,

Gz. Ganglienzelle,

Ho. Hodenbläschen,

Hz. Hüllzellen der Längsnervenstämme,

I. G.Plex. innerer Gefässplexus,

I. L. M. innerer Längsmuskel,

$K$. Kern,
$K b$. Körbchen,

$K k$. Kalkkörperchen,

Kz. Körbchenzelle,

$L$. $M$. Längsmuskel,

L. N. Längsnervenstamm,

M7. Muskelfaser,

My. Myoblast,'

N. Nerv,l

Ns. Niederschlag,

Plex. Plexus,

P.Z. Parenchymzelle,

Sc. Subcuticula,

S.L.Z. Sommer-Landors'sche

Zellen,

S. N. Seitennerv,

S. Z. Sinneszelle,

T.M. Transversalmuskel,

Wpt. Wimpertrichter. 
Fig. 1. Theil eines Querschnittes durch die Randpartie der dorsalen Seite von Ligula. Insertion der Mm. dorsoventrales an der Cuticula. Ein Theil des Nervenplexus und der Sinneszellen imprägnirt. 350:1.

Figg. 2 u. 3. Theile eines Querschnitts durch die Randpartie der ventralen Seite von Ligula. Insertion je einer dorsoventralen Muskelfaser in der untersten Schicht der Cuticula. 350:1.

Fig. 4. Dasselbe von Schistocephalus dimorph. 550:1.

Fig. 5. Querschnitt durch den Seitenrand von Ligula. Verlauf und Insertion der dorsoventralen Muskeln. 100:1.

Fig. 6. Theil eines Querschnittes durch die Cuticula und das Epithel von Ligula. Die Myoblasten der äussern Ring- und Längsmuskeln (Sommer-LandoIs'sche Zellen) imprägnirt nebst deren Verbindung mit dem subepithelialen Nervenplexus.

Figg. 7 u. 8. Dasselbe. Die Verbindung der Sinneszelle in Fig. 8 mit einem Myoblasten ef. Text S. 42. 350:1.

Fig. 9. Zwei Transversalmuskeln von Ligula, welche vermittels ihrer Myoblasten innervirt werden. $145: 1$.

Fig. 10. Dorsoventralmuskel von Ligula wird von einer aus dem Längsnerven $L . N$. kommenden Nervenfaser innervirt. $350: 1$.

Fig. 11. Zwei Transversalmuskeln von Ligula $(M k)$ werden von zwei zwischen ihnen verlaufenden Nervenstämmen aus innervirt. 235:1.

Fig. 12. Theil eines Querschnitts durch einen Längsnerven von Ligula. Aus dem Längsnerven gehen seitliche Nerven ab, von denen einer die imprägnirte Transversalmuskelfaser innervirt. $235: 1$.

Fig. 13 a. Vier Dorsoventralmuskeln von Ligula werden theils durch, theils ohne Vermittlung ihrer Myoblasten innervirt. 350:1.

Fig. $13 \mathrm{~b}$. Zwei Dorsoventralmuskeln mit ihren Myoblasten von Schistocephalus. $550: 1$.

Figg. 14 u. 15. Zwei Transversalmuskeln von Ligula mit ihren Nerven. Fig. 14 350:1, Fig. 15 235: 1 .

Fig. 16. Theil eines Querschnittes durch die Mittelschicht von Ligula. Vier Parenchymzellen nebst ihren Ausläufern imprägnirt. Dio Ausläufer dieser Zellen begleiten die Muskelfasern und dringen in die querdurchschnittenen Längsmuskelbündel (L.M.) ein. Eine Transversalmuskelfaser imprägnirt (T.M.). Der quer durchschnittene Längsnerv ist mit einem Chromsilberniederschlag bedeckt. $N$. zwei abgehende Nervenfasern. 235: 1 .

Fig. 17. Eine einzelne Parenchymzelle aus einem Querschnitt durch Ligula, ihre Beziehung zu den Transversal- und Dorsoventralmuskeln. $350: 1$.

Fig. 18. Eine Parenchymzelle aus einem Querschnitt von Ligula. Ihre Ausläufer umspinnen die Parenchymmuskeln. 350:1.

Fig. 19. Eine reich verzweigte Parenchymzelle aus einem Querschnitt von Ligula. Die Ausläufor dringen in die Längsmuskelbündel (L. M.) ein und begleiten die Transversalmuskeln (T.M.) in dichten Zügen. $N$. sind zwei Nervenfasern, welche das Gesichtsfeld quer durchzichen; sie waren bis in den Längsnerv einerseits und bis zum Plexus anderseits zu verfolgen. $350: 1$. 
Fig. 20. Theil eines Querschnittes durch die Mittelschicht von Ligula. Einzelne Dorsoventralmuskeln nebst Myoblasten, zwischen ihnen zwei Parenchymzellen mit Kernen und deren Ausläufer. Orange G-Hämatoxylin. $1 / 18$ Oelimm. Oc. 2.

Fig. 21. Theil eines Flächenschnittes durch die Mittelschicht von Ligula, zwei Parenchymzellen und deren Ausläufer an die quer durchschnittenen Dorsoventralmuskeln gehend. $R$. Rindenschicht, $M$. Markschicht der Muskelfasern. Orange G-Hämatoxylin. 1/18 Oelimm. Oc. 2.

Fig. 22. Querschnitt durch die Randpartie von Ligula. Man sieht die vom inneren Gefässplexus kommenden Capillaren (Cap.) in den äusseren Gefässplexus (A.G.Plex.) einmünden. $235: 1$.

Fig. 23 u. 24. Querschnitt durch die Randpartie von Ligula. Ein Ast des äusseren Gefässplexus mit den parallelen Längsfasern in der Gefässwand. $145: 1$.

Fig. 25. Ein Stück eines Gefässes des inneren Gefässplexus von Ligula aus einem Flächenschnitt. Die Fasern in der Gefässwand gehen auf die vom Hauptgefäss abgehende Anastomose über. 145: 1.

Fig. 26. Querschnitt durch den einen Seitenrand von Ligula. Der äussere Gefässplexus und eine glockenförmige blinde Ausbuchtung desselben gegen die Cuticula. 145: 1 .

Fig. 27 u. 28. Dasselbe. In Fig. 28 ist der blinde G'efässast gablig getheilt. $145: 1$.

Fig. 29. Theil eines Flächenschnittes von Ligula. Der änssere Gefässplexus vollständig imprägnirt. $70: 1$.

Fig. 30. Die Hälfte eines Querschnittes durch die Mittelschicht von Ligula. Die Stämme des inneren Gefässplexus und deren Anastomosen imprägnirt, sowie die abgehenden Büschel der Capillaren. 145: 1.

Fig. 31. Theil eines Querschnitts durch den Seitenrand von Ligula. Der äussere Plexus nebst einer Oeffnung desselben nach aussen imprägnirt. $145: 1$.

Fig. 32. Dasselbe nach einem Injectionspräparat. $145: 1$.

Fig. 33. Querschnitt durch den Seitenrand von Ligula. Die von dem äussersten Längsgefäss des inneren Gefässplexus zum äussern Plexus abgehenden Capillaren umgreifen den Längsnerven $(L . N$.) und breiten sich dann nach allen Seiten gegen die Oberfäche aus. Sie gehen zum Theil in den äussern Plexus über. S.Z. Sinneszellen. E. B. Endbäumchen einer freien Nervenendigung. $70: 1$.

Fig. 34. Totalpräparat vom Hinterende von Ligula. Die Gefässe des äusseren Plexus mit Berlinerblau injicirt. Seitlich und auf der Endspitze sind Seitenöffnungen des Gefässplexus zu sehen.

Fig. 35. Theil eines Querschnittes durch die Randpartie von Ligula. Der äussere Gefässplexus nebst Wimpertrichtern und deren Capillaren imprägnirt. Die Transversal- und innern Längsmuskeln zum Theil eingetragen. S.Z. Sinneszellen. Kk. imprägnirte Kalkkörperchen. 175:1.

Fig. 36. Theil eines Querschnittes durch die Randpartie von Ligula. Der subepitheliale Nervenplexus, Ganglienzellen, welche frei endenden Nerven den Ursprung geben, und Sinneszellen sind imprägnirt. 350:1. 
Fig. 37. Theil eines Querschnittes durch die Randpartie von Ligula. Der subepitheliale Nervenplexus und zahlreiche Sinneszellen. Sc. Subcuticula. Do. Dotterstücke. I. L.M. Innere Längsmuskeln. D. V.M. Dorsoventralmuskelfaser. $235: 1$.

Fig. $38 \mathrm{a}, \mathrm{b}$, c. Einzelne Sinneszellen aus Querschnitten durch die Cuticula und das Epithel von Ligula. 38 a. Verbindung des Zellkörpers mit dem Plexus. 38b. Vom Zellkörper geht eine feine, frei endende Fasern ab. $38 \mathrm{c}$. Vom peripheren Sinneszellfortsatz gehen zwei feine Faser ab, die frei enden. 350:1.

Fig. 39. Theil eines Querschnittes durch die Cuticula und Epithelschicht von Ligula. Freie Nervenendigungen solcher Nerven, die nicht aus Ganglienzellen des Plexus stammen, sondern bis in die Tiefe zu verfolgen waren. $550: 1$.

Fig. 39a. Theil eines Querschnittes durch die Cuticula und die Epithelschicht von Ligula. Zwei Ganglienzellen des Plexus mit ihren zahlreichen Endbäumchen unter der Cuticula. Letztere ist hier zum Theil zerrissen und an der Unterlage abgehoben. 350:1.

Fig. 40. Theil eines Querschnittes durch die Epithelschicht von Ligula. Der subepitheliale Nervenplexus und zwei Sinneszellen imprägnirt. Vom periphern Fortsatz der einen gehen zwei Fasern ab, von denen die eine frei endet, die andere in den Plexus übergeht. 350:1.

Fig. 41. Die Hälfte eines Querschnittes durch Triaenophorus. Zwei Sinneszellen, deren centrale Fortsäze in den Längsnerv gehen. Ex. Excretionsgefässe. L.N. Längsnerv. $235: 1$.

Fig. 42. Theil eines Querschnittes durch den Seitenrand von Ligula, dicht vor dem Hinterende. Zwei Ganglienzellen, welche frei endenden Nervenfasern den Ursprung geben, liegen nicht in der Zone des subepithelialen Plexus, sondern sind bis in die innern Längsmuskeln in die Tiefe gerückt. Ex. Excretionsgefäss. $350: 1$.

Figg. 43 u. 45. Einzelne Epithelzellen aus Querschnitten durch Triaenophorus. Die Zellen sind nicht ganz durch das Chromsilber geschwärzt. Sie besitzen einen Kern und feine Ausläufer gegen die Cuticula. $550: 1$.

Fig. 44. Dasselbe, hier sind die Epithelzellen gänzlich imprägnirt. Der Chromsilberniederschlag füllt hier die $Z$ wischenräume zwischen den Zellausläufern gegen die Cuticula aus. S.Z. Sinneszëlle. 550:1.

Fig. 46. Kleiner Theil eines Längsschnittes durch die Cuticula von Ligula. Die Endbläschen der Sinneszellfortsätze (E.Bl.). Cu. Cuticula. $C u_{1}$ äussere Schicht derselben. Orange G-Hämatoxylin. 1/18 Oelimm. Oc. 4 .

Fig. 47. Theil eines Längsschnittes durch den Längsnerv von Ligula Die wurzelförmig entspringenden Seitennerven imprägnirt. Der dicke schwarze Balken ist dadurch entstanden, dass hier das Chromsilber zwischen mehreren Längsnervenfasern ausgefallen. 1/12 Imm. Oc. 2.

Fig. 48. Theil eines Längsschnittes durch den Längsnerv von Ligula. Drei Seitennerven und deren Auflösung im Centralorgan. 1/1, Imm. Oc. 2. 
Fig. 49. Theil eines Längsschnitts durch den Längsnerv von Ligula. Eine Ganglienzelle mit ihren Ausläufern imprägnirt. N.S. Chromsilberniederschlag zwischen mehreren Nervenfasern. 1/12 Imm. Oc. 2.

Fig. 50. Theil eines Längsschnitts durch den Längsnerv von Ligula. Eine bipolare Ganglienzelle G.Z.I., deren Ausläufer im Längsnerv verlaufen, ist imprägnirt, sowie einzelne Längsnervenfasern. Eine ausserhalb der Längsnerven liegende multipolare Ganglienzelle G.Z.III. sendet ihre fein verzweigten Ausläufer ins Centralorgan. Eine grosse bipolare Ganglienzelle (G.Z.II.) sendet einen Fortsatz in den Körper, einen ins Centralorgan. $1 / 12$ Imm. Oc. 2.

Fig. 51. Theil eines Querschnitts durch Ligula. Verbindungsnerven zwischen Plexus und Längsstamm imprägnirt; ihnen schliessen sich die centralen Fortsätze der Sinneszellen an. P.Z. Parenchymzellen. $145: 1$.

Fig. 52. Querschnitt durch den Längsnerv von Ligula. Ausserhalb desselben liegen drei bipolare Ganglienzellen. Man sieht einen Seitennerv abgehen. Orange G-Hämatoxylin. 1/ s Oelimm. Oc. 2.

Fig. 53. Theil eines Sagittalschnitts durch den Längsverv von Ligula. Man sieht einen Seitennerv abgehen und zwei grosse bipolare Ganglienzellen im Längsnerv.

Fig. 54. Theil eines Flächenschnitts durch den Längsnerv von Ligula. In ihm zwei grosse, dicht neben einander liegende bipolare Ganglienzellen. Beide Figuren nach einem Orange-G-Hämatoxylin-Präparat. $1 / 18$ Oel-Imm. Oc. 2.

Figg. 55 u. 56. Zwei Querschnitte durch die Längsnerven von Ligula. Die Hüllzellen zum Theil imprägnirt. 235: 1.

Fig. 57 u. 58. Zwei Hüllzellen von Ligula von der Fläche gesehen. In Fig. 57 sind einzelne Nervenfasern imprägnirt. 235:1.

Fig. 59. Querschnitt durch den Längsnerv von Ligula. Eine multipolare Ganglienzelle, deren Ausläufer sich im Centralorgan auflösen, imprägnirt. $350: 1$.

Fig. 60. Querschnitt durch den Längsnerv von Ligula mit zahlreichen abgehenden Seitennerven. 235: 1 .

Figg. 61-67. Körbchenzellen aus Querschnitten durch die Cuticula und die Epithelschicht von Ligula. In Figg. 61 u. 67 ist die Cuticulareinsenkung nicht imprägnirt. In Fig. 61 ist ausser der Körbchenzelle ein Endbläschen einer Sinneszelle sehr deutlich und ein Wimpertrichter des Excretionssystems imprägnirt. In Figg. 63 u. 66 sind die Fortsätze der Körbchenzellen gelblich gespalten und tragen jede je ein Körbchen. $550: 1$.

Fig. 68. Theil eines Querschnitts durch Triaenophorus. Sinneszellen mit ibren varicösen peripheren Fortsätzen. Nach einem Methylenblaupräparat gezeichnet, welches mit Ammon. picronitric. fixirt war. 1/1 2 Oel-Imm. Oc. 2.

Fig. 69 a, b. Sinneszellen vom Halstheil von Taenia serrata, nach lebenden Methylenblauobjecten gezeichnet. 69 a. Von der Fläche gesehen. 69 b. Im optischen Längsschnitt. 


\section{$-74-$}

Fig. 70 a b. Sommer-Landors'sche Zellen vom Scolex von Taenia serrata, nach Methylenblaubehandlung. 70 a. Von der Fläche gesehen. 70 b. Optischer Längsschnitt durch die Seite des Halsabschnitts.

Fig. $71 \mathrm{a}$-d. Vier Sommer-Landois'sehe Zellen von Triaenophorus in Verbindung mit äusseren Längsmuskeln, von der Fläche gesehen. Methylenblaupräparate. $700: 1$.

Fig. 72. Myoblast aus der Blasenwand von Cysticercus pisiformis in Verbindung mit vier Ringmuskelfasern. Das körnige Aussehen ist durch das Ausfallen des Methylenblaus während der Fixirung mit Ammon. picronitric. entstanden. 1/18 Oel-Imm. Oc. 2. 

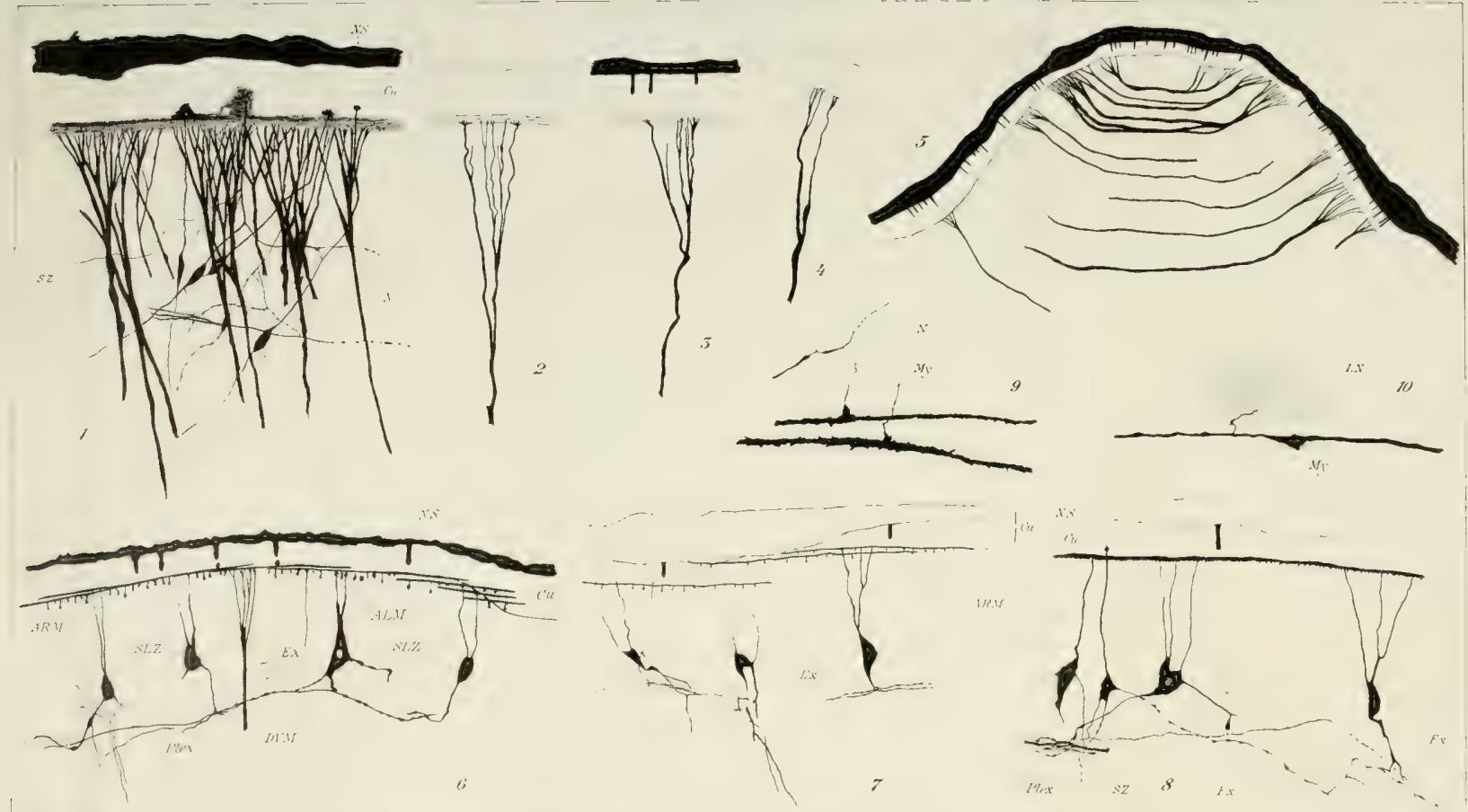


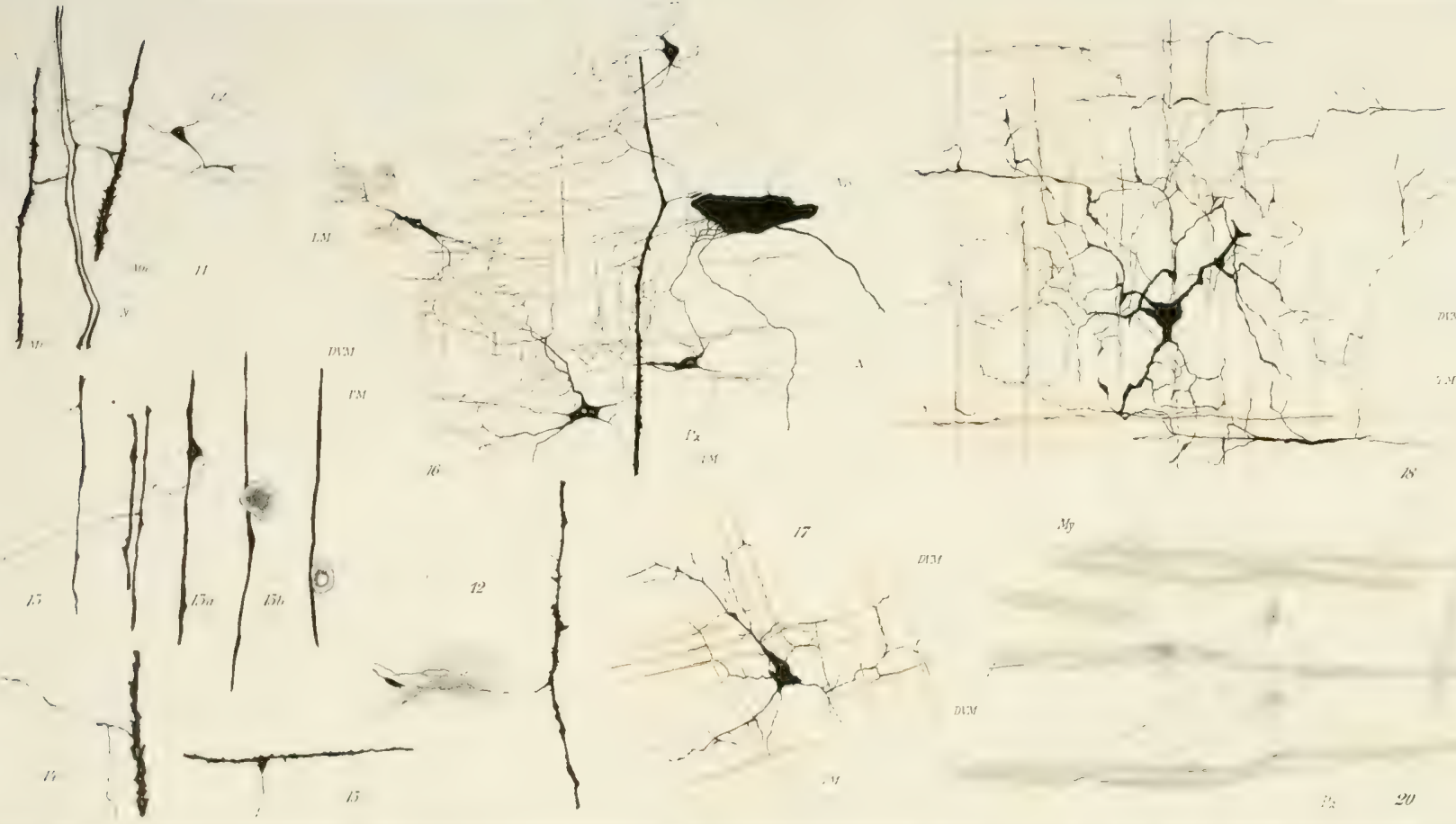


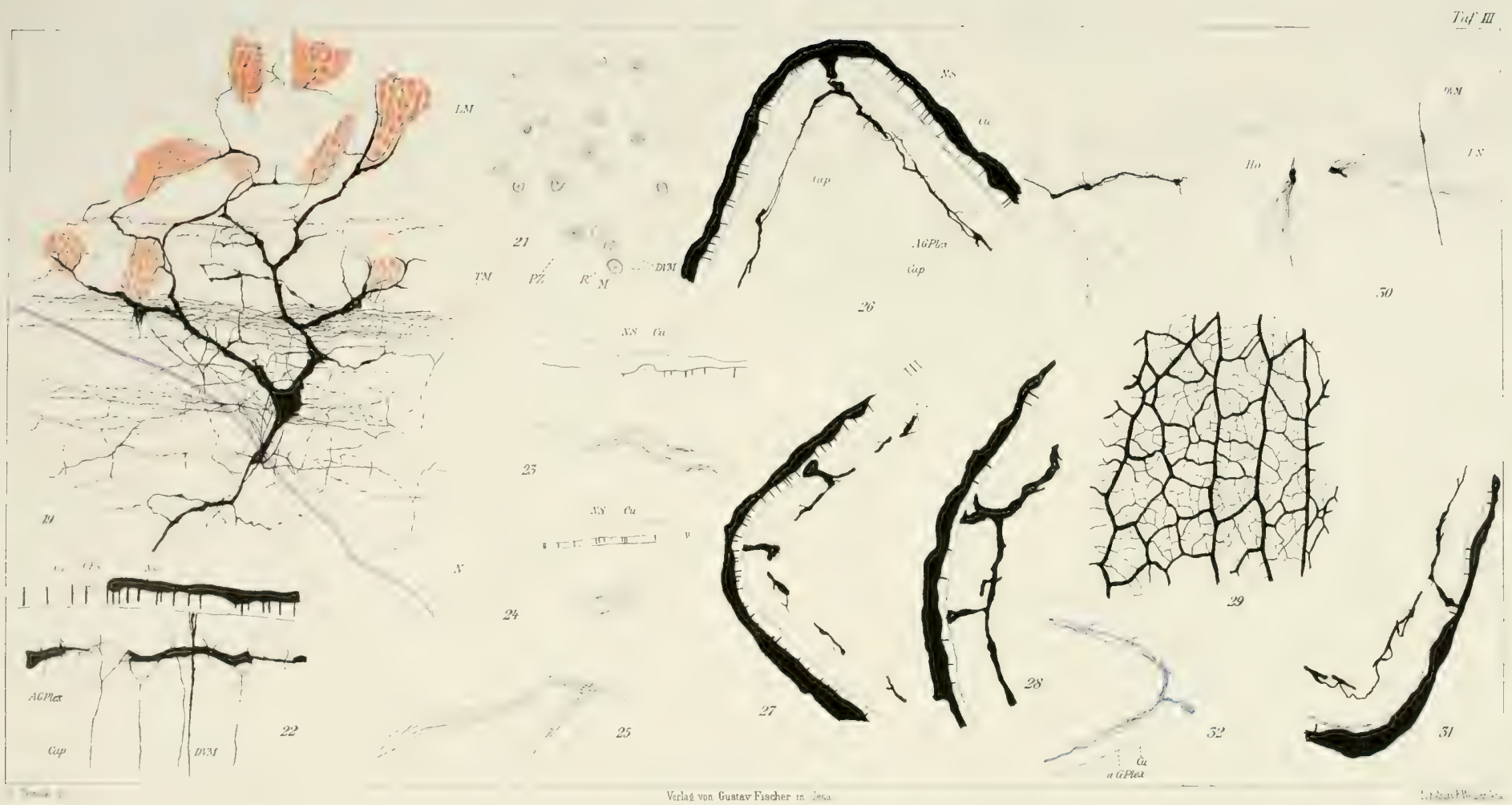



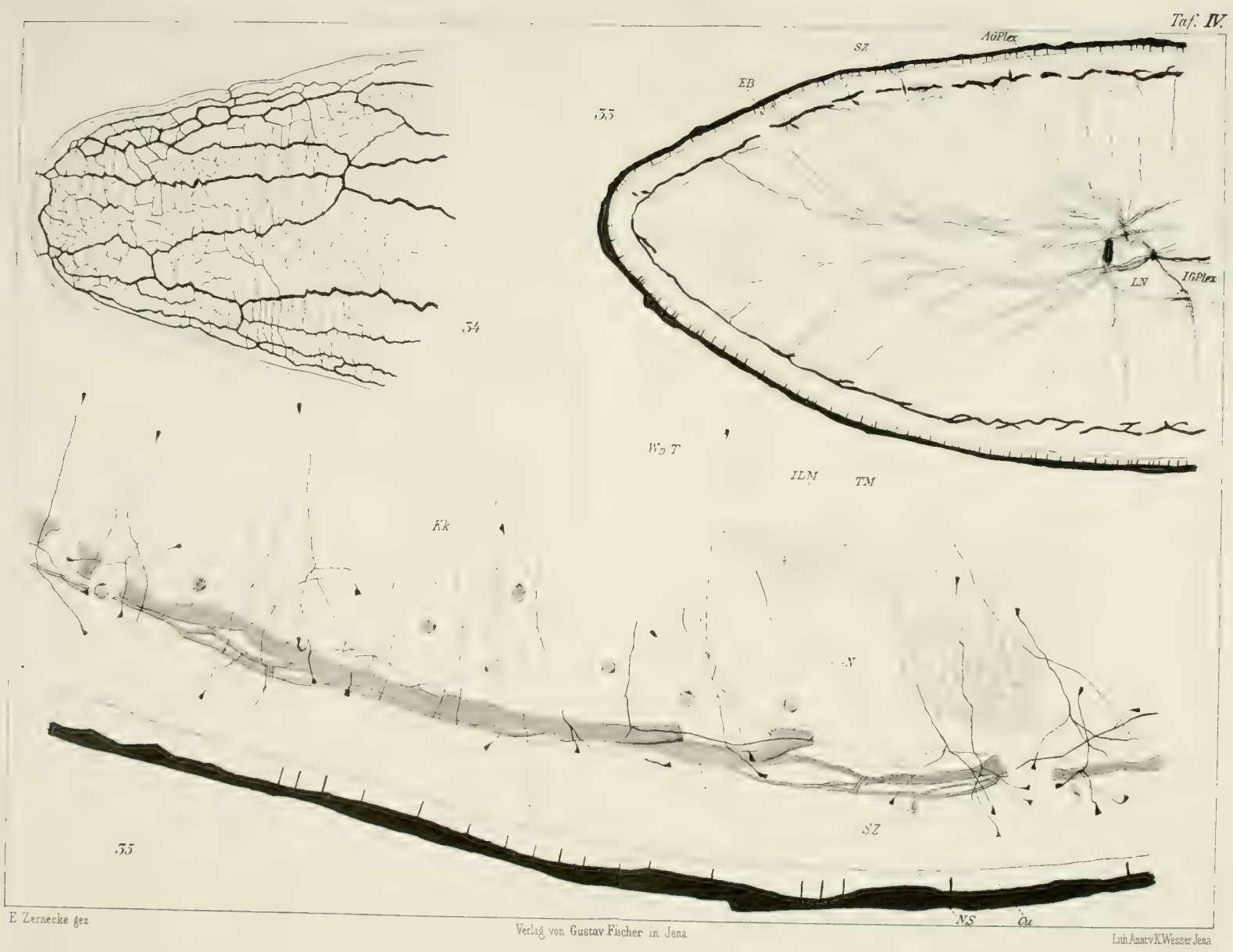






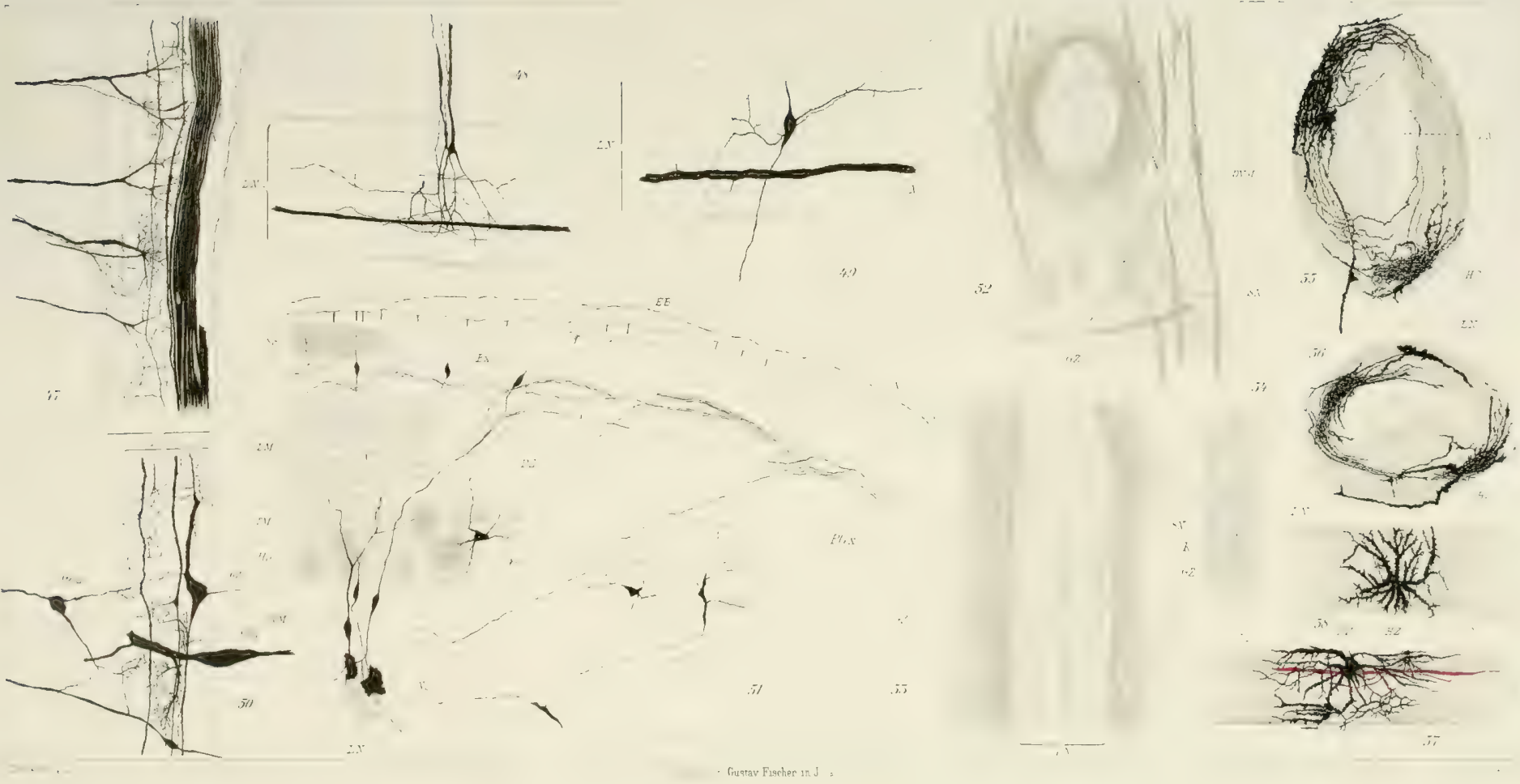

$3200 \mathrm{C}$ नी मीज्ञ $x+250$ 



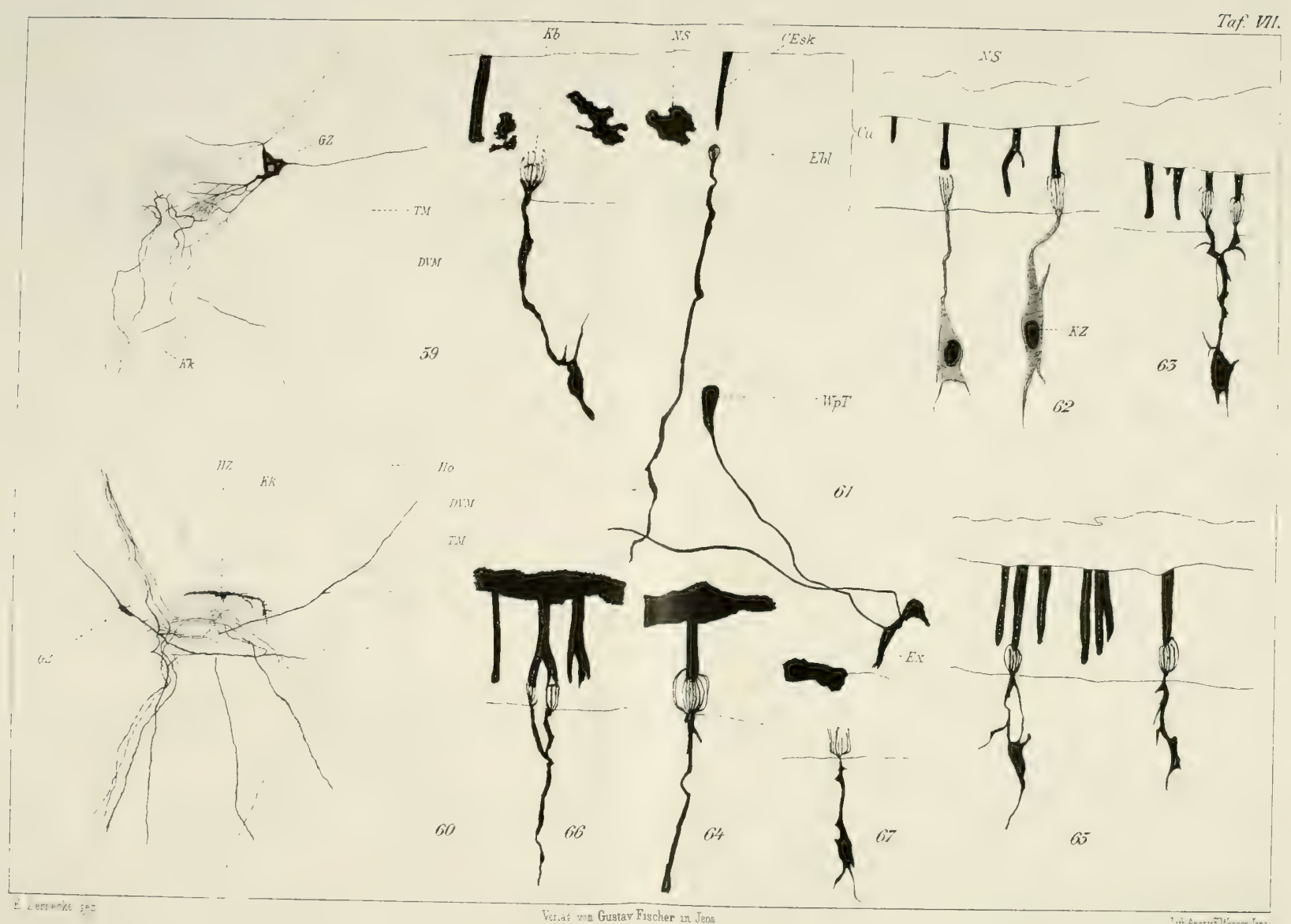





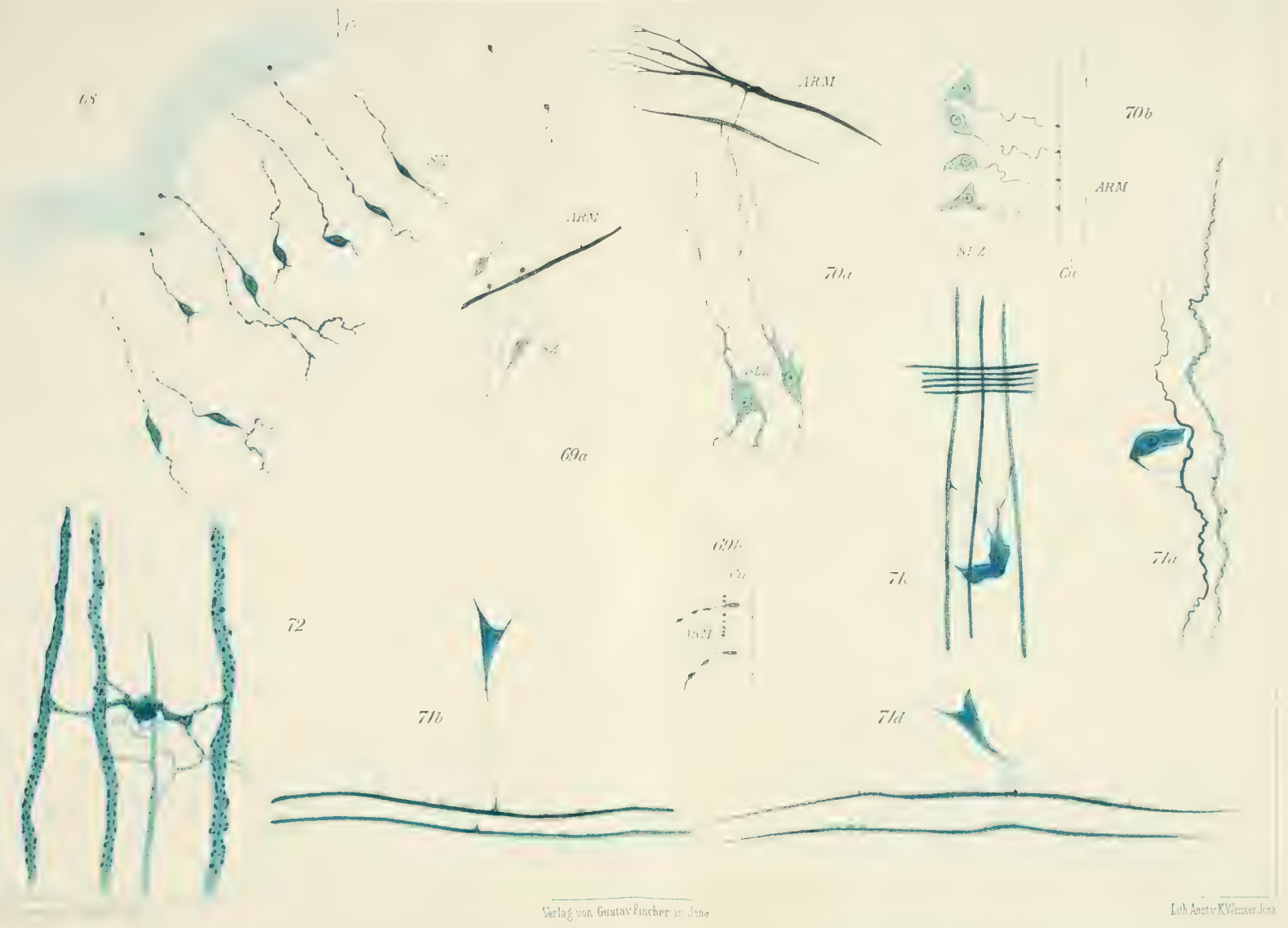





Gaylord Bros. Makers

Syracuse, N. Y. PAT. JAH. 21, 1908

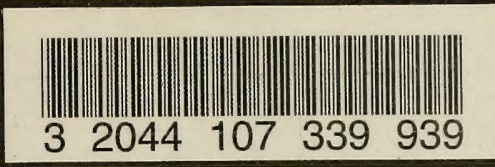


